FABIANO SALES DIAS FORTES

INFLUÊNCIA DO GERENCIAMENTO DE RISCOS NO PROCESSO DECISÓRIO: ANÁLISE DE CASOS

São Paulo 
FABIANO SALES DIAS FORTES

\title{
INFLUÊNCIA DO GERENCIAMENTO DE RISCOS NO PROCESSO DECISÓRIO: ANÁLISE DE CASOS
}

\author{
Dissertação apresentada à Escola \\ Politécnica da Universidade de São Paulo, \\ para obtenção do título de Mestre em \\ Engenharia Naval.
}


FABIANO SALES DIAS FORTES

\title{
INFLUÊNCIA DO GERENCIAMENTO DE RISCOS NO PROCESSO DECISÓRIO: ANÁLISE DE CASOS
}

\author{
Dissertação apresentada à Escola \\ Politécnica da Universidade de São Paulo, \\ para obtenção do título de Mestre em \\ Engenharia Naval. \\ Área de Concentração: \\ Engenharia Naval e Oceânica
}

Orientador:

Professor Doutor Marcelo Ramos Martins 
Este exemplar foi revisado e alterado em relação à versão original, sob responsabilidade única do autor e com a anuência de seu orientador.

São Paulo, de abril de 2011.

Assinatura do autor

Assinatura do orientador

FICHA CATALOGRÁFICA

Fortes, Fabiano Sales Dias

Influência do gerenciamento de riscos no processo decisório: análise de casos / F.S.D. Fortes. -- ed.rev. -- São Paulo, 2011. $145 \mathrm{p}$.

Tese (Doutorado) - Escola Politécnica da Universidade de São Paulo. Departamento de Engenharia Naval e Oceânica.

1. Administração de projetos 2. Administração de risco 3. Tomada de decisão (Administração) 4. Estratégia organizacional I. Universidade de São Paulo. Escola Politécnica. Departamento de Engenharia Naval e Oceânica II. t. 


\section{DEDICATÓRIA}

Dedico esta dissertação em primeiro lugar a Deus por ter me concedido saúde e disposição. Aos meus pais Hélcio e Maria José, exemplos de força e dedicação, bases da minha educação. A minha esposa Renata que soube entender os momentos de ausência para a realização deste trabalho e minha tia Corina que nos deixou neste ano para estar ao lado de Deus. 


\section{AGRADECIMENTOS}

Ao Prof. Dr. Marcelo Ramos Martins, pela orientação deste trabalho, especialmente pela disponibilidade, paciência e dedicação.

Aos professores da banca de qualificação por seus valiosos comentários.

À empresa que contribuiu com este trabalho, especialmente na figura de seus gerentes de projetos e site managers, que disponibilizaram as informações que serviram de base para a dissertação.

Aos meus pais, Hélcio e Maria José, por todo o apoio e carinho que sempre me foi dado.

À minha esposa, Renata Hungaro Fortes, pela paciência, incentivo e apoio que sempre recebi mesmo a deixando só por vários dias para a realização deste trabalho.

A todos os meus familiares, amigos e colegas, que muito incentivaram e apoiaram a realização deste trabalho.

Enfim, a todos aqueles que contribuíram direta ou indiretamente na elaboração desta dissertação.

E, principalmente, a Deus. 
"Nada é mais prático do que uma boa teoria"

(Kurt Lewin) 


\section{RESUMO}

A busca por um diferencial competitivo tem-se tornado cada vez maior nas organizações. Dentre as alternativas buscadas pelas empresas, a prática de gerenciamento de projetos tem-se tornado cada vez mais importante como forma de obter esta vantagem. Dentre as áreas de conhecimento de gerenciamento de projetos, o gerenciamento do risco, apesar de seu notável crescimento, ainda é uma disciplina que merece maiores estudos, uma vez que não se encontra integrada com os demais processos de gerenciamento de projetos, dificultando a tomada de decisão dos gerentes de projetos. Os projetos são afetados pela ocorrência de eventos indesejáveis e, no intuito de um melhor desempenho na execução dos mesmos, as empresas têm buscado a adoção de metodologias de gerenciamento de risco que contribua para o processo decisório dos gerentes de projetos. Este trabalho teve por objetivo confrontar a teoria com a prática no que diz respeito à metodologia de gerenciamento de riscos, bem como identificar possíveis influências e/ou impactos que o uso destas produz no processo decisório dos gerentes de projetos. Para atingir este objetivo, além de uma revisão bibliográfica a respeito do tema, realizou-se o estudo de caso de 3 projetos de modernização de usinas hidroelétricas, similares em termos complexidade, tipo de negócio, escopo e cliente, a fim de se obter um resultado mais eficaz e conclusivo em relação aos objetivos da dissertação, sendo que para a coleta de dados, utilizou-se como instrumento a realização de entrevistas e aplicação de questionários. Os principais resultados encontrados mostraram que os projetos que apresentaram uma metodologia de projetos mais consistente permitiram a realização de um gerenciamento de risco mais aprofundado e conseqüentemente subsidiaram o gerente do projeto no processo de tomada de decisão quanto ao tratamento dos eventos de perigo, contribuindo para a definição da melhor estratégia de respostas e resultados do projeto.

Palavras-chave: Gerenciamento de Projetos. Gerenciamento de Riscos. Processos Decisórios. 


\begin{abstract}
The search for a competitive edge has become increasingly in organizations. Among the alternatives considered by the companies, the practice of project management has become increasingly important as a way to obtain an advantage. Among the knowledge areas of project management, the risk management, despite its remarkable growth, it is still a subject that deserves further study, since it is not integrated with other project management processes, complicating the decision of project managers. The projects are affected by the occurrence of undesirable events and in order to perform better in their implementation, companies have sought to adopt methods of risk management that contributes to the decision making process of project managers. This study aimed to compare theory with practice regarding to the methodology of risk management, as well as identify possible influences and / or impacts that the use of these produce in the decision making process of project managers. To achieve this goal, besides a literature review on the subject, there was a case study of three projects for modernization of hydropower plants, similar in complexity, business type, scope and customer in order to obtain a more effective and conclusive results regarding the objectives of the dissertation and for data collection were used interviews and questionnaires. The main results showed that the projects had a more consistent design methodology have brought about a more detailed risk management and therefore supported the project manager in decisionmaking process regarding the treatment of hazard events, contributing to definition of the best response and project results.
\end{abstract}

Keywords: Project Management. Risk Management. Decision-Making process. 


\section{LISTA DE ILUSTRAÇÕES}

Figura 1. Áreas de especialização necessárias à equipe de gerenciamento de projetos .11

Figura 2. Interação de grupos de processo em um projeto ....................................14

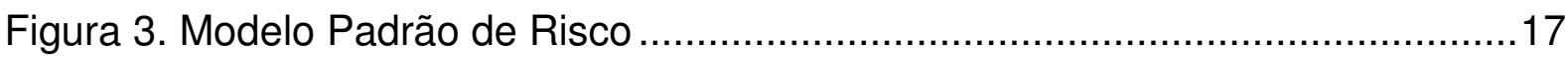

Figura 4. Espectro da Incerteza do Gerenciamento de Riscos ..............................19

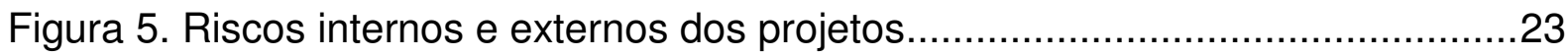

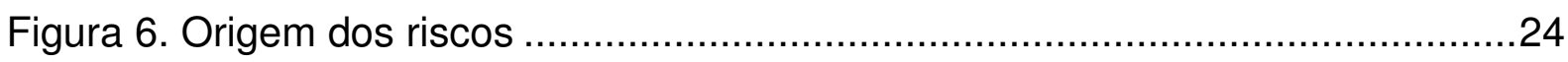

Figura 7. O processo de Gerenciamento de Riscos .........................................28

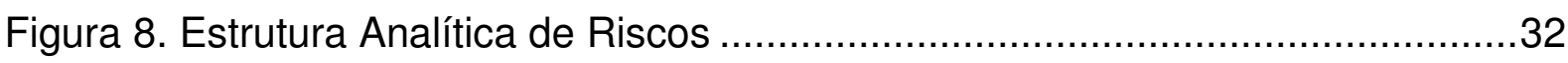

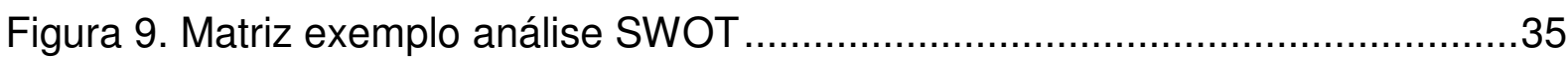

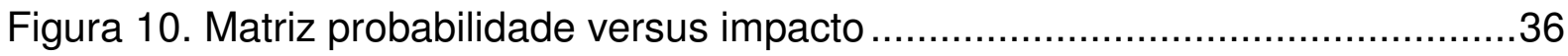

Figura 11. Definição das escalas de impacto por objetivo do projeto.........................37

Figura 12. Formulário de registro de informações de riscos ..................................44

Figura 13. Formulário de registro de informações de riscos ...................................44

Figura 14. A estrutura pesquisa-inferência do pensamento ....................................49

Figura 15. Comparativo da Intuição e da Razão na decisão ....................................56

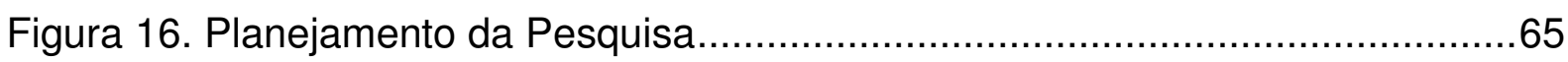

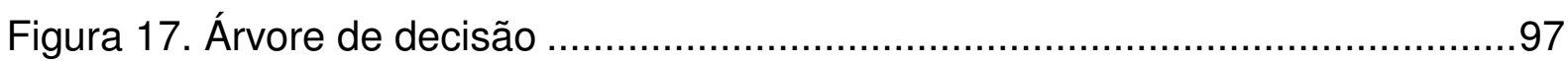




\section{LISTA DE GRÁFICOS}

Gráfico 1. Incerteza versus impacto do Risco no decorrer do projeto ......................19 


\section{LISTA DE TABELAS}

Tabela 1 - Percentual dos fatores críticos de sucesso - freqüência de menções .......4

Tabela 2 - Definição dos elementos do modelo padrão de Riscos............................17

Tabela 3 - Maturidade das oito áreas do gerenciamento de projetos.......................26

Tabela 4 - Modelos Gerais de Gerenciamento de Riscos ......................................28

Tabela 5 - Exemplo de descrição de Risco .........................................................

Tabela 6 - Exemplo de descrição de Risco ......................................................

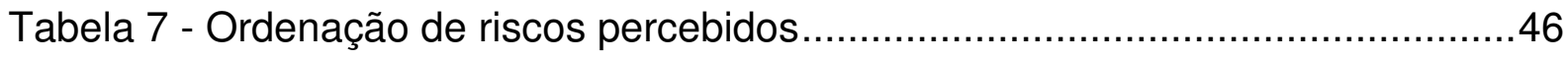

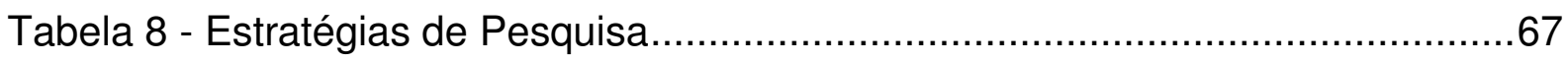

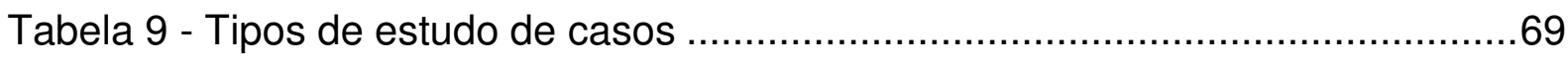

Tabela 10 - Resumo dos resultados .............................................................108 


\section{LISTA DE ABREVIATURAS E SIGLAS}

$\begin{array}{ll}\text { PERT } & \text { Program Evaluation and Review Technique } \\ \text { UHE } & \text { Usinas Hidrelétricas } \\ \text { PMI } & \text { Project Management Institute } \\ \text { NBR } & \text { Norma Brasileira } \\ \text { ISSO } & \text { International Organization for Standardization } \\ \text { RISKSIG } & \text { Relatório Final sobre Riscos Universais em Projetos } \\ \text { PMBOK } & \text { Project Management Body of Knowledge } \\ \text { SWOT } & \text { Strength, weakness, Opportunities e Threats } \\ \text { VME } & \text { Valor Monetário Esperado } \\ \text { EP } & \text { Exposição do Projeto a Riscos } \\ \text { EI } & \text { Valor de Perda Esperada } \\ \text { IDGR } & \text { Índice de desempenho do Gerenciamento de Riscos } \\ \text { GR } & \text { Gerenciamento dos riscos } \\ \text { GW } & \text { Gigawatt } \\ \text { KW } & \text { Quilowatt } \\ \text { MW } & \text { Megawatt } \\ \text { IEEE } & \text { Institute of Electrical and Electronics Engineers } \\ \text { WBS } & \text { Work Breakdown Structure } \\ \text { Pn } & \text { Probabilidade de ocorrência do Risco N } \\ \text { In } & \text { Impacto do Risco N } \\ \text { EAR } & \text { Estrutura Analítica de Riscos }\end{array}$




\section{SUMÁRIO}

1 INTRODUÇÃO

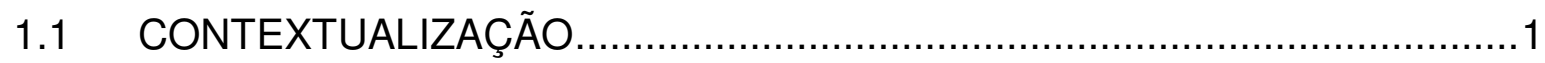

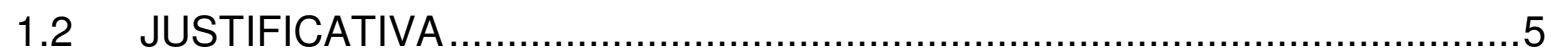

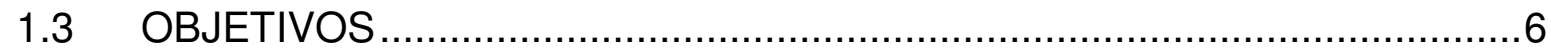

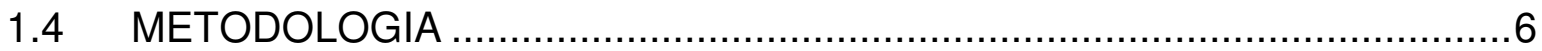

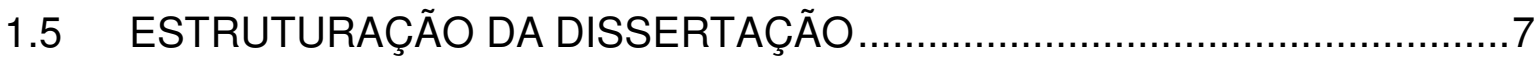

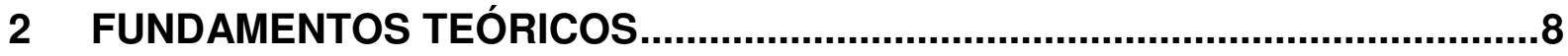

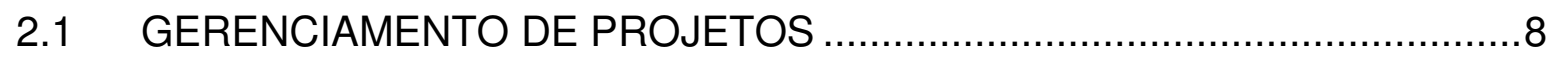

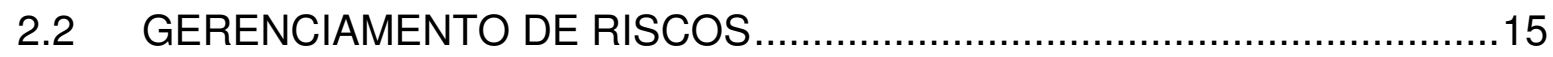

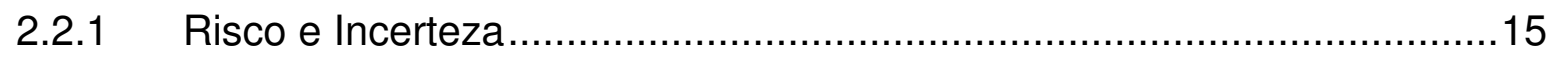

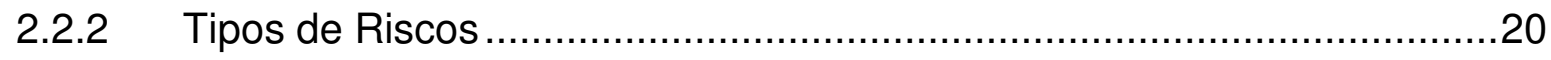

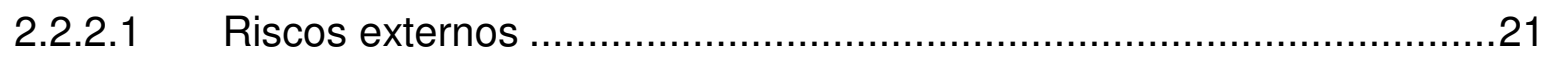

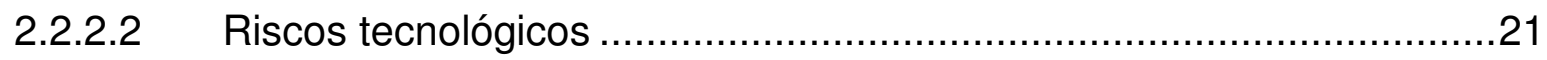

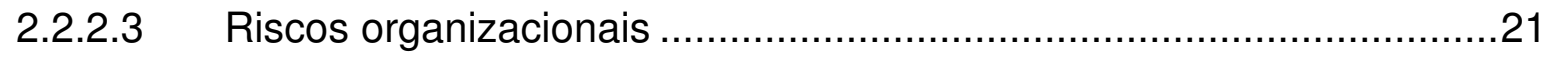

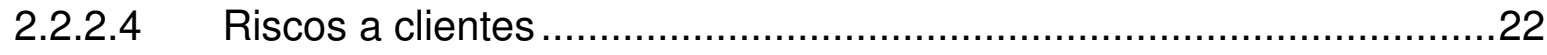

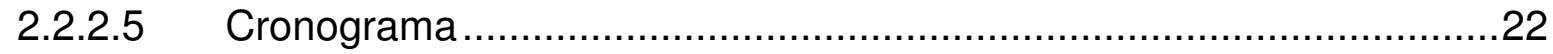

2.2.2.6 Requisitos e de especificações de escopo .......................................22

2.2.3 Gerenciamento de Riscos em Projetos .............................................25

2.2.4 Modelos Gerais de Gerenciamento de Riscos ..................................27

2.2.5 Processos do gerenciamento de riscos ............................................30

2.2.5.1 Planejamento do Gerenciamento do Risco.....................................30

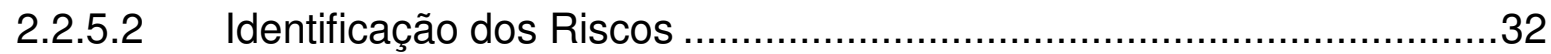

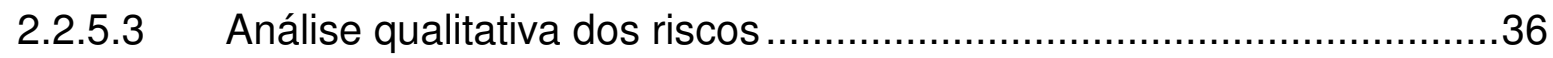

2.2.5.4 Análise quantitativa dos riscos ....................................................... 
2.2.5.5 Planejamento de Respostas a Riscos ….....................................38

2.2.5.6 Monitoramento e controle dos riscos ...........................................42

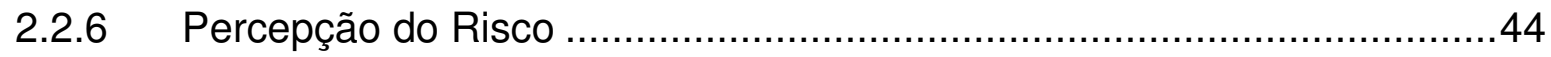

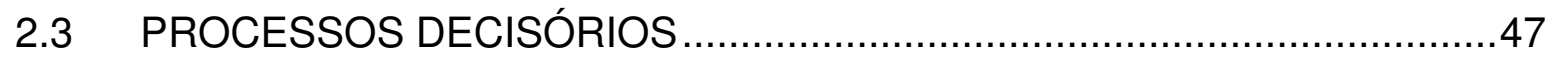

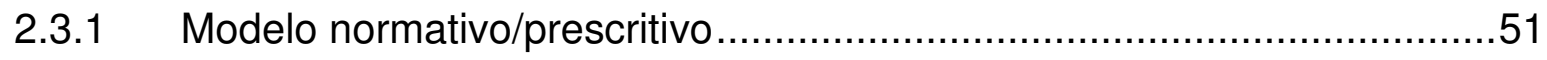

2.3.2 Modelo descritivo/cognitivo …………........................................54

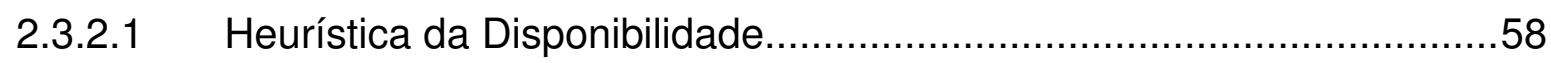

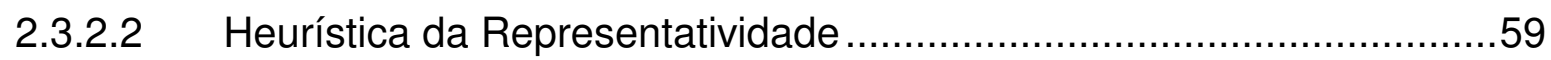

2.3.2.3 Heurística baseada na Ancoragem.................................................61

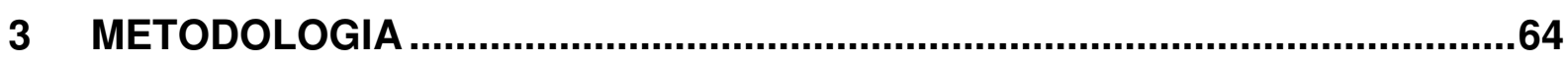

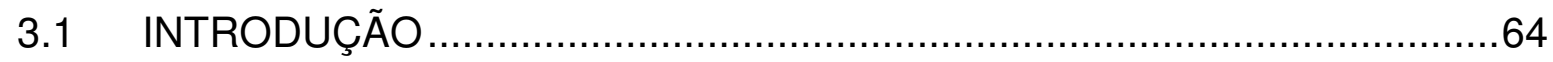

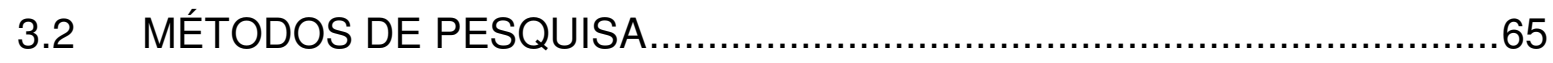

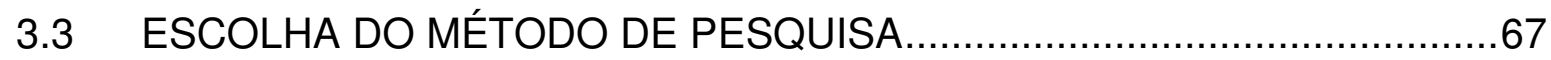

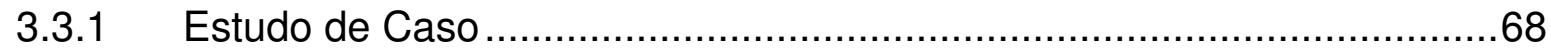

3.3.2 Instrumento e levantamento de dados ............................................70

3.3.3 Definição do Universo, da Amostra da pesquisa e dos casos .................72

3.3.4 Aplicação do questionário e entrevistas ...............................................74

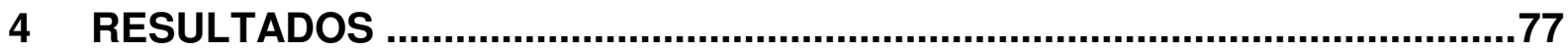

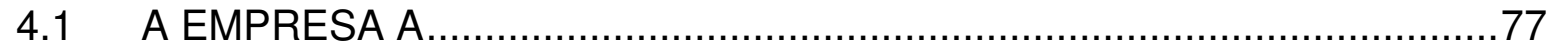

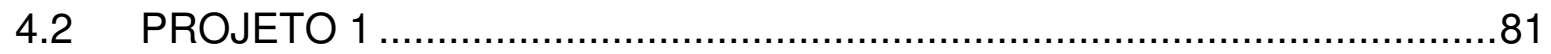

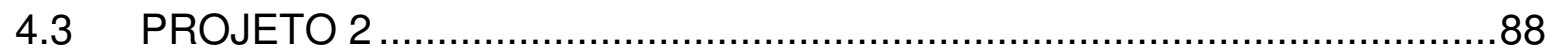

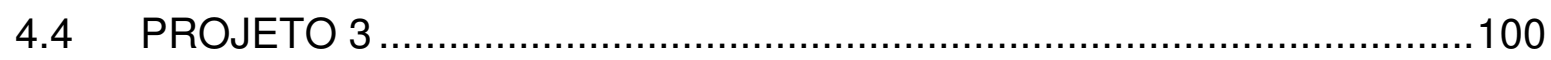

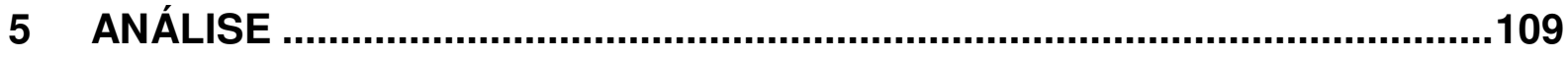

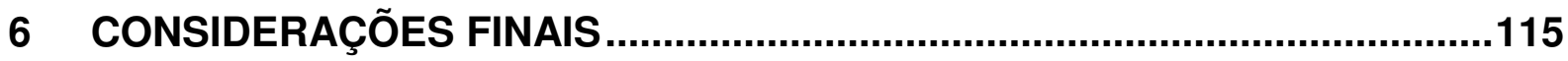

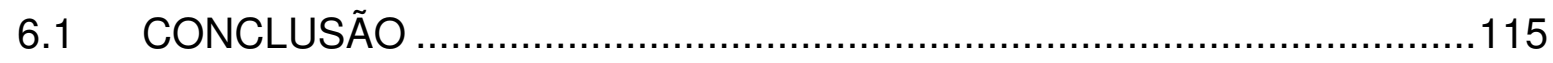

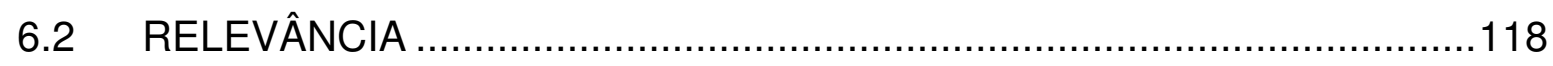




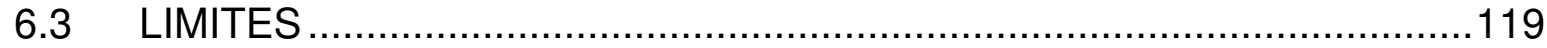

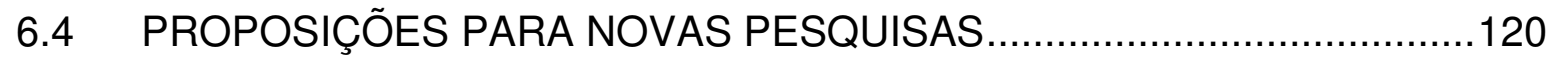

REFERÊNCIAS..................................................................................................121

APÊNDICE A - QUESTIONÁRIO DE PESQUISA .............................................133

APÊNDICE B - RESPOSTA COMPILADA DO QUESTIONÁRIO DE PESQUISA137 


\section{INTRODUÇÃO}

A crescente competitividade nas empresas em busca por um mercado globalizado impõe restrições cada vez maiores nos projetos. Como os clientes estão mais exigentes em termos de prazo, custo e qualidade observa-se um constante incremento na complexidade dos projetos, contribuindo de forma importante para o incremento dos riscos dos projetos.

Embora a sua incorporação ao Gerenciamento de Projetos foi relativamente tardia, somente na década de 1980, e seu crescimento na década de 1990, neste período muitos artigos e livros foram escritos sobre o tema. No entanto, o Gerenciamento de Riscos, apesar de reconhecida fortemente pela sua importância, ainda é uma área de difícil compreensão para a maioria dos gerentes de projeto.

Neste capítulo, será apresentada a contextualização no qual o trabalho está inserido. Posteriormente o problema da pesquisa será fundamentado e detalhado. Com os objetivos deste trabalho, buscam-se as referências a fim de responder as questões de estudo e embasar a pesquisa.

\subsection{CONTEXTUALIZAÇÃO}

Segundo Artto e Hawk (1999), o gerenciamento de projetos surgiu na década de 50 com o desenvolvimento de técnicas de planejamento tal qual Program Evaluation and Review Technique (PERT), mas foi somente na década de 80 que o gerenciamento de riscos se tornou uma área reconhecida na literatura de gerenciamento de projetos. Desta forma, o gerenciamento de riscos pode ser considerado como uma área de conhecimento ainda há ser explorada apesar de atualmente ser aceita como uma disciplina fundamental para os resultados dos projetos (ROYER, 2000; RAFELE; HILLSON; GRIMALDI, 2005; WIDEMAN, 1992). 
Apesar do notável crescimento da disciplina de gerenciamento de riscos em projetos, o que pode ser observado na extensa bibliografia que aborda este tema, o gerenciamento de riscos ainda não pode ser considerado como uma disciplina madura, uma vez que não se encontra integrada com os demais processos de gerenciamento de projetos, dificultando a tomada de decisão dos gerentes de projetos.

Segundo Bettman; Jonhson; Payne (1991), a questão da tomada de decisão está presente em praticamente todos os momentos da vida das pessoas e as pesquisas nesta área de estudo têm revelado que as pessoas têm capacidade limitada de processamento das informações e por isso usam freqüentemente heurísticas em suas tomadas de decisão.

No entanto, por causa da existência de limitações psicológicas dos seres humanos, para se tomar uma decisão com qualidade Clemen e Reilly (2001, p.11) entendem que uma decisão envolve compreensão profunda do problema e reflexão atenta em relação a questões importantes, enquanto os resultados, por sua vez, podem ser de sorte ou de azar, independentemente da qualidade da decisão. Esta compreensão profunda do problema dar-se-á somente com uma boa metodologia de gerenciamento de riscos.

Além das limitações dos seres humanos, o competitivo mercado de energia, especificamente no que abrange o segmento de hidrogeração, sempre esteve em busca de menores preços, melhores serviços, operações mais ágeis, confiáveis, seguras e, acima de tudo, de preservação do meio ambiente. Estas exigências têm sido vivenciadas desde 1883, quando a primeira usina hidrelétrica foi inaugurada no Ribeirão do Inferno na cidade de Diamantina e, em 1889, a primeira usina hidrelétrica de maior porte entrou em operação, a usina de Marmelos-Zero (ELETROBRÁS, 2009).

A partir daí, a construção de usinas hidrelétricas (UHE) no Brasil alcançou grande desenvolvimento especialmente nas décadas de 1920 a 1930, 1950 e 1970 (AGOSTINHO; GOMES; PELICICE, 2007). Mais de 600 barragens já foram construídas e ocupam uma área de aproximadamente $40.000 \mathrm{~km}^{2}$, com volume de 
$6,5 \times 10^{11} \mathrm{~m}^{3}$, com o principal intuito de gerar energia elétrica (AGOSTINHO; THOMAZ; GOMES, 2005).

$\mathrm{Na}$ década de 70 a industrialização brasileira apresentava extraordinário crescimento e sucesso que aquele período ficou conhecimento como a "década do milagre brasileiro". Havia um "boom" na construção civil, a produção industrial estava a todo vapor, o setor automobilístico estava em pleno crescimento, as pessoas tinham mais acesso a equipamentos eletrônicos e a siderurgia estava em marcha ascendente.

Neste mesmo período teve-se a entrada em operação de grandes usinas hidrelétricas para suprir este crescimento que conseqüentemente demandava mais energia, sendo alguns exemplos: UHE Marimbondo, Furnas, Paulo Afonso IV, Ilha Solteira, Itumbiara e etc. Também houve o início da mega construção da Usina Hidrelétrica de Itaipu que por mais de 20 anos foi considerada a maior Usina Hidrelétrica do mundo e atualmente é a segunda com 14.000 MW de potência instalada.

Uma usina hidrelétrica tem uma vida útil média de aproximadamente 35 anos. Após este período, precisam ser modernizadas para mantê-las confiáveis e lucrativas por mais 35 anos em média.

Atualmente o Brasil tem mais de 600 usinas hidrelétricas em operação sendo 15\% com mais de 30 anos e $35 \%$ tem entre 20 e 30 anos de operação comercial.

Através destas informações, observa-se um grande futuro para o mercado de modernizações, porém, assim como qualquer projeto, os projetos de modernizações são afetados pela ocorrência de eventos indesejáveis, denominados por alguns especialistas como incertezas e eventos de riscos, sendo a incerteza definida como um evento inesperado (PERMINOVA; GUSTAFSSON; WIKSTRÖM, 2008) ou impossível de se atribuir probabilidades (KERZNER, 2005), e evento de risco definido como um evento incerto com atributos de probabilidades de ocorrência e estimativa de impacto caso ocorra (MODARRES, 2006). 
Para melhorar o desempenho dos projetos, as empresas em geral têm investido muito dinheiro para criar uma metodologia de gerenciamento de riscos que subsidie o processo decisório dos gerentes de projetos objetivando um aumento significativo nos resultados das empresas. Este processo ainda encontra-se em fase de maturação, o que pode ser corroborado pela pesquisa de White e Fortune (2002) onde é apresentado que um número pequeno de gerente de projetos de empresas públicas e privadas dos Estados Unidos (em torno de 49,5\%) usa o gerenciamento de riscos como uma ferramenta de suporte as suas decisões. A Tabela 1 abaixo apresenta os resultados alcançados nesta pesquisa:

Tabela 1 - Percentual dos fatores críticos de sucesso - freqüência de menções

\begin{tabular}{llc}
\hline & \multicolumn{1}{c}{ Fatores } & $\%$ de respostas \\
\hline $1^{\circ}$ & Objetivos claros e definidos & $87,29 \%$ \\
$2^{\circ}$ & Cronograma Realista & $78,39 \%$ \\
$3^{\circ}$ & Suporte da Gerência & $74,58 \%$ \\
$4^{\circ}$ & Recursos Adequados & $69,49 \%$ \\
$5^{\circ}$ & Compromisso do usuário & $67,37 \%$ \\
$6^{\circ}$ & Canais de Comunicação Claros & $61,02 \%$ \\
$7^{\circ}$ & Liderança efetiva / resolução de conflito & $58,47 \%$ \\
$8^{\circ}$ & Feedback Ativo & $57,20 \%$ \\
$9^{\circ}$ & Abordagem flexiva para mudança & $56,36 \%$ \\
$10^{\circ}$ & Lições Aprendidas & $51,27 \%$ \\
$11^{\circ}$ & Influências externas & $51,27 \%$ \\
$12^{\circ}$ & Trabalho em equipe & $49,58 \%$ \\
$13^{\circ}$ & Gerenciamento dos Riscos & $49,58 \%$ \\
\hline \multicolumn{2}{c}{ (Fonte: adaptado de WHITE e FORTUNE, 2002). }
\end{tabular}

(Fonte: adaptado de WHITE e FORTUNE, 2002).

O presente trabalho se insere na área de gerenciamento de riscos em projetos e o processo decisório dos gerentes de projetos e explora sua aplicação em três projetos de modernização de uma empresa renomeada no mercado de Geração de Energia sendo dois bem sucedidos em relação aos resultados financeiros. $O$ mesmo não foi verificado no outro projeto, similar em escopo e tecnologia envolvida. Acredita-se que um dos principais fatores que contribuíram para a diferença no desempenho, em relação aos anteriores, foi a ausência de uma metodologia de gerenciamento de riscos. 


\subsection{JUSTIFICATIVA}

Segundo Patah (2004), o gerenciamento de projetos tem sido caracterizado como uma profissão acidental e as empresas perceberam que não podem mais conviver com este amadorismo.

Atualmente vive-se e trabalha-se em um tempo de rápidas mudanças, novos desafios e novas oportunidades. As empresas, com o intuito de sobreviver, incrementam constantemente seus processos. Os projetos são os principais veículos de mudanças e podem criar o futuro de uma empresa (BLOCK; FRAMA, 1998).

O The Standish Group (2008), baseando-se em uma pesquisa com mais de 10.000 projetos de tecnologia de informação, mostra que apenas 34\% dos projetos podem ser considerados bem executados. Segundo a mesma pesquisa o valor total de perda dos projetos nos EUA somado aos custos adicionais ultrapassa a marca de US\$ 55 bilhões. Grande parte destas perdas foi causada pela ausência de um procedimento estabelecido para a avaliação de riscos ou utilização de um procedimento não eficaz.

Baseado nas experiências vividas, os gerentes de projetos, bem como, seus administradores consideram somente os aspectos econômicos, como valor presente líquido, taxa interna de retorno entre outros em suas decisões.

Com o aumento da complexidade e diminuição da margem nos projetos, torna-se imprescindível analisar os riscos de uma maneira mais ampla. O suporte de uma metodologia para o gerenciamento de riscos durante a execução de um projeto auxilia o seu gerente a utilizar o fator racional em suas decisões.

Outra justificativa para a relevância deste estudo é que há poucas pesquisas que analisam a influência da metodologia de gerenciamento de riscos nos processos decisórios dos gerentes de projetos de forma a se obter melhores resultados na execução dos projetos. 
Neste contexto, é significativa a importância deste estudo uma vez que, em função da grande turbulência organizacional, as incertezas relativas aos projetos são cada dia maiores e uma decisão mal tomada pelo Gerente de Projetos poderá acarretar danos irreparáveis para a organização.

\subsection{OBJETIVOS}

O objetivo principal desta dissertação é confrontar a teoria com a prática no que diz respeito à metodologia de gerenciamento de riscos, bem como identificar as influências e/ou impactos que o uso desta produz no processo decisório dos gerentes de projetos.

Para ser alcançado este objetivo é necessário o atendimento dos seguintes objetivos secundários:

a) Identificar o conceito de riscos em projetos, seus principais tipos e conseqüências;

b) Identificar os conceitos de processos decisórios, suas principais características, aspectos cognitivos e prescritivos;

c) Identificar os conceitos e modelos de Gerenciamento de Riscos propostos na literatura a fim de observar os diferentes tipos e a maneira como cada modelo poderia influenciar a decisão dos gerentes de projetos;

\subsection{METODOLOGIA}

A metodologia adotada neste trabalho foi a realização de estudo múltiplo de casos, do tipo exploratório, indutivo, qualitativo e holístico.

Foram analisados 3 projetos de modernização de usina hidrelétrica, sendo estes de uma única empresa e semelhantes no que diz respeito a, complexidade, tipo de 
negócio, cliente, porém diferentes no que diz respeito a experiência do gestor de projetos, valores, momento econômico, diretoria do cliente e etc.

\subsection{ESTRUTURAÇÃO DA DISSERTAÇÃO}

O Capítulo 1 contextualiza o gerenciamento de projetos, mais especificamente o gerenciamento de riscos e os processos decisórios dos gerentes de projetos, principalmente no que tange os projetos de modernizações de usinas hidrelétricas. Apresenta o objetivo do trabalho e finaliza com a estruturação dos capítulos.

No Capítulo 2 faz-se uma fundamentação teórica, onde se aborda gerenciamento de projetos, eventos de risco e incerteza, o processo de decisão, a percepção do risco, o gerenciamento de risco e a metodologia do gerenciamento de risco.

O Capítulo 3 aborda a metodologia aplicada ao trabalho, os fundamentos da pesquisa científica, a escolha e justificativa do método, o processo metodológico, o instrumento de levantamento de dados e o protocolo do estudo de caso.

O Capítulo 4 apresenta a empresa pesquisada, os projetos analisados, o gerenciamento de projetos e de riscos nessa empresa, os conceitos utilizados e os resultados alcançados pela aplicação do questionário.

O Capítulo 5 apresenta as análises efetuadas mediante aos dados coletados e resultados encontrados.

O Capítulo 6 encerra o trabalho, apresentando as principais conclusões, relevâncias, os limites e a proposição para novas pesquisas.

O Capítulo 7 apresenta as referências bibliográficas utilizadas. 


\section{FUNDAMENTOS TEÓRICOS}

Neste capítulo, são abordados os fundamentos teóricos necessários ao desenvolvimento deste trabalho: gerenciamento de projetos, eventos de risco e incerteza, o processo de decisão, a percepção do risco, o gerenciamento de risco e a metodologia do gerenciamento de risco.

\subsection{GERENCIAMENTO DE PROJETOS}

Segundo PMI (2004), projeto é um empreendimento temporário com o objetivo de criar um produto ou serviço único, porém para Rabechini e Carvalho (1999), o conceito de projetos tem sido aprimorado a fim de estabelecer um entendimento comum nas organizações que trabalha com projeto.

A NBR ISO 10006 (2000) define projeto como um processo único, consistindo de atividades coordenadas e controladas com datas para início e término, empreendido para alcançar um objetivo conforme requisitos específicos, incluindo limitações de tempo, custo e recursos.

Para Tuman (1983), um projeto é uma organização de pessoas dedicadas visando atingir um propósito e objetivo específico. Segundo o autor, projetos geralmente envolvem gastos, ações únicas ou empreendimentos de altos riscos os quais têm que ser completados numa certa data por um montante de dinheiro, dentro de alguma expectativa de desempenho.

Segundo Patah (2004) o resultado das empresas está cada dia mais dependente dos resultados dos projetos, no entanto os projetos têm aumentado significativamente sua complexidade nos âmbitos de prazo, custo e qualidade. Para aumentar a probabilidade de êxito nos resultados, é imprescindível que o 
gerenciamento de projetos seja elemento chave no processo de transformação das empresas.

De acordo com o PMI (2004), o Gerenciamento de Projetos se refere à aplicação de conhecimentos, habilidades, métodos e ferramentas às atividades do projeto, a fim de atender aos seus requisitos.

Segundo Dinsmore (1993), a disciplina de gerenciamento de projetos teve como origem os trabalhos do U.S. Department of Defense, com os principais sistemas de desenvolvimento de armas, as missões espaciais da NASA e com os trabalhos de construção e manutenção de grandes obras executadas na Europa. Isto somente pôde ser realizado, principalmente devido à magnitude e a complexidade desses esforços, os quais motivaram a pesquisa de ferramentas que auxiliassem o planejamento, o gerenciamento, a tomada de decisão e o controle de todas as atividades envolvidas em projetos.

Segundo Pinto (2002), o gerenciamento de projetos é a interface entre os requisitos de gerenciamento geral, o gerenciamento operacional e o gerenciamento técnico, sendo que os aspectos operacionais estão relacionados à implementação de uma estratégia organizacional; os aspectos técnicos tendem a focar a teoria, tecnologia e a prática e os aspectos gerais de gerenciamento estão relacionados às competências.

Dentre os 3 requisitos supracitados, Fleury (2001) defende que para se obter uma boa gestão do projeto, é imprescindível que o time e, principalmente o gerente de projetos, desenvolva 3 grandes blocos de competências chaves: competências de negócios; competências técnico-profissionais e competências sociais.

Competências de negócios estão relacionadas à compreensão do negócio, seus objetivos e a relação com o mercado, cliente, competidores, assim como com o ambiente político e social. São competências de negócio:

- Planejamento: capacidade de estruturar e sistematizar ações para aproveitar oportunidades e pontos fortes e minimizar as ameaças e pontos fracos; 
- Visão estratégica: conhecimento do negócio, dos ambientes em que a empresa está inserida, identificando as oportunidades, ameaças, pontos fortes e pontos fracos. Comprometimento com a missão, visão e os valores da empresa pelo qual trabalha. Ter o foco no futuro a fim de desenvolver as competências chaves para o atendimento das metas.

Competências técnico-profissionais são competências específicas para certa operação, ocupação ou atividade e estão associadas à posse de informações e conhecimentos técnicos relativos à sua área de atuação.

Competências sociais são competências necessárias para a interação com as pessoas. São competências sociais:

- Comunicação: compreender o processo de comunicação em sua totalidade, garantindo o entendimento das mensagens pelos demais membros da organização;

- Trabalho em Equipe: criar e trabalhar com grupos de pessoas que detenham habilidades e conhecimentos diversos e complementares, propiciando 0 surgimento de sinergia;

- Negociação: ter capacidade de discutir, estimular e influenciar positivamente outras pessoas a colaborarem, efetivamente, para atingir os objetivos organizacionais, conduzir processos de obtenção de consenso, objetivando resultados satisfatórios para as partes envolvidas.

Segundo Pinto (2002), o PMI (Project Management Institute) promoveu a iniciativa de sistematizar o conhecimento acumulado sobre a disciplina gerenciamento de projetos, a fim de criar uma estrutura reconhecida e independente de conhecimento que pudesse levar a uma maior profissionalização das práticas aplicadas nesse setor. A motivação para o trabalho surgiu da constatação de que os principais aspectos do gerenciamento de projetos derivam das seguintes constatações:

a) Diferenças de percepções individuais dos envolvidos em projetos (mesmo sobre o mesmo evento); 
b) Diferenças entre experiência e resultados obtidos (mesmo para projetos similares);

c) Diferenças entre projetos (em termos de parâmetros tais como tamanho, complexidade, indústria, tecnologia, etc);

d) Visão limitada dos aspectos envolvidos na disciplina por parte das pessoas envolvidas em gerência de projetos.

PMI (2004) apresenta o gerenciamento de projetos como uma área de conhecimento que possui intersecções com as demais áreas de conhecimento em administração. A Figura 1 ilustra estas interseções.

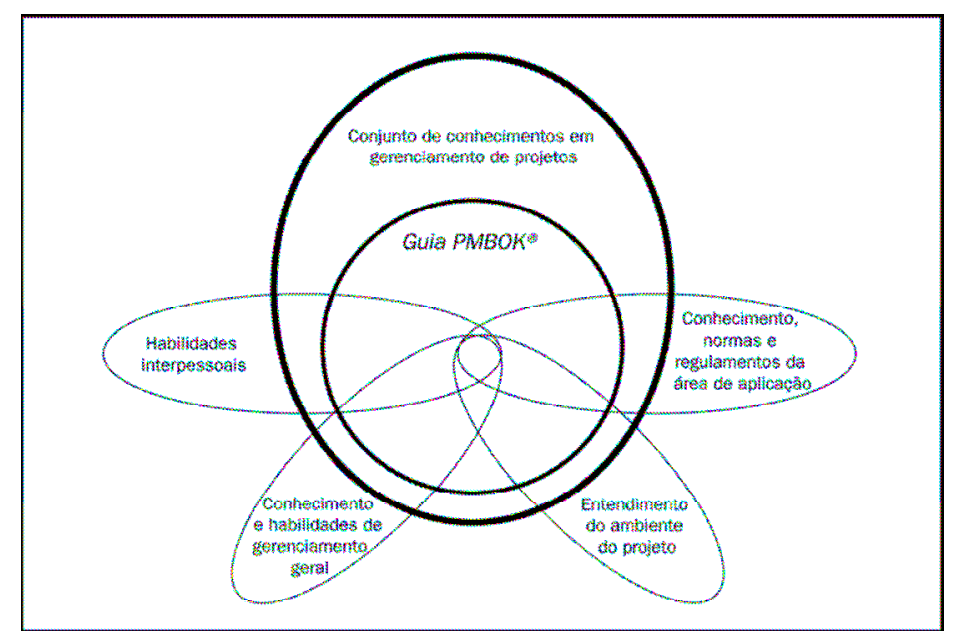

Figura 1. Áreas de especialização necessárias à equipe de gerenciamento de projetos FONTE: PMI, 2004, p.13

Atualmente o gerente de projetos é o ponto de contato entre os principais stakeholders, dentre eles, clientes, fornecedores, gerentes funcionais e alta administração da empresa. Segundo Crawford (2002) o gerente de projetos influencia em mais de $50 \%$ da boa execução de um projeto.

Casarotto; Fávero; Castro (1999) apresentam a seguinte lista de competências chaves para um gerente de projetos a fim de poder influenciar nesta boa execução destes projetos:

- Flexibilidade; 
- Iniciativa;

- Liderança;

- Agressividade;

- Confiança;

- Ambição;

- Fluência na comunicação;

- Integração;

- Organização;

- Disciplina;

- Generalista ao invés de especialista;

- Tomada de decisão;

- Administração do tempo.

Já Klose (2002) apud Patah (2004) apresenta a seguinte lista com os principais papéis dos gerentes de projetos:

- Coordenação;

- Motivação;

- Decisão;

- Avaliação;

- Análise;

- Liderança;

- Controle;

- Organização.

Segundo The Standish Group (1999) apud Patah (2004), as características mais importantes de um gerente de projetos são:

- Multilingual

- Controlador de custos

- Coordenador de recursos

- Condutor de equipe

- Parecidos com presidentes de pequenas empresas 
No entanto, visando a mitigação das incertezas inerentes aos projetos, além das competências, diversos autores tratam o gerenciamento de projetos segundo o enfoque de processos (VERZUH, 1999; KERZNER, 2002; DINSMORE; NETO, 2004; MAXIMIANO, 2002; PMI, 2004).

Verzuh (1999) propõe uma estruturação dos projetos por meio dos processos de definição, planejamento, execução e encerramento e menciona que estes processos ocorrem por várias vezes ao longo dos vários estágios do ciclo de vida do projeto.

Maximiano (2002) afirma que os processos de gerenciamento de projetos planejamento, organização, execução e controle são necessários para o projeto como um todo.

Kerzner (2002) ratifica a importância dos processos de gerenciamento de projetos e ressalta a importância da estrutura organizacional no gerenciamento de projetos. Afirma também que é muito difícil duas empresas gerenciarem seus projetos da mesma maneira e, por isso, a implementação do gerenciamento de projetos deve ter seu modelo estruturado dentro dos padrões de cada empresa.

Segundo Forsberg et al (1996), para se obter uma eficiência no gerenciamento de projetos, os modelos ou os processos devem seguir as seguintes características:

- Definição explícita e operacional, utilizando estruturas, variáveis e relacionamentos;

- Serem óbvios e intuitivos a todos os interessados no projeto;

- Aplicável ao ambiente do projeto e seus requisitos;

- Validados empiricamente no mundo real

Segundo o PMI (2004), o gerenciamento de projetos é realizado através de processos, usando conhecimento, habilidades, ferramentas e técnicas. Basicamente, existem duas categorias principais de processos em projetos:

a) Processos de gerenciamento de projetos: comuns à maioria dos projetos na maior parte do tempo, são associados entre si por seu desempenho visando um objetivo integrado. O objetivo é iniciar, planejar, executar, monitorar 
controlar, e encerrar um projeto. Esses processos interagem entre si de forma complexa.

b) Processos de gerenciamento de produtos: Os processos orientados ao produto especificam e criam o produto do projeto. São normalmente definidos pelo ciclo de vida do projeto e variam por área de aplicação.

Segundo PMI (2004), os grupos de processos de gerenciamento de projetos encontram-se agregados em cinco grupos, a saber:

- Grupo de processos de iniciação. Define e autoriza o projeto ou uma fase do projeto;

- Grupo de processos de planejamento. Define e refina os objetivos e planeja a ação necessária para alcançar os objetivos e o escopo para os quais o projeto foi realizado;

- Grupo de processos de execução. Integra pessoas e outros recursos para realizar o plano de gerenciamento do projeto para o projeto;

- Grupo de processos de monitoramento e controle. Mede e monitora regularmente o progresso para identificar variações em relação ao plano de gerenciamento do projeto, de forma que possam ser tomadas ações corretivas quando necessário para atender aos objetivos do projeto;

- Grupo de processos de encerramento. Formaliza a aceitação do produto, serviço ou resultado e conduz o projeto ou uma fase do projeto a um final ordenado.

Os grupos de processos acima propostos estão ligados pelos objetivos que produzem e raramente representam eventos distintos e únicos. Em geral têm atividades sobrepostas, que demandam diferentes níveis de esforço durante todo o projeto e que interagem entre si dentro de uma mesma fase ou ao longo de várias fases do ciclo de vida. A Figura 2 abaixo representa a estruturação dos grupos de processos ao longo de diferentes fases de um projeto e a sobreposição dos grupos.

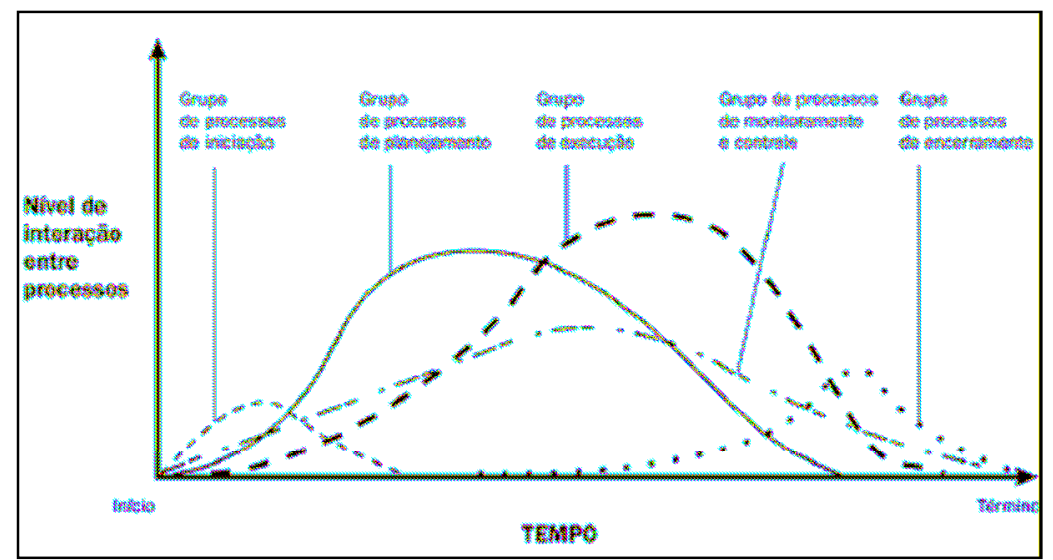

Figura 2. Interação de grupos de processo em um projeto FONTE: PMI, 2004, p.68 
Compreendidos nos cinco grupos de processos já mencionados, estão 44 processos de gerenciamento de projetos. Segundo o PMI (2004), esses processos estão distribuídos ao longo das nove áreas de conhecimento, a saber:

- Gerenciamento de integração: descreve os processos e as atividades que integram os diversos elementos do gerenciamento de projetos, que são identificados, definidos, combinados, unificados e coordenados dentro dos grupos de processos de gerenciamento de projetos;

- Gerenciamento do escopo: descreve os processos envolvidos na verificação de que o projeto inclui todo o trabalho necessário, e apenas o trabalho necessário;

- Gerenciamento de tempo: descreve os processos relativos ao término do projeto no prazo correto;

- Gerenciamento de custos: descreve os processos envolvidos em planejamento, estimativa, orçamentação e controle de custos, de modo que o projeto termine dentro do orçamento aprovado;

- Gerenciamento da qualidade: descreve os processos envolvidos na garantia de que o projeto irá satisfazer os objetivos para os quais foi realizado;

- Gerenciamento de recursos humanos: descreve os processos que organizam e gerenciam a equipe do projeto;

- Gerenciamento das comunicações: descreve os processos relativos à geração, coleta, disseminação, armazenamento e destinação final das informações do projeto de forma oportuna e adequada;

- Gerenciamento de riscos: descreve os processos relativos à realização do gerenciamento de riscos em um projeto;

- Gerenciamento de aquisições: descreve os processos que compram ou adquirem produtos, serviços ou resultados, além dos processos de gerenciamento de contratos.

Apesar de todo o detalhamento oferecido pelas bibliografias apresentadas, faz-se ressalva de que os conhecimentos, as habilidades e as técnicas não devem ser aplicados uniformemente em todos os projetos. Cabe ao gerente de projetos, juntamente com sua equipe selecionar os processos adequados para se alcançar o sucesso do gerenciamento do projeto.

\subsection{GERENCIAMENTO DE RISCOS}

\subsubsection{Risco e Incerteza}

O significado da palavra risco, segundo Houaiss e Villar (2001), indica probabilidade de insucesso, de malogro de determinada coisa, em função de acontecimento 
eventual, incerto, cuja ocorrência não depende exclusivamente da vontade dos interessados.

A origem etimológica da palavra "risco", no entanto, apresenta algumas versões. Bernstein (1997), aponta a origem como do italiano antigo, derivando de risicare, que tem como significado "ousar". Para Bueno (1974), esta palavra tem uma origem marítima (rhízikon, que deriva de rhiza), da linguagem dos navegantes, com o significado de borda de penhascos, de recifes, que representavam sempre grande perigo.

De acordo com Raz e Hilson (2005), não existe um consenso na literatura com relação à definição do termo risco. Dentro deste contexto, tais autores classificam a definição de risco em três grupos:

(i) riscos são eventos incertos que tem somente efeito negativo no projeto.

(ii) riscos são eventos incertos que podem ter tanto efeito positivo, denominado de oportunidade, quanto negativo (ameaça) no projeto e por fim

(iii) riscos são eventos incertos que tem efeitos no projeto. Essa última definição não explicita se os efeitos são negativos ou positivos.

O Project Management Institute (2004) define risco como um evento ou condição incerta que, se ocorrer, tem um efeito positivo ou negativo nos objetivos do projeto, mas não define incerteza no seu livro, o Project Management Body of Knowledge (PMBOK).

Para Modarres (2006), o termo risco significa não somente a ocorrência de um evento indesejável, mas também quão provável e quais as conseqüências caso ocorra.

Markowitz (1959) define o risco como a medida de dispersão entre o possível retorno de um ativo e o que se espera efetivamente ganhar. 
$\mathrm{Na}$ área financeira, Gitman (1997, p. 202) define risco como a possibilidade de prejuízo financeiro.

Para a Associação Brasileira de Normas Técnicas (2005, p. 2), risco é a combinação da probabilidade de um evento e de suas conseqüências, mas não faz menção à palavra incerteza.

Smith e Merritt (2002) propõem um Modelo Padrão de Risco que engloba outros elementos para a caracterização dos riscos. A Figura 3 apresenta o Modelo Padrão de Risco e sua representação gráfica que mostra o relacionamento entre os elementos do risco. A Tabela 2 apresenta a definição desses elementos.

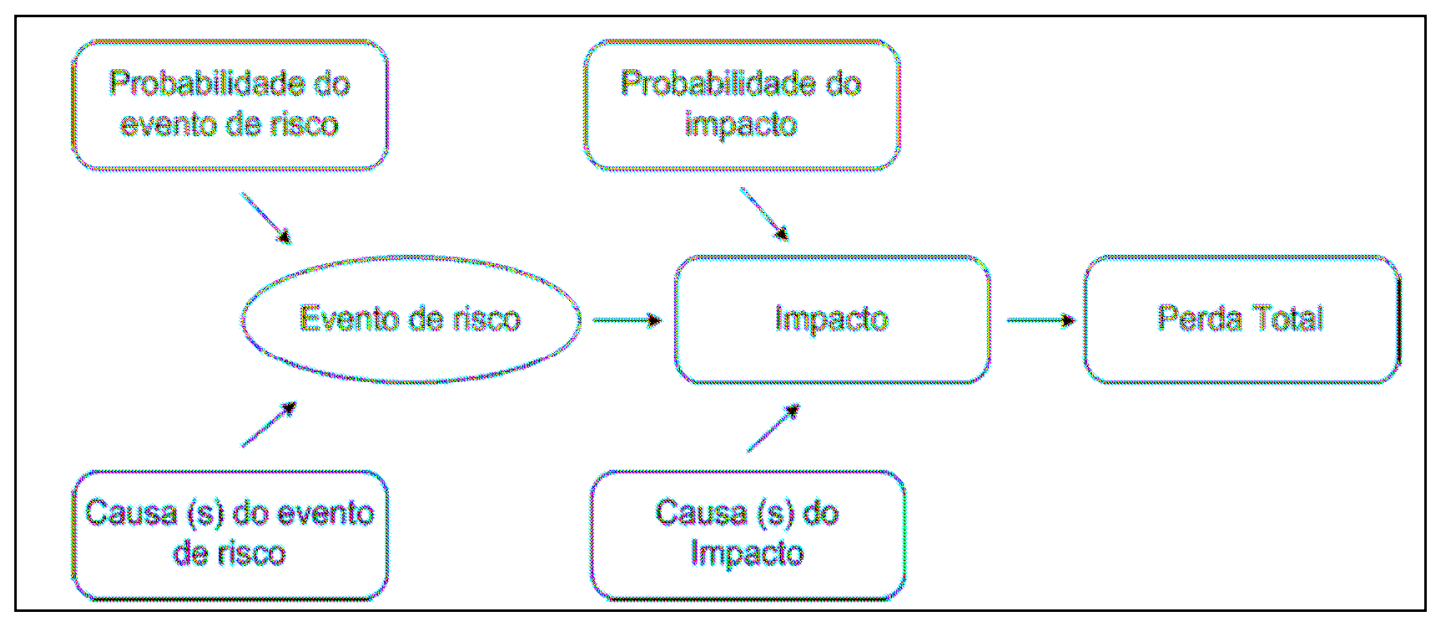

Figura 3. Modelo Padrão de Risco

Fonte: Smith e Merrit, 2002.

Tabela 2 - Definição dos elementos do modelo padrão de Riscos

\begin{tabular}{ll}
\hline \multicolumn{1}{c}{ ELEMENTOS } & \multicolumn{1}{c}{ DEFINIÇÃO } \\
\hline Evento de Risco & Evento Negativo que pode vir a causar uma perda. \\
Probabilidade do Evento de Risco & Probabilidade do risco ocorrer. \\
Causa(s) do evento de Risco & Razões que fazem o risco existir \\
Impacto & Conseqüências ou perdas que podem resultar da ocorrência \\
& do risco \\
Probabilidade do impacto & Probabilidade de o impacto ocorrer caso o risco se concretize. \\
& A probabilidade do impacto nem sempre é 100\% \\
Causas(s) do impacto & As causas dos impactos são todas as razões que levam a \\
& existência do impacto. O evento de risco é a causa principal do \\
& impacto, porém, podem existir no projeto, outras razões que \\
& acarretam a existência do impacto. \\
& Valor da perda resultante da ocorrência do risco. Recomenda- \\
Perda Total & se que esta perda total seja medida em dinheiro ou dias. Para \\
& obtenção da perda total pode se levar em consideração as \\
& estimativas feitas no planejamento do projeto e a opinião de \\
& especialistas. \\
\hline
\end{tabular}

Fonte: Smith e Merrit, 2002. 
Pritchard (2001) expressa que um risco é composto por três elementos fundamentais: o evento, a probabilidade e a severidade (impacto). O evento é a descrição do risco que pode ocorrer. Uma vez definido o evento do risco, a sua probabilidade de ocorrência pode ser estimada através de cálculos estatísticos e da teoria da probabilidade, o que nem sempre é possível de se obter objetivamente. Já a severidade, reflete o impacto da ocorrência do risco sobre os objetivos do projeto.

Segundo Raftery (1994), o risco está intimamente relacionado com a incerteza. Se a distinção usualmente adotada entre estes termos passar pelo fato de que a incerteza não tem atributos quantificáveis, o risco, por sua vez, é quantificado, em muito, por atributos subjetivos, baseados em opiniões, julgamentos profissionais ou graus de credibilidade sobre os eventos.

No entanto, como a palavra incerteza não é auto-explicativa e também não é um sinônimo de risco, pode-se dizer que o risco é uma das implicações de incertezas e não incertezas em si (PERMINOVA; GUSTAFSSON; WIKSTRÖM, 2008).

Segundo Olsson (2002), o risco é caracterizado pela incerteza de resultados futuros. Só há risco quando há incerteza, mas pode haver incerteza sem risco. Os riscos podem ser classificados, quanto à percepção que se tem do risco, em riscos conhecidos (certos e incertos) e riscos não conhecidos segundo PMI (2004).

Para Morgan e Henrion (1990) é preciso distinguir risco de incerteza, os riscos são eventos sobre os quais podemos refletir em termos de serem factíveis de ocorrer, enquanto que a incerteza é o domínio do imprevisível, daquilo sobre o qual, naquele momento não se pode elaborar previsões.

De acordo com Dinsmore (2003, p. 169), "no início do projeto, são maiores as incertezas e estas vão diminuindo à medida que se avança no seu desenvolvimento. O impacto dos riscos, ao contrário, aumenta à medida que o tempo passa e se caminha para as fases finais do projeto". Daí a importância de se conduzir o gerenciamento de riscos desde o início do projeto. O Gráfico 1, extraído de Dinsmore (2003), representa, de forma genérica, a evolução das incertezas e do impacto dos riscos ao longo do ciclo de vida do projeto. 


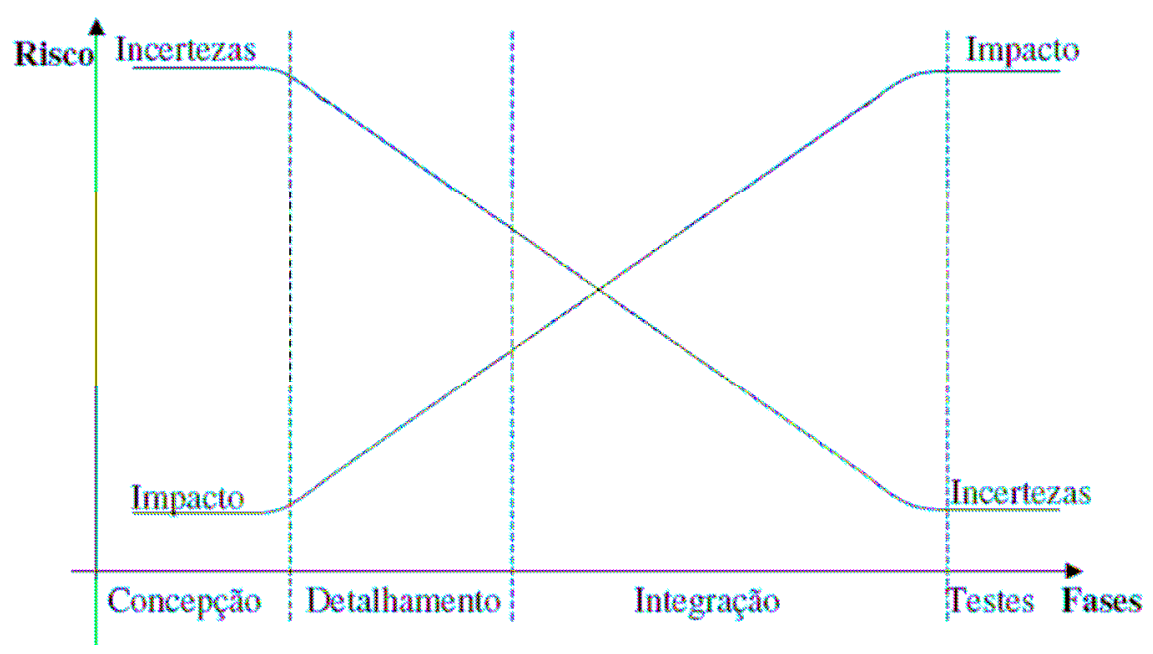

Gráfico 1. Incerteza versus impacto do Risco no decorrer do projeto Fonte: Dinsmore (2003)

Wideman (1992) comenta que a maioria das decisões é tomada sem o conhecimento da totalidade das informações, introduzindo um grau de incerteza sobre o resultado. Em certos casos, pode-se chegar à total falta de informação, onde nada é conhecido sobre o resultado, predominando, então, a absoluta incerteza. A Figura 4 traz um espectro sobre o grau de incerteza presente sobre os riscos do projeto.

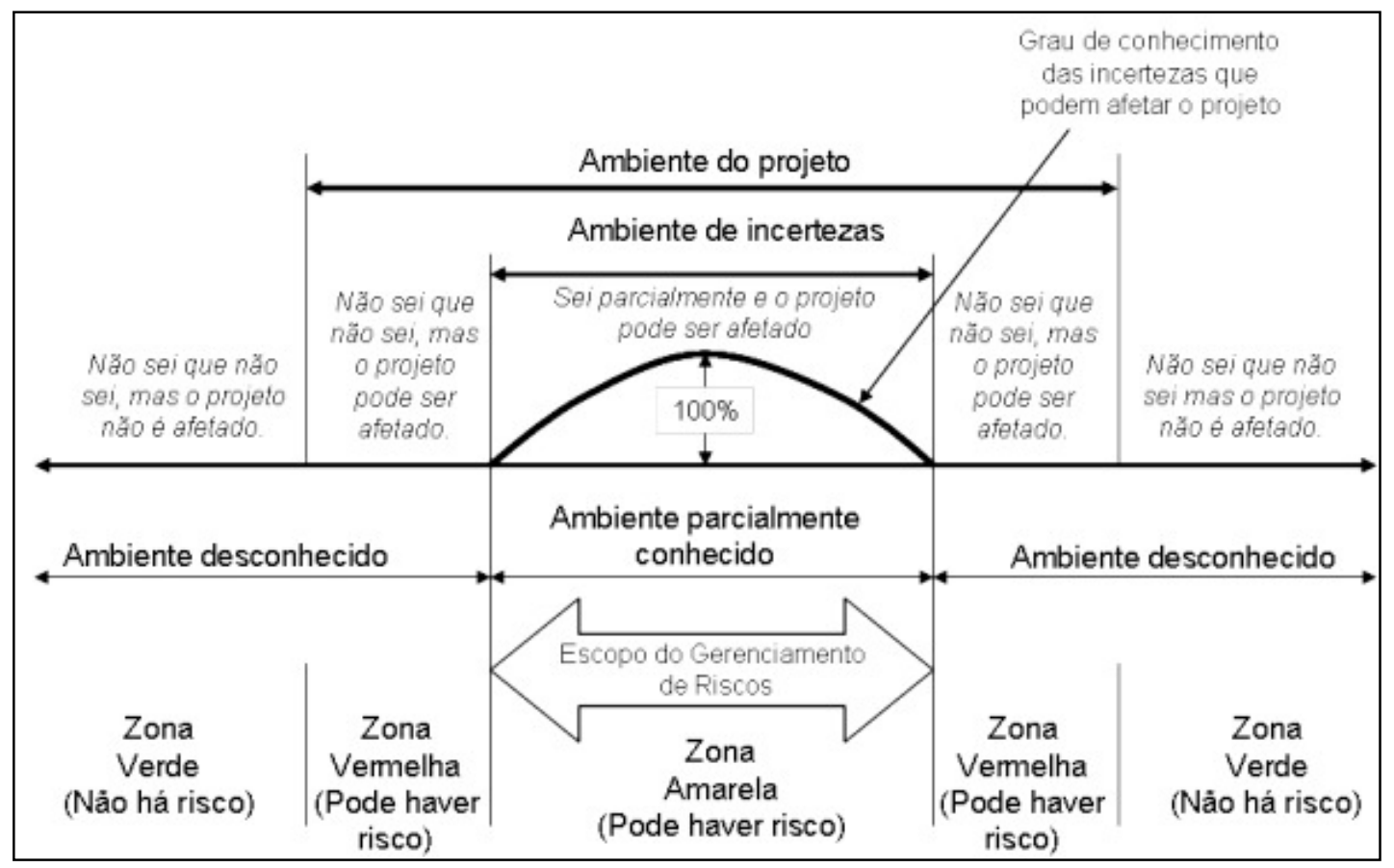

Figura 4

Figura 4. Espectro da Incerteza do Gerenciamento de Riscos

Adaptado de Wideman, 1992 apud Modica 2009. 
No âmbito dos projetos, o gerente de projetos poderia considerar os efeitos potencialmente negativos dos riscos e estabelecer medidas preventivas; já no caso da incerteza, tem-se um evento ou situação inesperada independentemente de ter sido ou não possível considerá-lo antecipadamente (PERMINOVA; GUSTAFSSON; WIKSTRÖM, 2008).

Segundo os mesmos autores supracitados, a forma como a incerteza é percebida pelos gerentes de projetos depende das competências pessoais, intuição e julgamento, portanto são incalculáveis e incontroláveis.

No entanto a maioria dos autores que tratam de Gerenciamento de Riscos considera a definição de risco em função de sua probabilidade e impacto. Tal definição apresenta, porém, algumas desvantagens: definição simplificada que não aborda elementos importantes do risco, como: causas, perda total, entre outros; além de não permitir o uso do conceito causa e efeito entre riscos, conceito importante em projeto que é a sua interdependência com as outras áreas de conhecimento.

As definições de risco e incertezas, bem como a relação entre elas, embora geralmente aceita como existente, não são objeto de um consenso conceitual entre os vários autores. Dessa forma, é importante ressaltar que, nesta pesquisa, será adotado para risco o conceito apresentado por Raz e Hilson (2005), que significa eventos incertos que tem efeitos no projeto podendo estes ser negativos ou positivos.

\subsubsection{Tipos de Riscos}

Segundo Hall e Hulett (2002) é imprescindível o entendimento da ampla gama de riscos que envolvem os projetos a fim de permitir a identificação dos potenciais riscos que poderão afetar as atividades, ou os objetivos de um determinado projeto. Nos próximos itens são apresentados alguns dos principais riscos definidos, conforme a divisão por áreas, categorias e por tipos de riscos do Relatório Final sobre Riscos Universais em Projetos, RISKSIG - PMI, de Hall e Hulett (2002). 


\subsubsection{Riscos externos}

Um conjunto razoável de riscos, além da capacidade de intervenção ou controle da empresa ou organização que detém o projeto. Áreas de riscos externos incluem as ações de terceiros (exemplos: clientes, outros interessados, fornecedores, reguladores, concorrentes, etc.), forças climáticas, demográficas, mercados, materiais e crescimento econômico.

\subsubsection{Riscos tecnológicos}

Um conjunto de riscos inerentes à tecnologia e processos usados em um projeto, produto, sistema ou análise. Riscos tecnológicos abrangem as capacidades, as tecnologias de apoio e processos de desenvolvimento e operação, bem assim a análise do produto/sistema final.

\subsubsection{Riscos organizacionais}

As organizações têm várias características, por exemplo, multi-projetos com problemas de recursos ou comunicações frágeis. A administração pode cobrir falhas mais específicas como falta de liderança, fraco controle sobre mudanças, estimativas imprecisas (poderia ser endêmico a organizações), aplicação fraca de ferramentas de administração de projetos (por exemplo, de programação), etc. Estas são características da organização que geram motivos para o não atingimento dos objetivos, a despeito da existência de um bom sistema para gerenciamento de projetos. 


\subsubsection{Riscos a clientes}

Indefinições e falta de controle das alterações de escopo e especificações incorretas, qualidade inadequada geralmente conduzem a riscos nas relações com os clientes. A cultura do cliente, sua estrutura organizacional, sua curva de experiência são indicadores de riscos nas relações com os clientes. Histórico de relações com os clientes pode evitar riscos nas referidas relações, vez que o conhecimento de sua conduta poderá revelar como se deve tratá-lo para melhor satisfazê-lo.

\subsubsection{Cronograma}

A maior parte dos cronogramas de projetos são imprecisos. Durante as análises de risco de cronogramas e custos, entrevistas revelam que as estimativas "mais prováveis" são novas ou revisadas. Isto se dá porque algo mudou ou porque as estimativas originais eram incompletas, ou eram subestimadas para ganhar da concorrência.

\subsubsection{Requisitos e de especificações de escopo}

Ainda, exigências e designs de implementação sempre estão mudando. Em um processo de desenvolvimento manual, mudanças nos requisitos causam muito retrabalho.

Segundo Wideman (1992), as fontes comuns de riscos são:

- Riscos externos - Direcionados à vulnerabilidade dos projetos em relação às mudanças na legislação, ações governamentais ou em desastres físicos, ambientais ou climáticos. 
- Riscos não-técnicos (gerenciamento) - Referem-se à complexidade dos processos envolvidos no gerenciamento de projetos, como a possibilidade de obter e utilizar fontes de dados defasadas ou o uso inadequado das disciplinas de gerenciamento de projetos. Também se atribui à inconsistência das organizações relacionadas com o projeto, como incoerências de objetivos, interrupções financeiras e deslocamento de prioridades.

- Riscos técnicos - Associados ao desenvolvimento ou melhoria da tecnologia, qualidade ou desempenho do projeto ou de seus produtos, que podem possibilitar uma melhor eficiência do que a planejada inicialmente.

- Riscos legais - relacionados com questões trabalhistas e contratuais.

Segundo Cleland e Ireland (2002) os riscos podem ser divididos em duas categorias: interno e externo, conforme mostra a Figura 5.

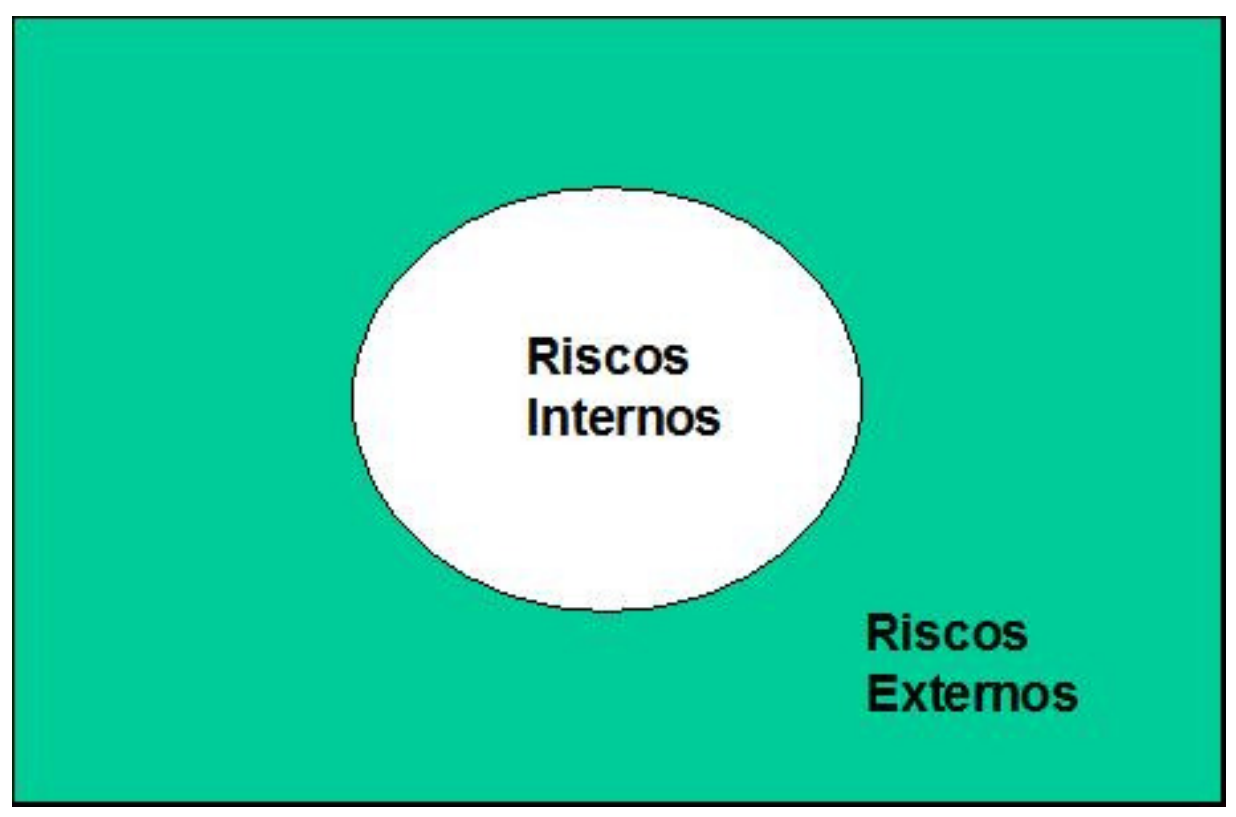

Figura 5. Riscos internos e externos dos projetos

Fonte: Adaptado de Cleland e Ireland (2002)

Para Cleland e Ireland (2002) o risco interno é inerente ao projeto, controlado pelo líder podendo reduzi-lo mediante ações diretas, com o desenvolvimento de planos 
de contingências. Já o risco externo encontra-se fora do controle dos líderes de projeto, como, por exemplo, as interfaces de projeto desconhecidas e cujas definições são feitas por terceiros.

A FERMA (2002) também usa o conceito de riscos internos e externos e diz que a classificação dos riscos pode ser ajustada, e faz a distinção dos mais relevantes entre os riscos puros e os de ordem estratégicos, financeiros, operacionais, etc. A Figura 6 abaixo propõe exemplos de alguns dos principais riscos.

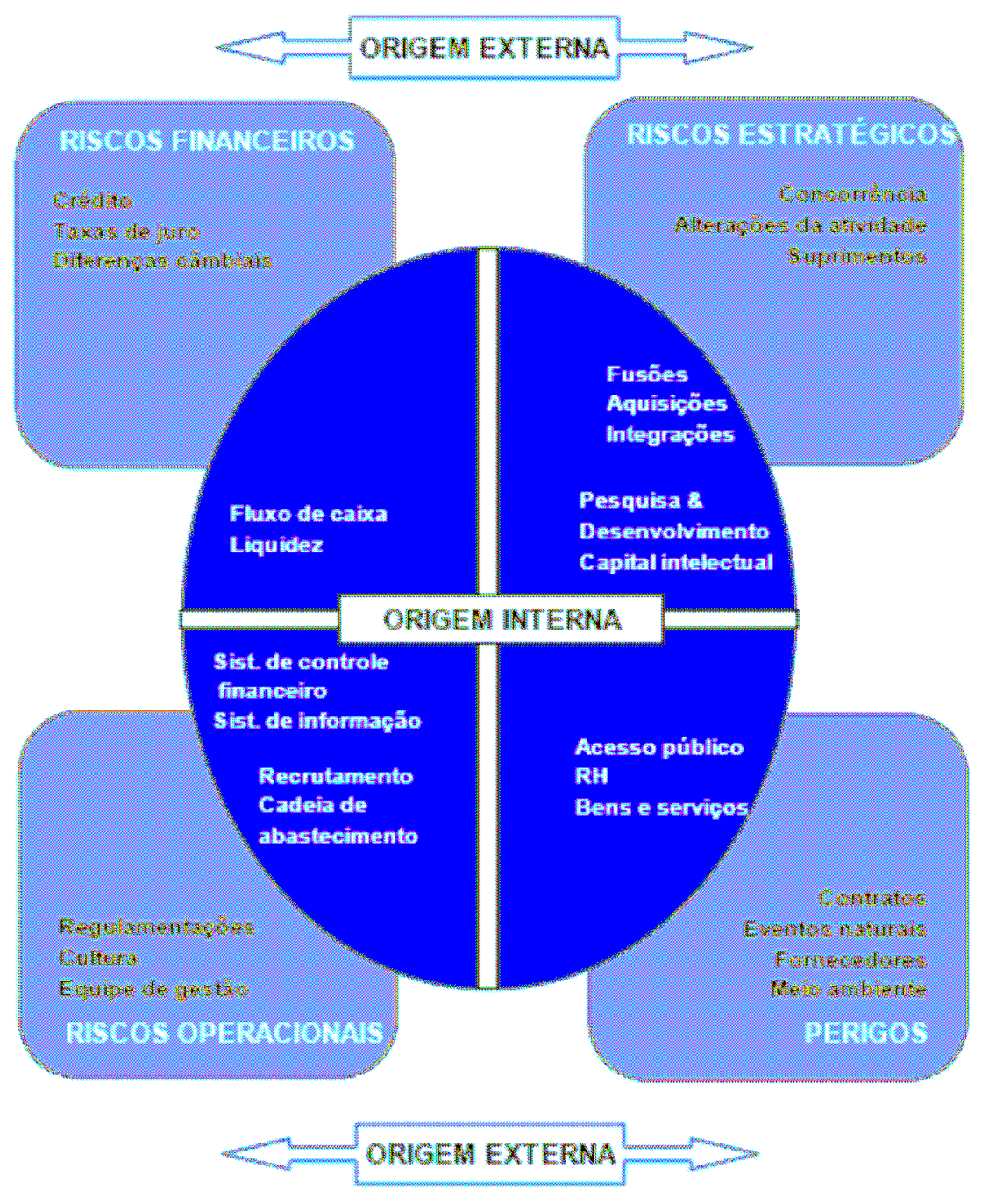

Figura 6. Origem dos riscos

Fonte: FERMA - Federation of European Risk Management Associations (2002) 


\subsubsection{Gerenciamento de Riscos em Projetos}

Módica (2009) relata que vários pesquisadores têm estudado o gerenciamento de riscos. Zwikael e Globerson (2006) pesquisaram os fatores críticos de sucesso entre duzentos e oitenta e dois gerentes de projeto; White e Fortune (2002) também pesquisaram os fatores de sucesso entre duzentos e trinta e seis gerentes de projeto; Raz e Michael (2001) identificaram as ferramentas mais utilizadas através da análise de oitenta e quatro questionários respondidos; Olsson (2007) pesquisou em oito companhias a utilização do gerenciamento de riscos para identificar oportunidades e não somente eventos negativos; Lyons e Skitmore (2004) pesquisaram em quarenta e quatro organizações a utilização de práticas de gerenciamento de riscos, ferramentas, técnicas e metodologias; Akintoye e MacLeod (1997) analisaram a percepção dos riscos em quarenta e três empresas; Baker, Ponniah e Smith (1999) identificaram as formas de respostas aos eventos de riscos através de cento e trinta e nove respondentes de cinqüenta e duas empresas.

lbbs e Kwak (2000) apud Módica (2009) pesquisaram durante aproximadamente dois anos a maturidade do gerenciamento de projetos em quatro diferentes grupos de empresas: engenharia e construção, telecomunicações, desenvolvimento de softwares e indústria de alta tecnologia. Participaram da pesquisa trinta e oito grandes companhias internacionais dos setores público e privado, sendo quinze de engenharia e construção, dez de telecomunicações, dez de tecnologia da informação e três indústrias de alta tecnologia.

Foram preparadas cento e quarenta e oito questões estratificadas pelas oito áreas de conhecimento do PMBOK (escopo, tempo, custo, qualidade, recursos humanos, comunicações, risco e aquisições) e o nível de conhecimento foi classificado segundo uma escala variando de um a cinco, sendo o um o nível mais baixo da maturidade em gerenciamento de projetos, e o cinco o nível mais alto.

Identificou-se com esta pesquisa que as empresas estão mais profissionalizadas no gerenciamento do custo, do escopo e do tempo, sendo o gerenciamento do risco a área de conhecimento menos desenvolvida. 
Os resultados da pesquisa foram obtidos através do calculo das médias das respostas de cada questão agrupadas por área de conhecimento, por tipo de companhia e total, sendo os mesmos apresentados na Tabela 3.

Tabela 3 - Maturidade das oito áreas do gerenciamento de projetos

\begin{tabular}{cccccc}
\hline $\begin{array}{c}\text { Áreas de conhecimento do } \\
\text { gerenciamento de projetos }\end{array}$ & $\begin{array}{c}\text { engenharia e } \\
\text { construção }\end{array}$ & telecomunicações & $\begin{array}{c}\text { desenvolvimento } \\
\text { de softwares }\end{array}$ & $\begin{array}{c}\text { indústria } \\
\text { de alta } \\
\text { tecnologia }\end{array}$ & $\begin{array}{c}\text { Total das 38 } \\
\text { companhias }\end{array}$ \\
\hline Escopo & 3.52 & 3.45 & 3.25 & 3.37 & 3.42 \\
Tempo & 3.55 & 3.41 & 3.03 & 3.50 & 3.47 \\
Custo & 3.74 & 3.22 & 3.20 & 3.97 & 3.06 \\
Qualidade & 2.91 & 3.22 & 2.88 & 3.26 & 3.12 \\
Recursos Humanos & 3.18 & 3.20 & 2.93 & 3.18 & 3.44 \\
Comunicações & 3.53 & 3.53 & 3.21 & 3.48 & 2.85 \\
$\quad$ Risco & 2.93 & 2.87 & 2.75 & 2.76 & 3.14 \\
Aquisições & 3.33 & 3.01 & 2.91 & 3.33 & 3.24 \\
\hline $\begin{array}{l}\text { Maturidade geral das áreas de } \\
\text { conhecimento do }\end{array}$ & 3.34 & 3.24 & 3.02 & 3.36 \\
\hline gerenciamento de projetos & & & &
\end{tabular}

Fonte: Ibbs e Kwak (2000) apud Modica (2009).

White e Fortune (2002, p. 7) citam que "[...] há abundante argumentação que muitos projetos fracassam devido a um inadequado gerenciamento de riscos [...]" e grande parte das referências sobre gerenciamento de riscos pesquisadas neste trabalho reconhece gerenciamento de riscos como fator crítico para a execução dos projetos.

O gerenciamento de riscos é "uma maneira organizada de identificação e mensuração dos riscos e desenvolvimento e seleção de opções para gerenciá-los" (KERZNER, 2004).

O gerenciamento de riscos do projeto tem como objetivo principal aumentar a probabilidade e o impacto dos eventos positivos e diminuir a probabilidade e 0 impacto dos eventos adversos ao projeto. E, segundo o PMI (2008), inclui os processos que tratam da realização de identificação, análise, respostas, monitoramento e controle e planejamento do gerenciamento de riscos em um projeto, sendo a maioria desses processos atualizada durante todo o projeto. 
Assim sendo, o Gerenciamento dos Riscos do Projeto se constitui numa das áreas de conhecimento mais desafiadoras e mais estimulantes do Gerenciamento de Projetos, dada a sua complexidade, abrangência, transitoriedade, inovação, escassez bibliográfica, incerteza, dentre outros fatores.

\begin{abstract}
O processo de gerenciamento dos riscos envolve a determinação da lista priorizada dos principais riscos que poderão afetar o projeto. Identificar as principais fontes de risco, com o objetivo de procurar atenuar o seu grau de impacto sobre o projeto, calcular a probabilidade específica de ocorrência dos eventos de riscos, identificar a severidade (intensidade) do risco sobre o projeto, determinar o seu grau de impacto ao nível de escopo, prazo e orçamento, desenvolver estratégias de contingenciamento dos riscos; calcular a provisão de reservas para o contingenciamento de riscos são os princípios básicos do processo de Gerenciamento dos Riscos do Projeto (PMI, 2004).
\end{abstract}

Segundo Goldberg e Weber (1998), constituem um dos focos de caráter mais estratégicos em termos de agressividade no Gerenciamento de Projetos, desenvolver um Plano de Gerenciamento dos Riscos, identificar os riscos, efetuar uma avaliação qualitativa e quantitativa, desenvolver um Plano de Respostas aos Riscos, monitorar continuamente os riscos do projeto com o objetivo de captar o sentido e a direção dos processos de propagação de riscos e sua conversão em problemas e ameaças ao projeto.

\title{
2.2.4 Modelos Gerais de Gerenciamento de Riscos
}

Kerzner (1998) afirma que um gerenciamento de riscos apropriado implica em controlar possíveis eventos futuros, de maneira pró-ativa e não reativa. Verzuh (1999) também enfatiza a importância do gerenciamento de riscos ser sistemático para aumentar a capacidade de controlar e reduzir os riscos em um projeto.

Sempre com os mesmos objetivos, diversas empresas elaboraram seus próprios modelos, conforme apresentado de maneira resumida na 
Tabela 4 abaixo. Vale ressaltar que em todos os modelos, os riscos são estruturados de forma detalhada, e seus elementos são obtidos de maneira ordenada ao longo dos processos.

Tabela 4 - Modelos Gerais de Gerenciamento de Riscos

\begin{tabular}{|c|c|}
\hline Fonte & Processo de Gerenciamento de Riscos \\
\hline $\begin{array}{l}\text { Prince } \\
(2002)\end{array}$ & $\begin{array}{l}\text { Identificação dos riscos } \\
\text { Avaliação dos riscos } \\
\text { Identificação de respostas adequadas para os riscos } \\
\text { Seleção de respostas para tratar os riscos } \\
\text { Planejamento (recursos, tempo) das respostas aos riscos } \\
\text { Monitoramento e comunicação }\end{array}$ \\
\hline $\begin{array}{l}\text { Smith e Merritt } \\
\text { (2002) }\end{array}$ & $\begin{array}{l}\text { Identificação dos riscos } \\
\text { Análise dos riscos } \\
\text { Mapeamento e priorização dos riscos } \\
\text { Resolução dos riscos } \\
\text { Monitoramento dos riscos }\end{array}$ \\
\hline $\begin{array}{l}\text { PMI } \\
(2004)\end{array}$ & $\begin{array}{l}\text { Planejamento do gerenciamento de riscos } \\
\text { Identificação de riscos } \\
\text { Análise qualitativa dos riscos } \\
\text { Análise quantitativa dos riscos } \\
\text { Planejamento das respostas aos riscos } \\
\text { Monitoramento e controle de riscos }\end{array}$ \\
\hline $\begin{array}{l}\text { NBR ISO } 10006 \\
(2006)\end{array}$ & $\begin{array}{l}\text { Identificação do risco } \\
\text { Avaliação do risco } \\
\text { Tratamento do risco } \\
\text { Controle do risco }\end{array}$ \\
\hline
\end{tabular}

Fonte: Elaborado pelo autor

Em outra abordagem, Goldbert e Weber (1998), propõe o processo de Gerenciamento dos Riscos do Projeto por meio da seguinte Figura 7:

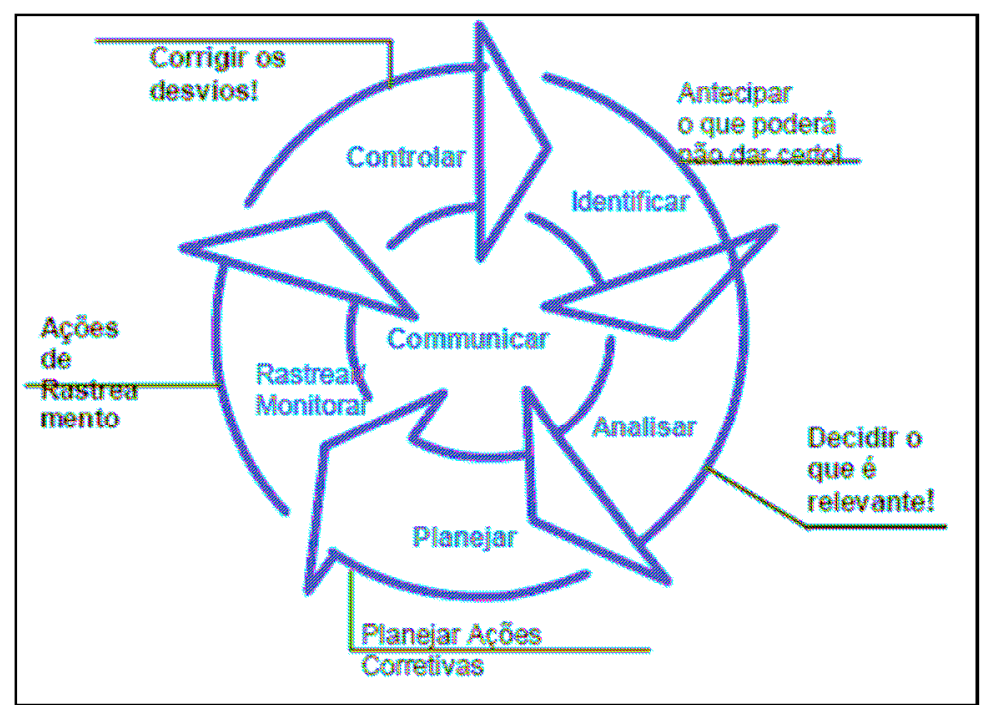

Figura 7. O processo de Gerenciamento de Riscos Fonte: Goldbert e Weber (1998) 
Para Baker, Ponniah e Smith (1999), o procedimento mais comum de gerenciamento de riscos consiste em três etapas: análise, avaliação e controle, que, se for seguido, obtêm-se um ambiente de risco controlado.

Clark, Pledger e Needler (1990) também consideram que o processo de gerenciamento de risco pode ser dividido em três estágios, porém nomeados como identificação, análise e gerenciamento da resposta.

Wideman (1992) define o Gerenciamento de Riscos como um processo sistemático de identificação, análise, desenvolvimento de respostas e controle dos riscos de projeto, durante o seu ciclo de vida e nos interesses de seus objetivos (de escopo, custo, prazo e qualidade), compreendendo as seguintes fases ou processos:

- Identificação dos Riscos - examinar a situação, identificar e classificar os riscos e suas causas;

- Análise dos Riscos (Qualitativa e Quantitativa) - efetuar a Análise Qualitativa dos riscos para determinar os prioritários; calcular (Análise Quantitativa) a probabilidade de ocorrência, a conseqüência e o impacto dos riscos:

- Desenvolvimento de Respostas aos Riscos - desenvolver, avaliar e implementar medidas para reduzir a probabilidade ou controlar os riscos, principalmente atuando sobre as causas;

- Controle dos Riscos - monitorar as causas e os riscos, assegurar a execução do plano de gerenciamento dos riscos e documentar as lições aprendidas.

Já o Project Management Institute (2008) define o gerenciamento dos riscos do projeto como os processos de planejamento, identificação, análise, planejamento de respostas, monitoramento e controle de riscos de um projeto. Os objetivos do gerenciamento dos riscos são aumentar a probabilidade e o impacto dos eventos positivos e reduzir a probabilidade e o impacto dos eventos negativos no projeto. Abaixo segue o resumo dos processos de gerenciamento dos riscos do projeto, que são:

- Planejamento do Gerenciamento do Risco - decidindo como abordar e planejar o gerenciamento dos riscos do projeto;

- Identificação do Risco - determinação de quais os riscos que podem afetar o projeto e documentação de suas características;

- Análise Qualitativa do Risco - execução de uma análise qualitativa dos riscos para avaliar seus efeitos nos objetivos do projeto e priorizálos;

- Análise Quantitativa do Risco - medição da probabilidade e conseqüência dos riscos e estimação de suas implicações nos objetivos do projeto; 
- Planejamento da Resposta ao Risco - elaboração e implementação de procedimentos e técnicas para reduzir as ameaças aos objetivos do projeto e para reforçar oportunidades;

- Monitoração e Controle do Risco - monitoração dos riscos residuais, identificação de novos riscos, execução de planos de redução dos riscos, e avaliação de sua eficácia durante todo o ciclo de vida do projeto.

Embora enunciando de diferentes formas no que se refere ao gerenciamento de riscos de projetos, a grande maioria dos autores converge para os conceitos das etapas de planejamento; identificação dos eventos de risco; avaliação desses eventos pela mensuração tanto da probabilidade de ocorrência quanto pelo impacto, caso ocorra; preparação de um plano de resposta; e a monitoração das ações constantes do plano de resposta, sempre observando o surgimento de novos eventos de riscos.

Por ser a metodologia mais utilizada no âmbito do gerenciamento de projetos, a estrutura de processos de gerenciamento de riscos fornecida pelo PMI (2008) será a utilizada neste trabalho para descrever os processos do gerenciamento de riscos.

\subsubsection{Processos do gerenciamento de riscos}

\subsubsection{Planejamento do Gerenciamento do Risco}

Segundo PMI (2008), planejar o gerenciamento dos riscos é o processo de definição de como conduzir as atividades de gerenciamento dos riscos de um projeto. $O$ planejamento cuidadoso e explícito aumenta a probabilidade de sucesso para os outros cinco processos de gerenciamento dos riscos. O planejamento dos processos de gerenciamento dos riscos é importante para garantir que o grau, o tipo e a visibilidade do gerenciamento dos riscos sejam proporcionais tanto aos riscos como à importância do projeto para a organização. O planejamento também é importante para fornecer tempo e recursos suficientes para as atividades de gerenciamento dos riscos e para estabelecer uma base acordada para a avaliação dos riscos. 
O plano deve ser confeccionado durante reuniões desenvolvidas em paralelo com o planejamento do projeto, tendo como participantes pessoas envolvidas com 0 projeto: o gerente do projeto, membros-chave da equipe do projeto, responsáveis pelo gerenciamento das atividades de execução e planejamento de riscos, além de pessoas interessadas ou necessárias ao desenvolvimento do plano. Cada projeto exige um Plano de Gerenciamento de Riscos específico, podendo ter como base os documentos do projeto e planos de projetos anteriores das organizações envolvidas (PMI, 2008).

Segundo ainda o PMI (2008), o plano de gerenciamento dos riscos descreve como o gerenciamento dos riscos será estruturado e executado no projeto. Ele se torna um subconjunto do plano de gerenciamento do projeto. Esse plano contém as seguintes informações:

- Metodologia. Define as abordagens, ferramentas e fontes de dados que podem ser usadas para realizar o gerenciamento dos riscos no projeto.

- Papéis e responsabilidades. Define o líder, o suporte e os membros da equipe de gerenciamento dos riscos para cada tipo de atividade do plano de gerenciamento dos riscos e explica suas responsabilidades.

- Orçamento. Atribui recursos, estima os fundos necessários ao gerenciamento dos riscos para inclusão na linha de base do desempenho de custos e estabelece os protocolos para aplicação das reservas para contingências (Seção 7.2.3.1).

- Prazos. Define quando e com que freqüência o processo de gerenciamento dos riscos será realizado durante o ciclo de vida do projeto, estabelece os protocolos para aplicação das reservas para contingências do cronograma e determina as atividades de gerenciamento dos riscos a serem incluídas no cronograma do projeto (Seção 6.5.3.1).

- Categorias de riscos. Fornece uma estrutura que garante um processo abrangente de identificação sistemática de riscos em um nível de detalhe consistente e contribui para a eficácia e a qualidade do processo de Identificar os riscos. A organização pode usar uma estrutura de categorização previamente preparada, que pode ter a forma de uma simples lista de categorias ou pode ser organizada em uma estrutura analítica dos riscos (EAR). A estrutura analítica dos riscos (EAR) é uma representação, organizada hierarquicamente, dos riscos identificados do projeto, ordenados por categoria e subcategoria de risco, que identifica as diversas áreas e causas de riscos potenciais. Um exemplo é apresentado na Figura 8. 


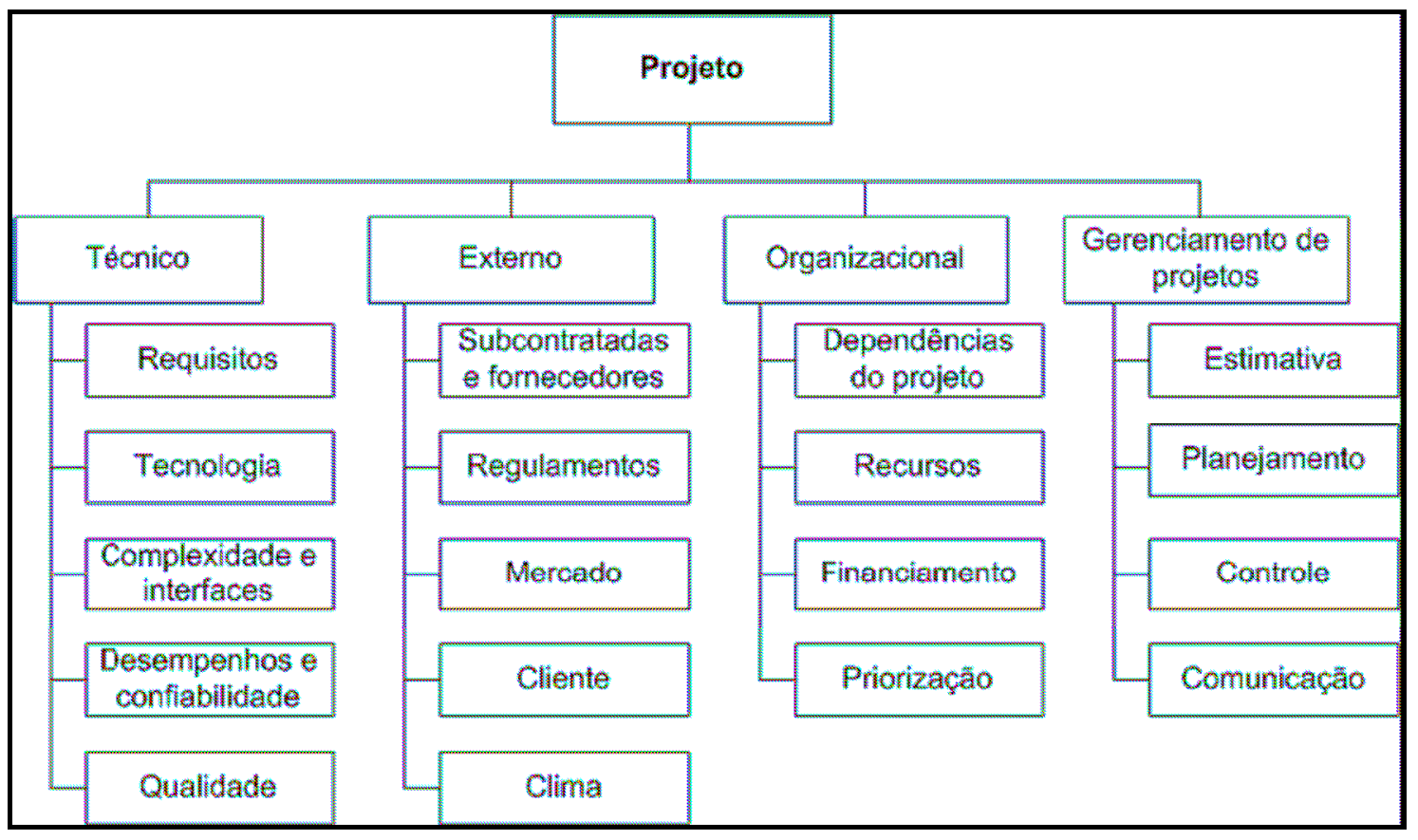

Figura 8. Estrutura Analítica de Riscos

Fonte: Project Management Institute (2008)

\subsubsection{Identificação dos Riscos}

Segundo PMI (2008), identificar os riscos é o processo de determinação dos riscos que podem afetar o projeto. Os participantes das atividades de identificação de riscos podem incluir todos os envolvidos no projeto e toda a equipe do projeto deve ser estimulada a identificar riscos.

Segundo Chapman (1998), a identificação e pré-avaliação de riscos são, talvez, os mais importantes processos do gerenciamento de riscos, isto porque o seu resultado tem um forte impacto sobre a precisão das análises posteriores dos riscos. $O$ processo é iterativo, devendo estar presente durante todo o ciclo de vida do projeto.

Valeriano (1998), Verzuh (1999) e Smith e Merritt (2002) salientam que os riscos devem ser descritos à medida que são identificados e que essa descrição deve ser feita de maneira concisa. Além da identificação e descrição, deve-se identificar e documentar os possíveis impactos gerados por cada risco. A Tabela 5 mostra um exemplo de como deve ser a descrição de um risco. 
Tabela 5 - Exemplo de descrição de Risco

\begin{tabular}{ll}
\hline & \multicolumn{1}{c}{ Identificação de Risco } \\
\hline Definição do & $\begin{array}{l}\text { A solução do projeto necessita de um sistema operacional de computador que } \\
\text { evento de risco }\end{array}$ \\
$\begin{array}{l}\text { ainda vai ser lançado e o fornecedor previsto é conhecido por lançar produtos } \\
\text { não confiáveis e com atraso. }\end{array}$ \\
$\begin{array}{l}\text { Se o sistema operacional não satisfazer as especificações, será necessário } \\
\text { criar um programa personalizado. Se o produto atrasar, todo o projeto sofrerá } \\
\text { um atraso. }\end{array}$ \\
\hline
\end{tabular}

Fonte: Verzuh (1999).

Segundo Kerzner (2001b), os métodos para se identificar riscos são numerosos, e é comum classificá-los conforme suas fontes de informação ou pesquisa, podendo ser objetivos ou subjetivos.

Os métodos objetivos são baseados em registros de informações, tanto de dados públicos como de projetos anteriores ou em documentos e procedimentos do projeto atual, dentre os quais podem destacar (KERZNER, 2001b):

- Revisão da documentação: Trata-se de uma revisão perspicaz da documentação do projeto, incluindo os planos, arquivos, informações, escopo e premissas do projeto, verificando se há inconsistências entre estes documentos e os requisitos do projeto, que podem ser indicadoras de riscos.

- Análise da lista de verificação: elaboradas através de informações históricas, baseadas no conhecimento acumulado com projetos similares realizados anteriormente ou em outras fontes de informação. É um método rápido e simples de identificação de riscos, porém é impraticável a elaboração de uma lista muito longa e completa, ficando limitada às categorias de risco utilizadas.

- Análise das Premissas: explora a validade das premissas em relação ao projeto.

Segundo Pritchard (2001), os métodos subjetivos baseiam-se em conhecimentos e experiências de pessoas, especialista em projetos ou envolvidos no projeto, dentre os quais se podem destacar: 
- Brainstorming: Consiste em se obter uma lista abrangente de possíveis riscos, através de idéias lançadas por um grupo multidisciplinar, envolvido com o projeto, sob a coordenação de um facilitador.

- Técnica de Grupo Nominal: Classificação consensual da lista de riscos identificada pelo grupo.

- Método CSM (Crawford Slip Method): ferramenta clássica de reunir informações sem o negativismo inerente em muitas discussões sobre risco. Esta técnica permite agregar um grande volume de informações em um curto intervalo de tempo, onde os membros do time ficam envolvidos em determinados temas.

- Técnica Delphi: Esta técnica busca o consenso de um grupo de diversos especialistas, que participam anonimamente, com relação aos riscos do projeto. Por intermédio de um facilitador, reúnem-se julgamentos individuais sobre determinados tópicos. As respostas são, então, circuladas entre os participantes para comentários adicionais. Através de uma seqüência de questionários, produzidos com o intuito de provocar uma revisão das principais opiniões emitidas no questionário anterior, o consenso.

- Entrevistas: identificam os possíveis riscos com base nas experiências do entrevistado.

- Análise SWOT: Essa técnica examina o projeto do ponto de vista de suas forças e fraquezas, oportunidades e ameaças, a fim de aumentar a abrangência dos riscos identificados, incluindo os riscos gerados internamente. A técnica começa com a identificação das forças e fraquezas da organização, enfatizando a organização do projeto ou 0 negócio mais amplo. Em seguida, a análise SWOT identifica as oportunidades do projeto resultantes das forças da organização, bem como as ameaças decorrentes das fraquezas. Essa análise também 
examina o grau em que as forças da organização compensam as ameaças e as oportunidades que podem superar as fraquezas. A Figura 9 exemplifica uma matriz hipotética.

\begin{tabular}{|c|c|c|c|c|c|}
\hline & $\begin{array}{l}\text { Opertumidade: } \\
\text { Podemos } \\
\text { encontrar uma } \\
\text { nova equipe }\end{array}$ & $\begin{array}{l}\text { Oportumilade: } \\
\text { Podemos } \\
\text { descobrir un } \\
\text { novo processo }\end{array}$ & $\begin{array}{l}\text { Ameaça: } \\
\text { Podemos perder } \\
\text { funcionánios }\end{array}$ & $\begin{array}{l}\text { Aneaça: } \\
\text { Podenos causar } \\
\text { prejuizos ao } \\
\text { cliente }\end{array}$ & $\begin{array}{l}\text { Ameaça: } \\
\text { O cliente pode } \\
\text { identificar um } \\
\text { novo fornecedor }\end{array}$ \\
\hline $\begin{array}{l}\text { Força: } \\
\text { Temos uma } \\
\text { otima equipe de } \\
\text { vendas }\end{array}$ & & & & & + \\
\hline $\begin{array}{l}\text { Forç: } \\
\text { Oferecemos un } \\
\text { otimo plano de } \\
\text { beneficios: } \\
\end{array}$ & + & & + & & \\
\hline $\begin{array}{l}\text { Franueza: } \\
\text { O gerenciamento } \\
\text { tende a ser muito } \\
\text { próximo }\end{array}$ & & - & - & + & \\
\hline $\begin{array}{l}\text { Fraqueza: } \\
\text { Utilizanos } \\
\text { processos } \\
\text { desatualizados }\end{array}$ & & + & - & - & - \\
\hline
\end{tabular}

Figura 9. Matriz exemplo análise SWOT

Fonte: Pritchard (2001)

Além destes métodos, as técnicas de diagramação, como o diagrama causa-efeito (Ishikawa) e o diagrama de influência e fluxogramas, auxiliam na obtenção de causas de riscos do projeto.

Sendo assim, o que se espera com estes métodos é a obtenção de uma lista de riscos, devidamente registrados e categorizados, para que os processos posteriores (Análise Qualitativa e Quantitativa) do gerenciamento de riscos do projeto possam ser realizados de forma plena e completa.

Um risco identificado apresenta duas dimensões-chave: probabilidade e impacto. A probabilidade é sua chance de ocorrer e o impacto é o seu efeito sobre os objetivos do projeto, caso o evento ou condição de risco venha a manifestar-se. A análise qualitativa é o processo onde se avalia a prioridade dos riscos identificados utilizando sua probabilidade e impacto. A prioridade atribuída a um risco será a chave para se definir se o mesmo passará por um processo de análise mais criterioso, utilizando métodos quantitativos, e para determinar o tipo de tratamento que cada risco receberá. 


\subsubsection{Análise qualitativa dos riscos}

Segundo PMI (2008), análise qualitativa de riscos é o processo de priorização de riscos para análise ou ação adicional através da avaliação e combinação de sua probabilidade de ocorrência e impacto.

Smith e Merritt (2002) consideram esse processo em dois estágios: análise dos riscos e priorização/mapeamento dos riscos. $\mathrm{Na}$ análise, são identificados causas dos riscos e dos impactos, as probabilidades de ocorrência dos riscos e dos impactos e a perda total, conforme apontado anteriormente na Figura 3.

Segundo Dinsmore (2003), na priorização e mapeamento, por sua vez, com base nos valores de probabilidade de ocorrência e perda total de cada risco, elabora-se um mapa de riscos conforme será mostrado na Figura 10, indicando os riscos prioritários do projeto representados pelos quadrantes de cor vermelha. Os quadrantes amarelos indicam os riscos de severidade moderada, os quais também deverão ser analisados quantitativamente. O quadrantes verdes indicam os riscos de severidade leve, os quais serão somente monitorados e em caso de alguma alteração na probabilidade e/ou impacto os riscos serão reavaliados.

\begin{tabular}{|c|c|c|c|c|c|}
\hline \multicolumn{7}{|c|}{ Intensidade de um Risco Especifico } \\
\hline Probab. (P) \% & \multicolumn{7}{|c|}{ Intensidade = P I } \\
\hline 0,9 & 0,05 & 0,09 & 0,18 & 0,36 & 0,72 \\
\hline 0,7 & 0,04 & 0,07 & 0,14 & 0,28 & 0,56 \\
\hline 0,5 & 0,03 & 0,05 & 0,10 & 0,20 & 0,40 \\
\hline 0,3 & 0,02 & 0,03 & 0,06 & 0,12 & 0,24 \\
\hline 0,1 & 0,01 & 0,01 & 0,02 & 0,04 & 0,08 \\
\hline & 0,05 & 0,10 & 0,20 & 0,40 & 0,80 \\
\cline { 2 - 6 } & \multicolumn{5}{|c|}{ Impacto (1) sobre um objetivo - Escala } \\
\hline
\end{tabular}

Figura 10. Matriz probabilidade versus impacto

Fonte: Dinsmore (2003)

Prince (2002), além de designar esse processo para a avaliação da probabilidade de ocorrência e impactos de cada risco, recomenda definir quando os riscos ocorrerão. 
Tal informação é considerada importante pelo autor, pois os riscos que estiverem mais próximos de ocorrer poderão receber mais atenção.

No entanto, o primeiro passo para a avaliação qualitativa dos riscos do projeto é a formatação de uma matriz de graduação do impacto dos riscos sobre os objetivos do projeto, Figura 11. Esta matriz deve ser concebida durante o processo de planejamento do gerenciamento de riscos, tendo uma graduação ordinal ou cardinal (linear ou não-linear).

\begin{tabular}{|c|c|c|c|c|c|}
\hline $\begin{array}{c}\text { Objetivo } \\
\text { do projeto }\end{array}$ & Muito baixo/0.05 & Baixo/0.10 & Moderato / 0.20 & Alto $/ 0.40$ & Muito alto / 0.80 \\
\hline Custo & $\begin{array}{c}\text { Aumento de custo } \\
\text { nâo significativo }\end{array}$ & $\begin{array}{c}\text { Aumento de custo } \\
10 \%\end{array}$ & $\begin{array}{c}\text { Aumento do eusto } \\
\text { de } 10 \% \text { a } 20 \%\end{array}$ & $\begin{array}{c}\text { Alamento de custo } \\
\text { de } 20 \% \text { a } 40 \%\end{array}$ & $\begin{array}{c}\text { Aumento de custo } \\
40 \%\end{array}$ \\
\hline Tempo & $\begin{array}{c}\text { Aumento de tempo } \\
\text { näo significastivo }\end{array}$ & $\begin{array}{l}\text { Aumento de tempo } \\
\qquad<5 \%\end{array}$ & $\begin{array}{c}\text { Aumento de tempo } \\
\text { de } 5 \% \text { a } 10 \%\end{array}$ & $\begin{array}{c}\text { Aumento de tempo } \\
\text { de } 10 \% \text { a } 20 \%\end{array}$ & $\begin{array}{c}\text { Aumento de tempo } \\
\quad>20 \%\end{array}$ \\
\hline Escopo & $\begin{array}{l}\text { Diminuicăo do } \\
\text { escopo quase } \\
\text { imperceptival }\end{array}$ & $\begin{array}{l}\text { Areas menos } \\
\text { importantes do } \\
\text { escopo afetadas }\end{array}$ & $\begin{array}{l}\text { Areas importantes } \\
\text { do escopo atetadas }\end{array}$ & $\begin{array}{c}\text { Reduça do escopo } \\
\text { inaceitivel para } \\
\text { patrocinader }\end{array}$ & $\begin{array}{c}\text { Item final do projeto } \\
\text { sem nenhum } \\
\text { utilidade }\end{array}$ \\
\hline Qualidade & $\begin{array}{l}\text { Degradaçăo da } \\
\text { qualidade quase } \\
\text { imperceptivel }\end{array}$ & $\begin{array}{c}\text { Somente as } \\
\text { aplicaçōes mais } \\
\text { critticas sầ afetadas }\end{array}$ & $\begin{array}{c}\text { Feduça da } \\
\text { qualidade exige a } \\
\text { aprovação do } \\
\text { patrocinador }\end{array}$ & $\begin{array}{c}\text { Pedugão da } \\
\text { qualidade } \\
\text { inaceitâvel para o } \\
\text { patrocinador }\end{array}$ & $\begin{array}{c}\text { Item final do projeto } \\
\text { sem nenhuma } \\
\text { utilidade }\end{array}$ \\
\hline
\end{tabular}

Figura 11. Definição das escalas de impacto por objetivo do projeto Fonte: Project Management Institute (2008)

Como resultado deste processo de análise, uma classificação global dos riscos do projeto pode ser realizada, assim como uma lista de riscos prioritários. Estes riscos priorizados podem ser avaliados separadamente. Os riscos significativos devem ter uma descrição das bases das estimativas para a probabilidade e os impactos considerados, podendo, inclusive, sofrer análises quantitativas adicionais.

\subsubsection{Análise quantitativa dos riscos}

Segundo o PMI (2008), a análise quantitativa dos riscos normalmente é realizada para os riscos que foram priorizados no processo de análise qualitativa. O processo 
de análise quantitativa dos riscos se caracterizada pela análise dos efeitos dos eventos de risco e pela atribuição de um valor numérico a suas dimensões de probabilidade e impacto. Dados históricos, análises estatísticas e entrevistas com especialistas são fontes valiosas de informação para a análise quantitativa. Os principais resultados do processo de análise quantitativa são: a probabilidade de se alcançar os objetivos de prazo e custo do projeto, considerando os riscos que o cercam, e a lista priorizada dos riscos quantificados.

Segundo Kerzner (1998), obter a quantificação de um risco específico requer, geralmente, alguma modelagem, sendo que os típicos métodos usados na análise quantitativa são: árvore de decisão e simulação Monte Carlo.

A árvore de decisão é uma ferramenta utilizada para a tomada de decisões. É estruturada em um diagrama onde os nós representam decisões, sendo que cada decisão leva a possíveis cenários. Para cada cenário é atribuída uma probabilidade de ocorrência, assim como o custo (ou retorno) desta escolha disponível. A multiplicação da probabilidade de ocorrência pelo custo (ou retorno) deste caminho, leva ao Valor Monetário Esperado (VME). Com o diagrama estruturado em todas as suas possibilidades, pode-se analisar cada escolha disponível e o melhor caminho lógico alternativo para se obter o menor custo ou o maior retorno.

A simulação de Monte Carlo permite a construção de distribuições de probabilidades, baseadas em cenários subjetivos ou em dados estatísticos, através da geração de números randômicos e centenas ou milhares de iterações dentro de modelos pré-estabelecidos. Para tanto, há a necessidade da utilização de softwares específicos.

\subsubsection{Planejamento de Respostas a Riscos}

Embora o processo de quantificação requeira muito trabalho detalhado e meticuloso, Kerzner (2002), acredita que o plano de respostas é crucial para o projeto, pois dependerá, em larga medida, do grau de adequação das estratégias de riscos aos 
riscos efetivos que o projeto estará exposto. Estratégias bem definidas produzirão os resultados esperados e assim poderão evitar em larga medida que os riscos se tornem problemas. A lista priorizada de riscos - que na verdade é uma lista classificada por tipo de risco, probabilidade de ocorrência e grau de impacto no projeto - é a base para a elaboração das demais etapas de análise de riscos do projeto, conforme Hulett (2002).

O principal objetivo deste processo é minimizar (ou eliminar) as ameaças e maximizar as oportunidades em relação aos objetivos do projeto, através da utilização da estratégia de resposta mais adequada (PMI, 2008).

O planejamento de respostas a riscos deve ser específico para cada risco e deve refletir a importância ou prioridade atribuída ao risco. É comum haver mais de uma ação de mitigação possível para um determinado risco e, neste caso, deve-se preferir aquelas que apresentam menor custo de implementação e que podem ser executadas mais rapidamente. Isto é importante para tornar o gerenciamento de riscos do projeto eficiente.

Segundo PMI (2008), há várias estratégias de respostas a riscos, mas as mais comuns são:

- Prevenção: consiste em alterar o plano de gerenciamento do projeto de modo a eliminar as condições que tornam possível a ocorrência do risco. Segundo o PMI (2004, p. 261), esta estratégia visa "isolar os objetivos do projeto do impacto do risco ou flexibilizar o objetivo que está sendo ameaçado, como por exemplo, a extensão do cronograma ou a redução do escopo";

- Transferência: nesta estratégia o risco é transferido para uma terceira parte que passa a ser responsável pelo seu gerenciamento. Esta estratégia não elimina o risco. Geralmente a transferência se dá por meio da contratação de seguro, contrato de garantia ou outro instrumento. Um exemplo típico de transferência de riscos é a contratação de uma empresa externa à organização, através de contrato do tipo firme - fixo, para que esta execute a parte do escopo do projeto que apresentava riscos significativos com relação aos objetivos de custos, caso fosse executado internamente pela organização executora do projeto;

- Mitigação: atua sobre as condições que cercam o evento de risco de forma a reduzir à chance de sua ocorrência e/ou a extensão de seu impacto, caso ele ocorra, até que estes fiquem dentro de um limite aceitável. A realização de uma compra de alarme para o carro é uma ação mitigadora muito comum em projetos de compra de carro. 
- Aceitação: nesta estratégia não se toma ação antecipada alguma a cerca de um determinado risco. É normalmente empregada quando não há outra estratégia de resposta viável ou quando o risco não é suficientemente significativo, a ponto de o projeto poder conviver com a possibilidade de sua ocorrência. A estratégia de aceitação se enquadra em dois tipos básicos: a passiva e a ativa. Na primeira não se toma nenhuma ação com relação ao risco. Já na segunda, se aprovisiona uma reserva de contingência, que pode ser de custos e/ou prazos, para o caso de ocorrência do risco;

Há também planos de respostas para os riscos positivos, denominados nesta dissertação como oportunidades:

- Exploração: tenta eliminar a incerteza associada a um risco positivo específico, fazendo com que a oportunidade efetivamente aconteça.

- Compartilhamento: atribui responsabilidades a terceiros que possam capturar melhor a oportunidade em benefício do projeto. Pode incluir a formação de parcerias, equipes, empresa de propósito específico ou empreendimentos conjuntos.

- Melhoramento: procura facilitar ou fortalecer a causa da oportunidade, direcionando e reforçando de forma pró-ativa suas condições de acionamento, podendo aumentar sua probabilidade de ocorrência.

Coppendale (1995), conforme mostra a Tabela 6, sugere ações para responder aos riscos, classificadas nas seguintes categorias: externa, gerenciamento de projetos, marketing, comercial, manufatura e técnica.

Tabela 6 - Exemplo de descrição de Risco

\begin{tabular}{|c|c|c|}
\hline Cat. & Riscos & Ações de gerenciamento de riscos \\
\hline 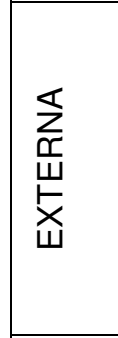 & $\begin{array}{l}\text { Fornecedores externos } \\
\text { podem limitar o progresso do } \\
\text { projeto }\end{array}$ & $\begin{array}{l}\text { - } \\
\text { - } \quad \text { Estabelecer condiçõares apropriadas de contrato; } \\
\text { - } \quad \text { Estabelecer boa comunicação com } \\
\text { fornecedores e monitorar seu progresso; } \\
\text { - } \quad \text { Revisar procedimentos de qualidade dos } \\
\quad \text { fornecedores; } \\
\text { - Estabelecer solução alternativa (reserva) para } \\
\text { itens críticos. }\end{array}$ \\
\hline \multirow{2}{*}{ 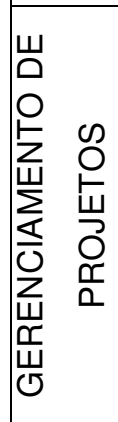 } & $\begin{array}{l}\text { Experiência com GP pode } \\
\text { não ser adequada }\end{array}$ & $\begin{array}{l}\text { - Alocar gerente de projeto com habilidades } \\
\text { apropriadas; } \\
\text { - Desenvolver estratégia global do } \\
\text { gerenciamento de projeto; } \\
\text { - Monitorar o progresso do projeto. }\end{array}$ \\
\hline & $\begin{array}{l}\text { Recursos Críticos podem } \\
\text { não estar disponíveis quando } \\
\text { solicitados }\end{array}$ & $\begin{array}{l}\text { - Redefinir o planejamento de recursos; } \\
\text { - Reservar recursos externos e internos com } \\
\text { antecedência; } \\
\text { - Identificar e fornecer treinamento necessário } \\
\text { com antecedência. }\end{array}$ \\
\hline
\end{tabular}




\begin{tabular}{|c|c|c|}
\hline \multirow{2}{*}{ 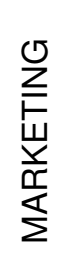 } & $\begin{array}{l}\text { Produto pode não atingir } \\
\text { fatia de mercado prevista }\end{array}$ & $\begin{array}{l}\text { - Garantir que a "voz do consumidor" esteja } \\
\text { incorporada no desenvolvimento das } \\
\text { especificações. }\end{array}$ \\
\hline & $\begin{array}{l}\text { Concorrentes podem reduzir } \\
\text { a fatia de mercado e/ou a } \\
\text { lucratividade do produto em } \\
\text { desenvolvimento }\end{array}$ & $\begin{array}{l}\text { - Monitorar atividade do concorrente; } \\
\text { Realizar programas de teste com produtos dos } \\
\text { concorrentes. }\end{array}$ \\
\hline \multirow{2}{*}{ 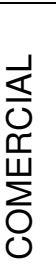 } & $\begin{array}{l}\text { Novo produto ou processo } \\
\text { pode infringir patentes } \\
\text { existentes }\end{array}$ & - Realizar, regularmente, busca de patentes. \\
\hline & $\begin{array}{l}\text { Produto ou processo pode } \\
\text { não ser viável } \\
\text { financeiramente }\end{array}$ & $\begin{array}{l}\text { Calcular custo de manufatura nas fases iniciais } \\
\text { do desenvolvimento do produto e revisar com } \\
\text { regularidade. }\end{array}$ \\
\hline \multirow{2}{*}{ 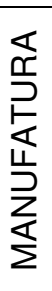 } & $\begin{array}{l}\text { Processos de manufaturas } \\
\text { podem não estar adequados }\end{array}$ & $\begin{array}{l}\text { Identificar, o quanto antes, todos os parâmetros } \\
\text { que afetam os processos, para garantir que } \\
\text { seus efeitos e interações estejam } \\
\text { determinados. }\end{array}$ \\
\hline & $\begin{array}{l}\text { Tolerâncias da manufatura } \\
\text { podem vir a afetar o } \\
\text { desempenho do produto }\end{array}$ & $\begin{array}{l}\text { Realizar o cálculo das tolerâncias da } \\
\text { manufatura o quanto antes e monitorá-las. }\end{array}$ \\
\hline \multirow{5}{*}{ 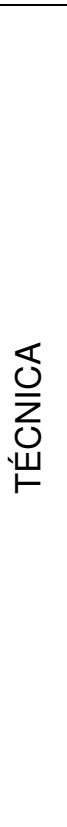 } & $\begin{array}{l}\text { Ciclo de vida do produto não } \\
\text { contempla todas as fases do } \\
\text { seu desenvolvimento }\end{array}$ & $\begin{array}{l}\text { - Identificar, no início do projeto, todas as fases } \\
\text { do ciclo de vida que o produto deverá passar. }\end{array}$ \\
\hline & $\begin{array}{l}\text { Nível de confiabilidade pode } \\
\text { não estar adequado para o } \\
\text { produto }\end{array}$ & $\begin{array}{l}\text { - Projeto para confiabilidade; } \\
\text { - Assegurar, o quanto antes, testes de } \\
\text { confiabilidade. }\end{array}$ \\
\hline & $\begin{array}{l}\text { Capacidade da manufatura } \\
\text { interna pode não ser } \\
\text { suficiente para a produção } \\
\text { do produto }\end{array}$ & $\begin{array}{l}\text { - Planejar os processo de produção com base } \\
\text { nas características do produto, assim que for } \\
\text { possível. } \\
\text { - Implementar um programa de aumento de } \\
\text { produção como parte do desenvolvimento do } \\
\text { produto. }\end{array}$ \\
\hline & $\begin{array}{l}\text { Produto pode não resistir ao } \\
\text { teste de resistência }\end{array}$ & $\begin{array}{l}\text { - Incorporar requisitos de teste de queda nas } \\
\text { especificações; } \\
\text { - Projetar o produto e sua embalagem de forma } \\
\text { a atenderem os requisitos de resistência. }\end{array}$ \\
\hline & $\begin{array}{l}\text { Tecnologia inapropriada } \\
\text { pode ser adotada }\end{array}$ & $\begin{array}{l}\text { - Garantir que todas as opções sejam } \\
\text { identificadas na fase conceitual; } \\
\text { - Comparar as opções de tecnologia com as } \\
\text { especificações. }\end{array}$ \\
\hline
\end{tabular}

Fonte: Coppendale (1995).

É importante ter em mente que o gerenciamento de riscos não ocorre de forma independente das outras áreas de conhecimento do gerenciamento de projetos e a escolha da estratégia de resposta poderá exigir a revisão do plano de gerenciamento do projeto, da base de custos e do cronograma do projeto. 


\subsubsection{Monitoramento e controle dos riscos}

Segundo PMI (2008), monitorar e controlar os riscos é o processo de implementação dos planos de respostas a riscos, acompanhamento dos riscos identificados, monitoramento dos riscos residuais, identificação de novos riscos e avaliação da eficácia do processo de riscos durante todo o projeto.

As respostas planejadas a riscos que são incluídas no plano de gerenciamento do projeto são executadas durante o ciclo de vida do projeto, mas o trabalho do projeto deve ser continuamente monitorado em busca de riscos novos, modificados e desatualizados.

Segundo PMI (2008), o processo de monitorar e controlar os riscos utiliza técnicas, como análises de variações e tendências, que requerem o uso das informações de desempenho geradas durante a execução do projeto. Outras finalidades do processo de Monitorar e controlar os riscos determinam-se:

- As premissas do projeto ainda são válidas;

- A análise mostra um risco avaliado que foi modificado ou que pode ser desativado;

- As políticas e os procedimentos de gerenciamento dos riscos estão sendo seguidos

- As reservas para contingências de custo ou cronograma devem ser modificadas de acordo com a avaliação atual dos riscos.

O monitoramento e o controle dos riscos podem envolver a escolha de estratégias alternativas, a execução de um plano alternativo ou de contingência, a adoção de ações corretivas e a modificação do plano de gerenciamento do projeto.

Tendo em vista a real importância deste processo para o sucesso dos negócios, Albeny (2007), após utilizar o Modelo Padrão de Riscos proposto por Smith e Merritt (2002) propôs um indicador para a monitoração e controle dos riscos, apresentado na equação abaixo: 


$$
\text { Percentual de Risco no projeto }=\frac{\text { Exposição do projeto a riscos }(\mathrm{EP})}{\text { Orçamento total do projeto }}
$$

O indicador na equação acima, expressa percentualmente o valor da exposição ao risco do projeto em relação ao seu orçamento total e permite a identificação de projetos com maior exposição relativa.

A variável EP é obtida por meio do somatório dos valores de perda esperada (El) dos riscos identificados e analisados.

Segundo Albeny (2007), um outro indicador é utilizado para medir a eficiência do gerenciamento de riscos em um determinado projeto ao longo da sua execução, o que pode ser visto na equação abaixo:

$$
\begin{aligned}
& \text { Índice de desempenho do } \\
& \text { erenciamento de Riscos (IDGR) }
\end{aligned}=\frac{\mathrm{EP}_{0}-\mathrm{EP}}{\mathrm{EP}_{0}}
$$

$\mathrm{O} E \mathrm{P}_{\mathrm{o}}$ se refere à exposição do projeto considerando os riscos iniciais e mostra qual seria a exposição projeto caso nenhuma ação para tratar os riscos fosse tomada.

Esse indicador consiste no somatório, das perdas esperadas iniciais $\left(E l^{\circ}\right)$ dos riscos identificados e analisados no projeto. Enquanto, o EP se refere ao somatório das perdas esperadas (El) dos riscos no momento em que o monitoramento é feito.

Com a implementação das ações contidas no plano de resposta aos riscos, esperase que a exposição a riscos do projeto (EP) diminua em relação a sua exposição a riscos inicial $\left(E P_{0}\right)$. Assim, em um cenário ideal onde se consegue a redução total da $E P$, o IDGR é igual a um.

Além dos indicadores, os formulários de registro de informações de riscos são um ponto importante no processo de registro do monitoramento e controle dos riscos e é apontado fortemente por Verzuh (1999) e Smith e Merritt (2002) conforme pode ser observado na Figura 12 e na Figura 13. 
Estes formulários contêm campos para registrar as informações do plano de riscos e a situação atual no acompanhamento dos riscos.

Kerzner (1998) sugere ainda que, no processo de monitoramento e controle dos riscos, documentar as lições aprendidas durante o Gerenciamento dos Riscos para que, no futuro, gerentes de projeto, conjuntamente com sua equipe, aprendam com os acertos e erros de projetos passados.

\begin{tabular}{|c|l|l|l|l|l|l|}
\hline \multicolumn{7}{|c|}{ MONITORAR OS RISCOS USANDO UM REGISTRO DE RISCOS } \\
\hline $\begin{array}{c}\text { Identidade } \\
\text { do risco }\end{array}$ & Prioridade & $\begin{array}{c}\text { Data de } \\
\text { ocorrência }\end{array}$ & Responsável & Descrição & Estratégia & $\begin{array}{c}\text { Estado atual do } \\
\text { andamento }\end{array}$ \\
\hline & & & & & & \\
\hline & & & & & & \\
\hline & & & & & & \\
\hline
\end{tabular}

Figura 12. Formulário de registro de informações de riscos Fonte: Versuh (1999)

\begin{tabular}{|c|c|c|c|c|c|c|c|c|}
\hline $\begin{array}{c}\text { Identificagão } \\
\text { do risco }\end{array}$ & Prioridade & $\begin{array}{c}\text { Responsável } \\
\text { pelo risco }\end{array}$ & $\begin{array}{l}\text { Data de } \\
\text { abertura }\end{array}$ & $\begin{array}{c}\text { Data de } \\
\text { fechamento }\end{array}$ & $\begin{array}{c}\text { Status } \\
\text { do } \\
\text { Risco }\end{array}$ & \multicolumn{3}{|c|}{ Perda atual } \\
\hline \multicolumn{2}{|c|}{ Evento de risco } & Impacto & & $\begin{array}{c}\text { Datas de } \\
\text { monitoramento }\end{array}$ & $P^{\prime}$ & $\mathrm{Pl}$ & $\mathrm{Lt}$ & $\mathrm{El}$ \\
\hline $\begin{array}{c}\text { Causas do } \\
\text { risco }\end{array}$ & $\begin{array}{l}\text { Planos de } \\
\text { Prevencăo }\end{array}$ & $\begin{array}{c}\text { Causas dos } \\
\text { impactos }\end{array}$ & $\begin{array}{c}\text { Planos } \\
\text { contingenciais }\end{array}$ & & & & & \\
\hline & & & & & & & & \\
\hline & & & & & & & & \\
\hline $\begin{array}{l}P^{\prime}=\text { Probabilid } \\
\mathrm{Lt}=\text { Perda tot }\end{array}$ & $\begin{array}{l}\text { le de oco } \\
E I=P e r\end{array}$ & $\begin{array}{l}\text { cia do risco; } \\
\text { sperada. }\end{array}$ & $=F$ & de ocorrência. & impac & & & \\
\hline
\end{tabular}

Figura 13. Formulário de registro de informações de riscos

Fonte: Smith e Merrit (2002)

\subsubsection{Percepção do Risco}

Segundo Skjong \& Wentworth (2001), se a análise de riscos, for utilizada de maneira racional, certamente contribuirá significativamente para o processo de tomada de decisão, uma vez que os valores e limitações serão levados em conta de forma realística. No entanto, há uma tendência de se aceitar a avaliação como uma medição real, quando na realidade há muita subjetividade envolvida. Segundo 
Kunreuther (2002), a subjetividade está relacionada com a percepção das pessoas e é afetada por vieses em seus julgamentos.

A nossa percepção ao risco muitas vezes é construída por meio de julgamentos realizados por indivíduos que possuem vieses cognitivos e emocionais (BAZERMAN, 2004) além de se utilizar de racionalidade limitada adotando modelos mentais baseados no seu repertório e experiência para antever o futuro Simon (1963). Desta forma não há como dissociar o fator humano do processo de criação e uso da metodologia de riscos.

De acordo com Slovic (1987) apud Módica (2009), pesquisas sobre a percepção de eventos de riscos descobriram um conjunto de estratégias mentais ou heurísticas que as pessoas empregam para encontrar algum sentido no mundo das incertezas, e embora essas regras sejam válidas em algumas circunstâncias, em outras elas podem levar a vieses com fortes implicações para o tratamento dos riscos.

As heurísticas podem ser definidas como regras básicas, ferramentas cognitivas que o ser humano utiliza para tomar suas decisões. É uma maneira simplificada de tratar o mundo complexo. (BAZERMAN, 2004).

Muitas vezes, em virtude das dificuldades em entender processos probabilísticos, cobertura da mídia, experiências pessoais, o repertório e ansiedades causam incertezas, eventos de riscos mal avaliados e julgamento de fatos sem confiabilidade pelo público em geral.

Slovic (1987) apud Módica (2009) pesquisou a percepção de risco nos Estados Unidos. $\mathrm{O}$ autor queria descobrir como as pessoas percebiam 0 risco de trinta atividades e tecnologias listadas na Tabela 7. Foi solicitado a cada um dos entrevistados que considerassem o risco de morte, na sociedade como um todo, decorrente dessa atividade ou tecnologia. Os participantes foram instruídos a atribuir o grau dez ao item que considerassem de menor risco e classificar os demais de forma proporcional a esse risco, como exemplo uma atividade considerada com grau dezoito significa que é oitenta por cento mais arriscada que a atividade de menor risco.

A pesquisa foi aplicada em quatro grupos distintos: quarenta membros da League of Women Voters, trinta estudantes universitários, vinte e cinco profissionais membros do Active Club e quinze profissionais escolhidos por seu envolvimento em análises de riscos que incluía, entre outros, um 
geógrafo, um analista de política ambiental, um advogado, um economista, um biólogo, um bioquímico e um membro da agência reguladora do governo de materiais perigosos.

Tabela 7 - Ordenação de riscos percebidos

\begin{tabular}{|c|c|c|c|c|}
\hline Atividade ou tecnologia & $\begin{array}{c}\text { Membros da League of } \\
\text { Women Voters }\end{array}$ & $\begin{array}{c}\text { Estudantes } \\
\text { universitários }\end{array}$ & $\begin{array}{c}\text { Membros do Active } \\
\text { Club }\end{array}$ & Especialistas \\
\hline Energia nuclear & 1 & 1 & 8 & 20 \\
\hline Veículos motorizados & 2 & 5 & 3 & 1 \\
\hline Armas de fogo manuais & 3 & 2 & 1 & 4 \\
\hline Fumo & 4 & 3 & 4 & 2 \\
\hline Motociclistas & 5 & 6 & 2 & 6 \\
\hline Bebidas alcoólicas & 6 & 7 & 5 & 3 \\
\hline Aviação privada & 7 & 15 & 11 & 12 \\
\hline Trabalho de policial & 8 & 8 & 7 & 17 \\
\hline Pesticidas & 9 & 4 & 15 & 8 \\
\hline Cirurgia & 10 & 11 & 9 & 5 \\
\hline Bombeiros & 11 & 10 & 6 & 18 \\
\hline Grandes obras & 12 & 14 & 13 & 13 \\
\hline Caça & 13 & 18 & 10 & 23 \\
\hline Aerossóis & 14 & 13 & 23 & 26 \\
\hline Alpinismo & 15 & 22 & 12 & 29 \\
\hline Ciclismo & 16 & 24 & 14 & 15 \\
\hline Aviação comercial & 17 & 16 & 18 & 16 \\
\hline Energia elétrica (não nuclear) & 18 & 19 & 19 & 9 \\
\hline Natação & 19 & 30 & 17 & 10 \\
\hline Anticoncepcionais & 20 & 9 & 22 & 11 \\
\hline Esqui & 21 & 25 & 16 & 30 \\
\hline Radiografia & 22 & 17 & 24 & 7 \\
\hline Futebol Americano escolar & 23 & 26 & 21 & 27 \\
\hline Ferrovia & 24 & 23 & 29 & 19 \\
\hline Conservantes de alimentos & 25 & 12 & 28 & 14 \\
\hline Corante de alimentos & 26 & 20 & 30 & 21 \\
\hline Cortador de grama motorizado & 27 & 28 & 25 & 28 \\
\hline Antibióticos controlados & 28 & 21 & 26 & 24 \\
\hline Utensílios domésticos & 29 & 27 & 27 & 22 \\
\hline Vacina & 30 & 29 & 29 & 25 \\
\hline
\end{tabular}

Fonte: Slovic (1987) apud Módica (2009).

Os autores concluíram que a percepção dos especialistas em relação aos riscos estava muito associada aos históricos anuais de fatalidades. Já os leigos, entretanto, notou-se uma relação apenas moderada entre as percepções e os históricos de fatalidades. 
Os resultados da pesquisa de Slovic (1987) apud Módica (2009) têm total relação com o gerenciamento de riscos, ao mostrar que os especialistas conseguem se aproximar dos valores apurados por dados históricos, e, contrariamente, os leigos não têm sensibilidade para opinar sobre os eventos de risco.

\subsection{PROCESSOS DECISÓRIOS}

Segundo Quelopana (2003), a ciência da decisão, apesar de ser um campo relativamente novo, se comparada com a filosofia, psicologia e sociologia, vem sendo ultimamente foco de atenção das diversas áreas de estudo. Entretanto, as diferentes perspectivas do processo decisório vêm gerando novos termos, novas linguagens e novos modelos que, além de enriquecer o conhecimento e a literatura, podem apresentar contradições e atrapalhar o seu aperfeiçoamento.

A grande preocupação desta ciência é o entendimento e a melhoria dos processos decisórios em todos os níveis em que é necessário tomar uma decisão.

Segundo ainda Quelopana (2003), tomar uma decisão pode ser definido como uma escolha intencional e refletida em resposta às necessidades percebidas. No processo decisório, utiliza-se todo o conhecimento produzido desde os primeiros fundamentos proporcionados pela religião, pela literatura e pela filosofia, até os mais recentes avanços realizados conjuntamente pela filosofia, economia, psicologia e sociologia.

Segundo Pereira \& Fonseca (1997) a palavra decisão é formada pelo prefixo de (prefixo latino aqui com o significado de parar, extrair, interromper) que se antepõe à palavra caedere (que significa cindir, cortar). Tomada ao pé da letra, a palavra decisão significa "parar de cortar" ou "deixar fluir". Uma decisão precisa ser tomada sempre que estamos diante de um problema que possui mais que uma alternativa para a sua solução. 
Edwards e Fasolo (2001, p.582) definem decisão como uma escolha irrevogável de uma ação que possui conseqüências relevantes e um valor.

Segundo Turban \& Meredith (1994), a decisão pode ser classificada de acordo com o grau de conhecimento que o decisor tem sobre a situação, sendo usual a divisão em três categorias:

1) Decisão tomada sob certeza - neste tipo de decisão é assumido que o decisor dispõe de informações completas, de tal forma que ele conheça exatamente o resultado de cada alternativa de ação que seja adotada. Este tipo de decisão também é chamado de decisão determinística.

2) Decisão tomada sob risco - também conhecida como decisão probabilística ou estocástica, é aquela na qual pode haver dois ou mais resultados possíveis para cada alternativa de ação devido à impossibilidade de controle dos estados da natureza por parte do decisor. Se for assumido que o decisor conhece ou pode estimar a probabilidade de ocorrência dos estados da natureza, então é dito que a decisão é tomada sob risco.

3) Decisão tomada sob incerteza - quando o decisor, assim como na decisão sob risco, se defronta com mais de um resultado possível para cada ação e, além disso, não conhece, nem pode estimar a probabilidade de ocorrência dos estados da natureza, diz-se que decide sob incerteza. Entretanto, é assumido que o decisor conhece os possíveis estados da natureza.

Lindblom (1981) afirma que o processo decisório é extremamente complexo, sem princípio nem fim, com limites que são incertos. O autor complementa que para seu estudo é preciso, antes de qualquer coisa, "entender as características dos participantes, os papéis desempenhados, a autoridade e o poder envolvidos, como lidam uns com os outros e se controlam mutuamente.".

Segundo Cury (1983), existe duas formas típicas de se tomar decisões nas empresas:

a) o enfoque tradicional, que considera a decisão um ato isolado e individual;

b) o enfoque behaviorista, que leva em conta o ambiente e considera a decisão um ato coletivo e mais racional. 
Segundo Yates \& Stone (1994) em um processo decisório, as pessoas selecionam uma alternativa de ação com a intenção de conseguir resultado ao menos tão satisfatório quanto aquele que teria com qualquer outra opção disponível. Quando esse objetivo é alcançado, diz-se que a decisão foi um sucesso; de outra forma, será um fracasso.

Para Baron (1994), a decisão é uma escolha de ação. No entanto, as decisões são tomadas para se conseguir determinados objetivos e muitas vezes, para se conseguir tal objetivo, são baseadas em crenças.

Segundo ainda o mesmo autor, existe uma estrutura de pensamento, chamada de pesquisa-inferência, como a base da tomada de decisão. O processo inicia-se com uma dúvida ou questão que tenha alguma importância para a pessoa. Para remover essa dúvida, é realizada uma pesquisa que envolve as possibilidades de solução, evidências e objetivos. Após a pesquisa, é realizada a inferência ou uso das evidências, onde cada alternativa será fortalecida ou enfraquecida. Este processo pode não ocorrer em uma ordem fixa e é perfeitamente possível a sobreposição das etapas. A Figura 14 ilustra o processo do pensamento conforme proposto por Baron (1994).

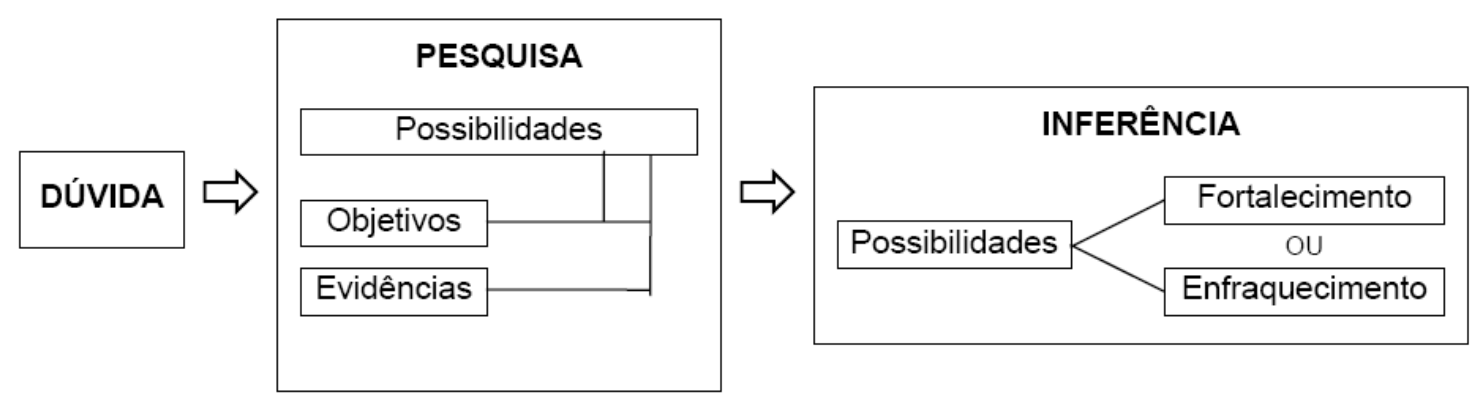

Figura 14. A estrutura pesquisa-inferência do pensamento Fonte: Baron (1994)

Segundo Gilovich \& Griffin (2002), o processo tradicional da tomada de decisões é baseado no modelo clássico da escolha racional que segue uma estrutura normativa. A teoria normativa investiga como fazemos escolhas sob condições ideais. De acordo com este modelo, o tomador de decisão racional escolhe uma opção, avaliando as probabilidades de cada possível resultado, julga a utilidade que obterá de cada resultado e escolhe a opção que oferece a combinação ótima. 
Entretanto, tradicionalmente, tomamos decisões sob condições de incerteza e não temos informações completas, ou conhecimento sobre a situação, ou até mesmo tempo suficiente para uma análise isto é, não sabemos quais são as possíveis alternativas, ou as probabilidades de ocorrência, ou mesmo os resultados que serão obtidos.

Segundo Bazerman (2004), é importante considerarmos dois aspectos nos estudos de julgamento e tomada de decisão. Primeiro, sabemos que indivíduos normalmente não são nem racionais nem consistentes com suas afirmações quando fazem julgamentos sob condições incertas. Segundo, essa estrutura normativa fornece um fundamento para ilustrar os desvios sistemáticos em relação à racionalidade a que os indivíduos estão propensos quando tomam decisões sob incerteza.

De acordo com Browne (1992), os modelos prescritivos ou normativos consistem numa série de passos a respeito de como uma decisão deve ser tomada numa organização. No modelo descritivo a decisão é de fato tomada e se preocupa com o que realmente ocorre numa organização, não no que deveria acontecer segundo modelos prescritivos. A abordagem descritiva é baseada em observações do mundo real das organizações e permite a influência de valores, do meio ambiente, e um elemento comportamental de irracionalidade.

Ansoff (1990) afirma que os dois enfoques, tanto o descritivo quanto o normativo (ou prescritivo), são complementares.

Desta forma, sintetizando algumas das diferentes definições encontradas na literatura, pode-se entender que uma decisão insere-se num contexto e pode desenvolver-se na forma de um processo - explícito ou não, rastreável ou não, sujeito à influência de expectativas, da emoção e da ocorrência de idéias súbitas - e, após um processo de avaliação em relação ao alcance de um objetivo, um determinado curso de ação - resultante de múltiplas alternativas ou não e cujas conseqüências podem eventualmente ser atribuídas a um valor - é escolhido.

Portanto, a seguir, será discutido o modelo normativo/prescritivo e o modelo descritivo dos processos decisórios. 


\subsubsection{Modelo normativo/prescritivo}

Segundo Simon (1955), na teoria econômica tradicional assume-se que o homem "econômico" tenha conhecimento de todos os fatores relevantes de seu ambiente, tenha um sistema de preferências bem organizado e estável, e tenha uma habilidade computacional que o habilita a calcular, entre os cursos de ação alternativos disponíveis para ele, aquele que o permita alcançar o ponto mais alto em sua escala de preferência.

Segundo ainda o mesmo autor, o modelo racional de escolha pressupõe que 0 comportamento humano é calculado e instrumental, ou seja, possui algum propósito.

Após alguns anos, Simon (1988) defende que a introdução dos computadores mudou a maneira pela qual os executivos são capazes de chegar a uma decisão, pois eles podem vê-la agora em termos de um conjunto muito maior de conseqüências inter-relacionadas. Como conseqüência, a teoria do comportamento racional precisaria dar conta não somente da racionalidade substancial, isto é, o grau com que os cursos apropriados de ação são escolhidos, mas também a racionalidade de procedimentos - que diz respeito à efetividade dos procedimentos usados para escolher as ações, à luz das limitações humanas.

Segundo Gilovich \& Griffin (2002), o processo tradicional da tomada de decisões é baseado no modelo clássico da escolha racional que segue uma estrutura normativa. A teoria normativa investiga como fazemos escolhas sob condições ideais. De acordo com este modelo, o tomador de decisão racional escolhe uma opção, avaliando as probabilidades de cada possível resultado, julga a utilidade que obterá de cada resultado e escolhe a opção que oferece a combinação ótima.

Clemen e Reilly (2001, p.11) entendem que uma boa decisão envolve compreensão profunda do problema e reflexão atenta em relação a questões importantes, enquanto que resultados, por sua vez, podem ser de sorte ou de azar, independentemente da qualidade da decisão. 
Howard (1988) sugere que a qualidade de uma decisão passa pela avaliação dos seguintes fatores: 1) o enquadramento ou estruturação do problema de decisão; 2) informações acessadas; 3) criatividade na geração de alternativas significativamente diferentes; 4) valores bem definidos; 5) integração e avaliação lógica; 6) balanceamento do tempo gasto com as diferentes etapas e 7) compromisso para a ação.

Robbins (2000) argumenta que o modelo de tomada de decisão é dividido em seis etapas, a saber: definição do problema, identificação dos critérios, ponderação dos critérios, geração de alternativas, classificação das alternativas frentes aos critérios ponderados e cálculo da decisão ótima.

Clemen e Reilly (1996, p.6), acrescentaram outras etapas relevantes ao processo: decompor e modelar o problema (estrutura, incerteza, preferências) após a identificação do mesmo e o desenvolver uma análise de sensibilidade, após a escolha de uma alternativa, visando mensurar o quão robusta é a decisão em diferentes cenários futuros.

Daft (2005) e Bateman \& Snell (2006) complementam as etapas anteriormente apresentadas acrescentando uma avaliação da decisão e feedback ao final do processo decisório.

Outros autores desenvolveram modelos mais detalhados, como é o caso de Gomes (1999), o qual inclui as seguintes etapas:
a) Identificação, formulação e análise do problema;
b) Definição de objetivos e preferências;
c) Identificação das restrições e/ou relaxações;
d) Identificação de critérios e/ou atributos de decisão;
e) Construção e teste de um modelo para estudo;
f) Realimentação do modelo de estudo;
g) Estabelecimento de medidas de eficácia;
h) Identificação de alternativas que solucionem o problema;
i) Mensuração das conseqüências das alternativas e do grau que permite alcançar o objetivo;
j) Comparação das alternativas;
k) Escolha(s) da(s) alternativa(s);
l) Implementação;
m) Realimentação. 
Além das etapas ora apresentadas por diversos autores na bibliografia apresentada, Luppe (2006) apresenta alguns modelos normativos de tomada de decisão, são eles:

\section{1 - Valor Esperado}

Segundo PMI (2008), o valor esperado é um conceito estatístico que calcula o resultado médio quando o futuro inclui cenários que podem ocorrer ou não. Ele é calculado multiplicando o valor de cada resultado possível pela sua probabilidade de ocorrência e somando esses produtos.

O cálculo do valor esperado torna-se mais complicado, quando não se pode especificar a probabilidade baseada em dados estatísticos de todos os resultados possíveis que poderão ocorrer. Por exemplo, para avaliar o valor subjetivo esperado do faturamento de uma empresa daqui a 12 meses, tem-se de avaliar a probabilidade dos vários fatores que podem impactar o faturamento da empresa, no período, e calcular a possível influência de cada fator para a obtenção do valor esperado.

Bazerman (2004) apud Luppe (2006) diz que à medida que os problemas se tornam mais complexos, tais avaliações podem se tornar muito difíceis, com um grande potencial de viés.

Para Bazerman (2004) apud Luppe (2006), uma regra simples para tomar decisões é sempre selecionar a alternativa com o maior valor esperado. A premissa para tal regra de decisão pelo valor esperado é que decisões tomadas segundo essa regra, no conjunto, serão ótimas, isto é, os erros aleatórios a favor ou contra se cancelarão com o tempo. Para ser preciso, entretanto, erros aleatórios não se cancelam uma crença que contribui para a 'falácia do jogador', mas sim diminuem ao longo do tempo. 


\section{2 - Equivalente de Certeza}

O equivalente de certeza determina o valor certo que faria o tomador de decisões ficar indiferente, entre um evento incerto e aquele valor certo. (BAZERMAN, 2004 apud LUPPE, 2006)

Por meio de um exemplo simples, Luppe (2006) ilustra esta associação. Se considerar um jogo, no qual o participante tem $60 \%$ de ganhar $\$ 100$ e $40 \%$ de possibilidade de não ganhar nada, perguntamos por qual valor ele estaria disposto a abrir mão de participar deste jogo. Caso esse valor, o equivalente de certeza, seja menor que o valor esperado do jogo (\$60), então há postura de aversão ao risco. Da mesma forma, se o equivalente de certeza for maior do que o valor esperado há uma postura de propensão ao risco. Caso os dois valores sejam iguais, a postura é de neutralidade.

Em suma, nos modelos anteriormente citados, há ênfase na racionalidade, ou seja, trata-se de modelos racionais, prescritivos ou normativos, os quais indicam como a decisão deve ser tomada na teoria, não necessariamente como a decisão é tomada na prática, no dia-a-dia das empresas. Os modelos racionais podem ser aplicados em determinadas ocasiões, mas em se tratando de um processo decisório em gerenciamento de projetos, é mais provável encontrar-se um modelo de racionalidade limitada ou modelo descritivo. Neste caso, cumpre-se explicitar algumas derivações dos modelos descritivos organizacionais, apresentadas pela literatura ao longo das últimas décadas, visando uma melhor classificação e compreensão dos modelos de racionalidade limitada.

\subsubsection{Modelo descritivo/cognitivo}

Segundo Tversky e Kahneman (1981), escolhas racionais são aquelas que obedecem a princípios de coerência e consistência. Para Bazerman (2004) a racionalidade refere-se ao processo de tomada de decisão que esperamos que leve ao resultado ótimo, dada uma avaliação precisa dos valores e preferências de risco 
do tomador de decisões. Entende-se, assim, que o modelo racional é fundamentado em um conjunto de proposições que determinam como uma decisão deve ser tomada em vez de descrever como uma decisão é tomada.

No entanto, em 1955, Simon reconheceu a capacidade cognitiva limitada da mente humana quando introduziu o conceito da racionalidade limitada. No seu trabalho sugeriu que o julgamento individual fica restringido pela sua racionalidade e que 0 conceito da racionalidade limitada propicia uma estrutura para o questionamento das suposições históricas do modelo racional, bem como fornece a base para o estudo dos desvios do julgamento dito racional. Ele argumenta que o homem não se comporta de forma racional não porque não queira, mas porque não consegue. Suas capacidades cognitivas e computacionais são bastante limitadas quando comparadas com o mundo à sua volta.

Bazerman (2004) enfatiza que, embora os conceitos da racionalidade limitada seja importante para mostrar que o julgamento se desvia da racionalidade, eles não nos dizem como o julgamento sofrerá vieses.

Slovic \& Fischhof \& Lichtenstein (1982), observam que na maior parte das vezes, as pessoas não utilizam evidências estatísticas para avaliar as situações de risco. Ao contrário, é comum o uso de regras gerais de inferência. Essas regras de julgamento, conhecidas como heurística, são empregadas para simplificar o processo cognitivo. Embora sejam válidas e úteis em determinadas circunstâncias, podem provocar grandes e persistentes vieses, com sérias implicações para a tomada de decisão.

Bazerman (2006) salienta a importância do estudo de estruturas descritivas por propiciar um meio adequado de ilustrar desvios sistemáticos da racionalidade, uma vez que alguns fatores impedem que as decisões puramente racionais se tornem $100 \%$ eficazes como, por exemplo, restrição de tempo e custo, pouca informação retida na memória dos tomadores de decisões, vieses e estratégias simplificadoras que os seres humanos carregam consigo. 
Simon (1997) sugere que o julgamento individual fica restringido pela sua racionalidade e que se pode entender melhor o processo de decisão explicando processos de decisão reais e não-normativos ("o que deveria ser feito").

Segundo Stoner e Freeman (1992), a busca por uma solução satisfatória, ao invés de ótima, é importante no discernimento de que o julgamento se desvia da racionalidade.

Kahneman (2003) destaca que a maior parte das decisões são tomadas intuitivamente e a intuição funciona de forma similar à percepção (SISTEMA 1). "Intuição" indica processos espontâneos e imediatos e "Razão" se refere a processos mentais deliberados (esforço) (SISTEMA 2), conforme pode ser demonstrado na Figura 15.

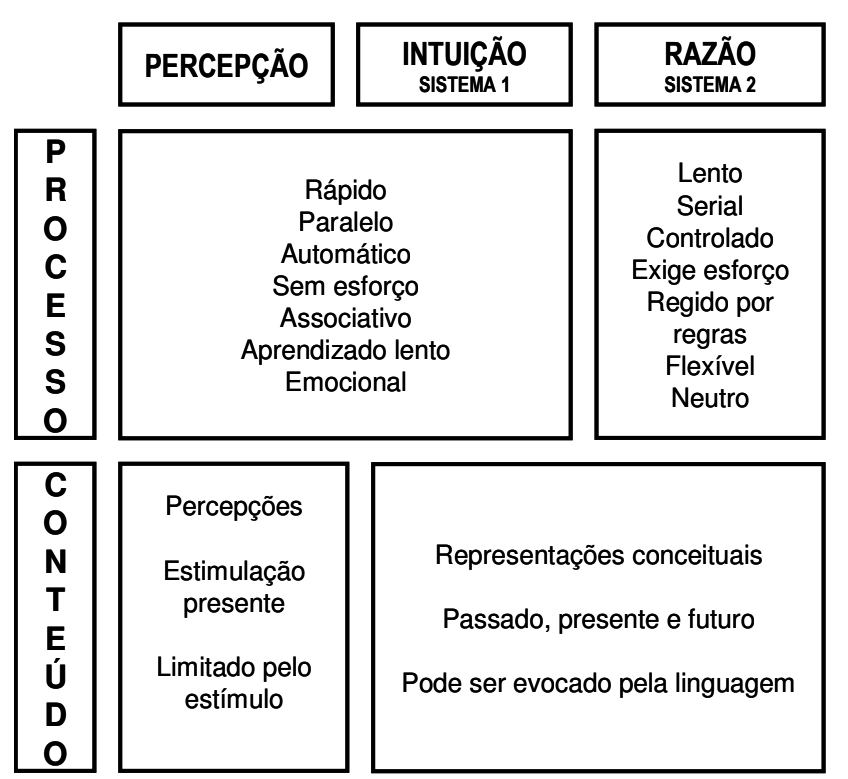

Figura 15. Comparativo da Intuição e da Razão na decisão Fonte: Kahneman (2003)

Segundo Kahneman (2003), o Sistema 1 se refere ao sistema intuitivo, que é tipicamente rápido, automático, sem esforço, implícito e emocional. Na maioria das decisões tomadas, utiliza-se o Sistema 1. Em contraste, o Sistema 2 se refere ao raciocínio que é mais lento, consciente, trabalhoso, explícito e lógico. 
Direcionados por este mesmo princípio, Epley e Gilovich (2005) indicam que o processo predominante do nosso julgamento é automático - inconsciente, intencional, sem esforço e, portanto incontrolável.

Deste modo, o Sistema 1 propõe rapidamente respostas intuitivas aos problemas de julgamento assim que eles surgem, e o Sistema 2 monitora a qualidade das propostas, as quais podem endossar, corrigir ou anular. Claramente, um processo completo do Sistema 2 não é necessário para todas as decisões que tomamos diariamente. Em muitas situações, nosso Sistema 1 é totalmente suficiente e seria impraticável, por exemplo, raciocinarmos logicamente em cada escolha que fazemos enquanto estamos fazendo compras em um supermercado, porém a lógica do Sistema 2 deveria influenciar preferencialmente as nossas decisões mais importantes. (BAZERMAN, 2006)

Identificar e ilustrar as heurísticas e seus vieses específicos próprios do cenário gerencial torna-se fundamental num estudo descritivo do processo decisório.

As heurísticas podem ser definidas como regras básicas, ferramentas cognitivas que o ser humano utiliza para tomar suas decisões. É uma maneira simplificada de tratar o mundo complexo (BAZERMAN, 2004). Ainda segundo ele, existem 3 grupos básicos de heurísticas de julgamento usadas por decisores trabalhando sobre pressão de tempo: Heurística da disponibilidade, da representatividade e baseada na ancoragem.

Em todos os casos, as três heurísticas do julgamento permitem que o tomador de decisão foque um conjunto limitado de informações para chegar a uma decisão. Estas heurísticas são bastante econômicas e usualmente eficazes, no entanto, podem levar a alguns erros sistemáticos e previsíveis. Um melhor entendimento destas heurísticas e dos vieses, que derivam de cada uma delas, pode melhorar os julgamentos e as decisões em situações de incerteza. 


\subsubsection{Heurística da Disponibilidade}

Segundo Bazerman (2004), heurística da disponibilidade são modelos que podem ser úteis para minimizar o uso de heurísticas irrelevante que influenciam uma decisão. O modelo ajuda a avaliar as heurísticas de forma objetiva, através de testes estatísticos, esclarecendo sobre situações irrelevantes.

Segundo Kahneman e Tversky (1972), heurística da disponibilidade são situações, em que as pessoas avaliam a freqüência, a probabilidade ou as prováveis causas de ocorrência de um determinado evento pela facilidade com que exemplos ou ocorrências do mesmo estão "disponíveis" na memória. Eventos são julgados mais prováveis de ocorrer se são fáceis de imaginar ou recordar.

Segundo ainda o mesmo autor supracitado no parágrafo anterior, em muitos casos, esta heurística nos levará a julgamentos corretos porque, em geral, exemplos de eventos de maior freqüência se revelam mais rapidamente em nossas mentes do que eventos menos freqüentes. É extremamente importante, entretanto, percebermos que o uso incorreto da heurística da disponibilidade pode levar a erros sistemáticos porque a disponibilidade de informações é afetada por outros fatores que não estão relacionados com a freqüência do evento julgado.

\section{Vieses que emanam da heurística da disponibilidade}

Facilidade de Lembrança: Segundo Bazerman (2004), indivíduos julgam que eventos mais facilmente recuperados da memória, com base na recentidade e vividez, são mais numerosos do que eventos de igual freqüência cujos exemplos são lembrados com menos facilidade.

Recuperabilidade: Segundo Bazerman (2004), a avaliação que os indivíduos fazem da freqüência de eventos sofre viés com base no modo como as estruturas de suas memórias afetam o processo de busca - viés do comportamento de busca. Segundo Kahneman e Tversky (1972), para a 
maioria dos problemas de estimação, por causa das pessoas não construírem e enumerarem todas as possibilidades de ocorrência de um evento, elas tentam construir alguns exemplos e julgam a freqüência pela disponibilidade, isto é, por uma avaliação da facilidade com que esses exemplos estão disponíveis na memória

Associações Pressupostas: Segundo Bazerman (2004), indivíduos tendem a superestimar a probabilidade de dois eventos ocorrerem concomitantemente com base no número de associações semelhantes que podem recordar facilmente, seja pela experiência, seja por influência social.

\subsubsection{Heurística da Representatividade}

Segundo Bazerman (2004), heurística da representatividade está associada ao fato das pessoas buscarem peculiaridades que muitas vezes estão em estereótipos e mesmo em comportamentos irracionais como o preconceito e a discriminação. O modelo pode auxiliar na possibilidade de um julgamento mais preciso para 0 problema em questão

Segundo Kahneman e Tversky (1972) sugerem que uma pessoa, ao usar a heurística da representatividade, julga a probabilidade de um evento incerto, ou uma amostra, de acordo com: (1) o quanto ele é similar ou representativo das propriedades da população da qual se origina e, (2) o grau em que ele reflete os aspectos proeminentes do processo pelo qual é gerado. Esta abordagem para o julgamento de probabilidade pode levar a sérios erros, pelo fato de semelhança, ou representatividade, não ser influenciada por diversos fatores que podem afetar os julgamentos de probabilidade. 


\section{Vieses que emanam da heurística da representatividade}

Insensibilidade aos índices básicos: Ao avaliar a probabilidade de eventos, indivíduos tendem a ignorar os índices básicos caso seja fornecida qualquer outra descrição informativa - mesmo que seja relevante.

Insensibilidade ao tamanho da amostra: Segundo Bazerman (2004), ao avaliar a confiabilidade de informações amostrais, indivíduos freqüentemente falham na avaliação do papel do tamanho da amostra. Tversky e Kahneman (1971) demonstraram uma crença no que eles chamaram de "a lei dos pequenos números", pela qual mesmo pequenas amostras são vistas como altamente representativas das populações das quais elas foram retiradas. As pessoas falham na apreciação do tamanho da amostra, mesmo quando tais dados são enfatizados na formulação do problema.

Interpretações erradas de chance: Segundo Bazerman (2004), indivíduos esperam que uma seqüência de dados gerada aleatório pareça "aleatória" mesmo quando a seqüência for muito curta para que essas expectativas sejam estatisticamente válidas. Para um evento incerto ser representativo, não é suficiente que o evento seja similar à população de origem, ele deveria também refletir as propriedades dos processos incertos dos quais foram gerados, isto é, deveriam parecer aleatórios e a maior característica da aparente aleatoriedade é a falta de padrões sistemáticos.

Regressão a média: Segundo Bazerman (2004), indivíduos são propensos a ignorar o fato de que eventos extremos tendem a regredir à média em tentativas subseqüentes.

A falácia da conjunção: Segundo Bazerman (2004), indivíduos julgam erroneamente que conjunções são mais prováveis do que um conjunto mais global de ocorrências do qual a conjunção é um subconjunto. 


\title{
2.3.2.3 Heurística baseada na Ancoragem
}

Segundo Bazerman (2004), heurística baseada na ancoragem ocorre quando o decisor toma como ponto de partida (ou âncora) valores anteriores (baseados em situações anteriores) que podem não ser parâmetros válidos. Processos de modelagem devem validar inclusive as amostras e universos sobre os quais 0 decisor deseja agir em busca de vieses previamente utilizados e que podem estar refletidos nos dados históricos.

Segundo Tversky e Kahneman (1971), a ancoragem ocorre quando uma pessoa utiliza um ponto inicial ou "âncora", por exemplo, um preço que pode ser apresentado, estimado ou subentendido e então, utiliza esta informação como base para avaliar uma dada opção ou na escolha de um curso de ação. O ajustamento ocorre quando a pessoa toma está "âncora" como um ponto de partida e adiciona ou subtrai valores deste valor para estimar as probabilidades dos resultados potenciais.

\section{Vieses que emanam da heurística de ancoragem e ajuste}

\begin{abstract}
Ajuste insuficiente da âncora: Indivíduos estimam valores com base em um valor inicial e usualmente fazem ajustes insuficientes a partir daquela âncora para estabelecer um valor final.
\end{abstract}

Vieses de eventos conjuntivos e disjuntivos: Indivíduos exibem um viés em relação à superestimação da probabilidade de eventos conjuntivos e à subestimação da probabilidade de eventos disjuntivos.

Excesso de confiança: Indivíduos tendem a demonstrar excesso de confiança quanto à infalibilidade de seus julgamentos ao responder perguntas moderada ou extremamente difíceis. 


\section{Outros vieses mais gerais:}

Armadilha da confirmação: Indivíduos tendem a buscar informações confirmatórias para o que eles acham que é verdadeiro e deixam de procurar evidências desconfirmatória.

Maldição do conhecimento: Após saber se um evento ocorreu ou não, indivíduos tendem a superestimar até que grau eles teriam previsto 0 resultado correto. Além do mais, não ignoram informações que eles têm mas que os outros não têm ao prever o comportamento dos outros.

Dentre as diversas abordagens apresentadas neste capítulo, para esta dissertação considerou-se, no que diz respeito aos conceitos de Gerenciamento de projetos, a definição de Pinto (2002), segundo a qual Gerenciamento de projetos é a interface entre os requisitos de gerenciamento geral, o gerenciamento operacional e o gerenciamento técnico, sendo que os aspectos operacionais estão relacionados à implementação de uma estratégia organizacional; os aspectos técnicos tendem a focar a teoria, tecnologia e a prática e os aspectos gerais de gerenciamento estão relacionados às competências.

Com relação ao conceito de riscos, utilizou-se a abordagem de Raz e Hilson (2005), que o divide em três grupos:

(i) riscos são eventos incertos que tem somente efeito negativo no projeto.

(ii) riscos são eventos incertos que podem ter tanto efeito positivo, denominado de oportunidade, quanto negativo (ameaça) no projeto e por fim

(iii) riscos são eventos incertos que tem efeitos no projeto. Essa última definição não explicita se os efeitos são negativos ou positivos.

Também considerou-se a abordagem de Cleland e Ireland (2002), quanto a classificação dos riscos em dois tipos, interno e externo. O risco interno é inerente ao projeto, controlado pelo líder podendo reduzi-lo mediante ações diretas, com o 
desenvolvimento de planos de contingências. Já o risco externo encontra-se fora do controle dos líderes de projeto, como, por exemplo, as interfaces de projeto desconhecidas e cujas definições são feitas por terceiros.

Quanto ao gerenciamento de riscos, embora diversos autores apresentam modelos similares sobre como os riscos são estruturados, utilizou-se o modelo proposto pelo PMI (2004).

No que diz respeito ao processo decisório, embora haja diferentes abordagens quanto aos aspectos utilizados (Prescritivo ou descritivo), utilizou-se parcialmente o modelo adotado por Ansoff (1990), que afirma serem estes complementares. No entanto, procurou-se mostrar os benefícios de se utilizar o modelo prescritivo adotado por Clemen e Reilly (1996), no qual através de um estudo estruturado, obtém-se decisões mais assertivas. 


\section{METODOLOGIA}

Este capítulo justifica, a seguir, a escolha do tipo e do método de pesquisa utilizados e descreve os instrumentos de levantamento de dados e o método aplicado.

\subsection{INTRODUÇÃO}

Para Lakatos e Marconi (2007) pesquisa é um procedimento reflexivo sistemático, controlado e crítico, que permite descobrir novos fatos ou dados, relações ou leis, em qualquer campo de conhecimento.

Para Gil (1999), a pesquisa tem um caráter pragmático, é um "processo formal e sistemático de desenvolvimento do método científico". O objetivo fundamental da pesquisa é descobrir respostas para problemas mediante o emprego de procedimentos científicos.

Silva (2001) descreve a pesquisa como um conjunto de ações, propostas para encontrar a solução para um problema, que têm por base procedimentos racionais e sistemáticos. A pesquisa é realizada quando se tem um problema e não se tem informações para solucioná-lo.

Silva (2001) destaca que uma vez que a pesquisa também é a construção de conhecimento original de acordo com certas exigências científicas, é extremamente importante estruturar o planejamento da pesquisa, obedecendo-se critérios de coerência, consistência, originalidade e objetivação. Para isto é desejável que uma pesquisa científica preencha os seguintes requisitos:

a) a existência de uma pergunta que se deseja responder;

b) a elaboração de um conjunto de passos que permitam chegar à resposta;

c) a indicação do grau de confiabilidade na resposta obtida. 
Segundo Silva (2001) o planejamento de uma pesquisa dependerá basicamente de três fases; decisória, construtiva e redacional. Na fase decisória o tema é escolhido e é feita a definição e delimitação do problema de pesquisa. Na fase construtiva é desenvolvido o plano de pesquisa e finalmente na fase redacional são analisados os dados e informações obtidas na fase construtiva, visando à organização e sistematização das idéias e a elaboração do relatório final.

Cervo \& Bervian (1983) descreve de forma gráfica na Figura 16 o planejamento de um projeto de pesquisa, dividindo-a numa parte investigativa e numa segunda de comunicação da pesquisa.

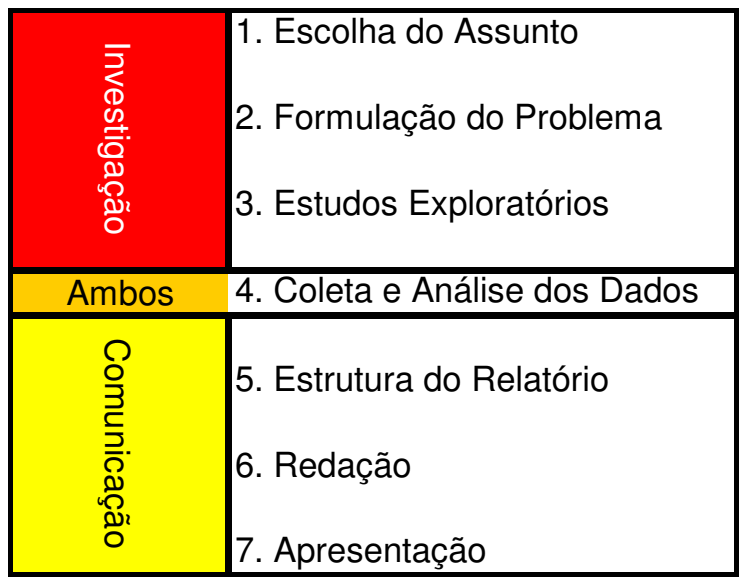

Figura 16. Planejamento da Pesquisa

Fonte: Adaptado de Cervo e Bervian (1983)

\subsection{MÉTODOS DE PESQUISA}

Não existe um consenso entre os diversos autores da área quanto à classificação da pesquisa científica para identificar o tipo de método. Mattar (1999) observa que as diferentes classificações da pesquisa são resultantes da utilização de variáveis distintas. Assim, conforme a variável considerada, a pesquisa pode ser classificada em: a) qualitativa ou quantitativa; b) descritiva ou causal; c) exploratória ou conclusiva; d) por comunicação ou por observação; e) estudo de caso, estudo de campo ou levantamento amostral; f) ocasional ou evolutiva; g) experimental ou expost facto e h) realizada no campo, em laboratório ou por simulação. 
Lakatos \& Marconi (1986) apud Patah (2004) definem quatro métodos de abordagem mais amplos, sendo eles:

- Indutivo: o entendimento dos fenômenos de forma abrangente indo das constatações particulares, mais específicas para as leis ou teorias, fazendose conexões ascendentes, portanto;

- Dedutivo: parte-se de teorias e leis fazendo-se conexões descendentes chegando-se aos fenômenos particulares;

- Hipotético-Dedutivo: inicia-se pela identificação de uma lacuna no conhecimento, formulando hipóteses e, por inferência dedutiva testa a ocorrência dos fenômenos;

- Dialético: inserido nos fenômenos através de uma ação recíproca, da contradição inerente ao fenômeno e da mudança dialética que ocorre na natureza e na sociedade.

Yin (2002) emprega a denominação estratégia de pesquisa para identificar o tipo de método e apresenta cinco possibilidades de estratégia: 1) experimento; 2) levantamento (survey); 3) análise de arquivo; 4) história e 5) estudo de caso. Cada uma destas estratégias pode ser usada com a finalidade exploratória, descritiva ou explanatória.

Para Davis (1996) existem quatro níveis de métodos científicos, conforme o grau de entendimento que se busca da situação problema. Os níveis são:

- Descrição: é a simples identificação das principais variáveis de um problema.

- Predição: é realizada quando o pesquisador pode identificar uma variável ou um conjunto de variáveis que está associada com alguma outra variável.

- Explanação: é conseguida quando o pesquisador pode responder, porque um certo fenômeno ou relação existe na realidade.

- O controle: é o nível mais alto, existe quando o pesquisador está apto a manipular uma ou mais variáveis em uma situação problema para provocar mudanças em outras variáveis.

Com tudo isso, Campagna (1996) afirma que o conceito de métodos científicos é muito abrangente. Inclui as ações que definem de modo operativo a metodologia, e ainda conceitos de métodos e processos de objetivação do investigador. Estes últimos têm como finalidade orientar que se assuma sem subjetivismo a situaçãoproblema, posta como objeto de investigação. 


\subsection{ESCOLHA DO MÉTODO DE PESQUISA}

Yin (2002) identifica várias maneiras de se fazer pesquisa, tais como: estudo de caso - experimentos, levantamento, história e análise de informações de arquivos. Cada estratégia adotada na escolha do método é analisada mediante os critérios de:

- Tipo do problema;

- Controle do pesquisador sobre o comportamento dos eventos e;

- Enfoque no contemporâneo versus fenômeno histórico.

Para melhor entendimento da tipologia de estratégias de pesquisa proposta por Yin (2002) a seguinte Tabela 8 é ilustrativa:

Tabela 8 - Estratégias de Pesquisa

\begin{tabular}{|c|c|c|c|}
\hline Estratégia & Forma da Questão & Controle Eventos & $\begin{array}{l}\text { Foco em Eventos } \\
\text { Contemporâneos }\end{array}$ \\
\hline Experimento & Como, Por que & Sim & Sim \\
\hline Levantamento & $\begin{array}{l}\text { Quem, o quê, onde, } \\
\text { quando }\end{array}$ & Não & Sim \\
\hline Análise de Arquivo & $\begin{array}{l}\text { Quem, o quê, onde, } \\
\text { quando }\end{array}$ & Não & Sim / Não \\
\hline História & Como, Por que & Não & Não \\
\hline Estudo de Caso & Como, Por que & Não & Sim \\
\hline
\end{tabular}

Fonte: Yin (2002).

Nesta dissertação escolheu-se como método de pesquisa o estudo de caso devido às seguintes razões:

a) Pouca familiaridade do pesquisador com o assunto.

Para Stake (1995), quando o objeto de pesquisa não está suficientemente compreendido pelo pesquisador, o estudo de caso Ihe possibilita desenvolver sua compreensão do assunto. É comum denominar o trabalho de estudo de caso como "progressivamente enfocado".

b) Tipo de questão proposta pela pesquisa. 
Para Yin (2002), o tipo de questão de pesquisa serve para orientar o pesquisador na escolha do tipo de pesquisa mais adequado. Assim, questões de pesquisa com base no pronome interrogativo "que" indicam a condução de um estudo exploratório, onde o objetivo principal é o desenvolvimento de hipóteses e proposições a serem posteriormente verificadas. As questões que utilizam "como" e "por que" são mais explanatórias e provavelmente mais adequadas às estratégias de estudo de caso, história e experimentos.

c) A amplitude de controle do investigador sobre os eventos comportamentais.

De acordo com Yin (2002), o estudo de caso é a estratégia mais indicada quando não existe a possibilidade do investigador manipular os comportamentos relevantes, em um evento contemporâneo.

\subsubsection{Estudo de Caso}

Para Yin (2002) o estudo de caso está sendo cada vez mais utilizado como ferramenta de pesquisa, com pelo menos quatro tipos de aplicações possíveis:

- Às ligações causais das intervenções na vida real;

- À descrição do contexto da vida real na qual uma intervenção tenha ocorrido;

- À descrição, a partir de um caso ilustrativo;

- À estratégia do uso do caso para explorar situações que não têm um conjunto de resultados claros.

Yin (2002) apresenta quatro tipos de estudos de caso, considerando o número de casos envolvidos no projeto - um caso ou múltiplos casos - e a unidade de análise holística ou específica, os quais podem ser visualizados na Tabela 9. 
Tabela 9 - Tipos de estudo de casos

\begin{tabular}{ccc}
\hline ABORDAGEM & CASO SIMPLES & CASOS MÚLTIPLOS \\
\hline Holística & Tipo 1 & Tipo 2 \\
Específica & Tipo 3 & Tipo 4 \\
\hline
\end{tabular}

Fonte: Yin (2002).

Para justificar a escolha de um caso simples, Yin (2002) apresenta três razões:

- Um caso crítico que serve para testar uma teoria bem formulada;

- Um caso único que serve para estudar uma determinada situação rara que, através do caso pode ser documentado e analisado o problema;

- Um caso revelador. Este caso acontece quando um pesquisador pode observar e analisar um fenômeno previamente inacessível pela investigação científica.

Quanto a múltiplos casos, Yin (2002) aborda que os mesmos são passíveis de replicação como se fossem múltiplos experimentos. Assim, cada caso precisa ser cuidadosamente selecionado para prever resultados similares, ou seja, produzir resultados diferentes, mas com razões similares.

Ainda, segundo Yin (2002), a opção pelo método de estudo de caso dá como alternativa o uso de ferramentas adicionais como técnicas de levantamento de dados, entrevistas e análise de documentos, entre outras fontes, visando enriquecer a massa de dados a ser tratada.

Com relação aos tipos de caso, apresentado na tabela 9 vale lembrar que Yin (2002) os enquadra em dois grupos distintos: os holísticos, que se caracterizam por focalizar o contexto geral dos fenômenos e os específicos, que focaliza em partes componentes de um contexto mais amplo.

Nesse sentido conclui-se que este trabalho teve um foco holístico uma vez que a abordagem considera os projetos como um todo e não em uma determinada parte específica. 
No que se refere ao número de casos a serem selecionados para o estudo, optou-se pela abordagem das evidências de múltiplos casos, pois, conforme postulado por Yin (2002), as provas resultantes de casos múltiplos são consideradas mais convincentes e os casos estudados não contemplam nenhum dos quatro tipos de aplicações possíveis para o estudo de somente um caso.

\subsubsection{Instrumento e levantamento de dados}

Definiu-se para este trabalho, o estudo de três casos. Foi utilizado como critério para seleção, projetos similares em termos complexidade, tipo de negócio, escopo e cliente, a fim de se obter um resultado mais eficaz e conclusivo em relação aos objetivos da dissertação.

Faz-se importante salientar que um dos estudos de caso desta dissertação contou com a presença de observação participante.

Segundo Yin (2002) o observador pode assumir uma variedade de funções dentro do estudo de caso e pode participar, de fato, dos eventos que estão sendo estudados.

Para a coleta de dados, utilizou-se como instrumento a realização de entrevistas e questionários.

Segundo Silva (2001) a entrevista é a obtenção de informações de um entrevistado, sobre determinado assunto ou problema, podendo ser de dois tipos:

- padronizada ou estruturada: roteiro previamente estabelecido;

- não padronizada ou não-estruturada: não existe rigidez de roteiro. Podemse explorar mais amplamente algumas questões. 
Silva (2001) lembra que o questionário é uma série ordenada de perguntas que devem ser respondidas por escrito pelo informante, sendo importante que 0 questionário seja objetivo, limitado em extensão e estar acompanhado de instruções.

Young e Lundberg apud Almeida (2008) fizeram uma série de recomendações úteis à construção de um questionário, dentre as quais podem destacar:

- O questionário deverá ser construído em blocos temáticos obedecendo a uma ordem lógica na elaboração das perguntas;

- A redação das perguntas deverá ser feita em linguagem compreensível ao informante. A linguagem deverá ser acessível ao entendimento da média da população estudada. A formulação das perguntas deverá evitar a possibilidade de interpretação dúbia, sugerir ou induzir a resposta;

- Cada pergunta deverá focar apenas uma questão para ser analisada pelo informante;

- O questionário deverá conter apenas as perguntas relacionadas aos objetivos da pesquisa. Devem ser evitadas perguntas que, de antemão, já se sabe que não serão respondidas com honestidade.

Para aproveitar ao máximo o potencial dos casos a serem estudados optou-se por utilizar as entrevistas nas formas padronizadas e não padronizada, dando liberdade ao entrevistado para apresentar informações complementares de forma que se pudessem capturar itens não identificados contribuindo para a conclusão dos estudos.

Para o questionário se optou por utilizar tanto questões de múltiplas escolhas quanto questões abertas dirigidas para identificação de práticas complementares do objeto de estudo.

O roteiro de coletas de dados foi dividido, basicamente, em quatro seções:

A primeira seção teve por objetivo levantar informações gerais do projeto a fim de que permitir a identificação do ambiente no qual o projeto a ser analisado está inserido. A principal contribuição desta seção para o trabalho foi apresentar as similaridades dentre os projetos, considerando principalmente a quantidade de interfaces e subcontratações, as quais possuem direta influência nos riscos dos 
projetos. Visando o melhor entendimento do gerenciamento dos riscos faz-se necessário o entendimento prévio do projeto e de suas principais características.

A segunda seção teve por objetivo identificar a experiência dos participantes com relação ao gerenciamento de projetos e, mais especificamente com relação ao gerenciamento de riscos, verificando se os mesmos já utilizaram alguma metodologia de riscos em projetos anteriores, analisando assim os possíveis benefícios desta utilização no projeto em análise.

A terceira seção teve por objetivo identificar a existência de uma metodologia de gerenciamento de riscos na empresa analisada, suas principais etapas e procedimentos, a aplicabilidade da mesma nos respectivos projetos bem como, identificar a existência de um departamento de apoio ao gerenciamento de riscos, beneficiando a identificação e análise dos eventos de riscos e conseqüentemente as decisões frente à estes eventos.

A quarta e última seção teve por objetivo identificar como são tomadas as decisões no projeto frente aos eventos de riscos bem como a existência de ferramentas/ processos de apoio.

instrumento de pesquisa completo pode ser encontrado no Anexo I desta dissertação.

\subsubsection{Definição do Universo, da Amostra da pesquisa e dos casos}

O universo inicial desta pesquisa foi o setor energético, e dentro deste setor somente as empresas fornecedoras eletromecânicas de grande porte para Usinas Hidrelétricas, entre as quais se encontram: Alstom, Siemens, Voith Hydro, GE, Andritz, Areva, ABB e Scheider.

Após a listagem das principais empresas, o processo de seleção da empresa foi elaborado de forma não aleatória, procurando, a empresa onde o autor desta 
pesquisa dispunha de acesso e facilidade para a obtenção dos dados, quando do processo de elaboração de entrevistas sistematizadas e observação direta não participante.

A amostra da pesquisa é não-probabilística por conveniência, onde a seleção inicial da amostragem é de responsabilidade do entrevistador, conforme esclarece Malhotra (1996, p.306). O mesmo autor destaca que as vantagens deste tipo de amostra giram em torno de custos (menos dispendiosa), rapidez e conveniência. Entretanto, como desvantagens, o autor alerta para um eventual viés de seleção.

A opção por este tipo de amostra foi feita em função da dificuldade existente em conseguir empresas que tenham interesse e disponibilidade para participar da pesquisa, além de se encaixarem nos principais critérios, a saber: empresas que desenvolveram nos últimos 10 anos projetos de modernização de usinas hidrelétricas e que possuem uma metodologia de análise de riscos dentro de seus procedimentos.

A seleção dos casos que compõem a amostra da pesquisa foi feita em duas etapas:

A primeira etapa ocorreu em 2008 e se limitou a identificar empresas que se encaixassem nos principais critérios exigidos pela pesquisa. Após um levantamento preliminar, foram detectadas três empresas que aparentemente se encaixavam no principal critério. Em 2009 houve um contato direto com tais empresas visando agendar uma reunião inicial para apresentar de forma detalhada o conteúdo da pesquisa e identificar as empresas que tinham interesse e disponibilidade para participar da pesquisa. Após tais reuniões, do total de três empresas, todas preenchiam de forma plena os requisitos necessários para participação na pesquisa. Após alguns meses de contato, duas das empresas selecionadas, por motivos estratégicos decidiram por não participar da pesquisa e, portanto, foram descartadas.

Na segunda etapa, houve a participação da diretoria da empresa selecionada, que conhecendo os objetivos da pesquisa, apresentou 3 projetos similares que foram executados por gerentes de projetos de perfis semelhantes, com o mesmo cliente, 
porém com valores diferentes e momentos econômicos distintos e que certamente poderiam apresentar estudos comparativos pertinentes aos objetivos propostos.

Visando a confidencialidade das informações, conforme solicitado pela empresa selecionada, não será referenciado nem o nome da empresa nem o nome dos projetos que serão analisados.

Nesta dissertação, visando uma maior clarividência das informações, a empresa será nomeada a partir deste momento como empresa " $A$ " e os casos, denominados de casos "1, 2 e 3 ".

\subsubsection{Aplicação do questionário e entrevistas}

A aplicação do questionário e das entrevistas foi realizada utilizando os seguintes passos:

Primeiramente selecionou-se um gerente de projetos com sólida experiência em gerenciamento de projetos e colaborador de uma empresa multinacional do ramo energético para a realização de um "pré-teste".

Mattar (1999) expõe que após ter sido construído o primeiro rascunho do questionário, procede-se a inúmeras revisões junto à própria equipe de pesquisa. Para a aplicação do instrumento, segundo Pádua (2000), pode-se fazer um pré-teste a fim de verificar se há dificuldade de entendimento das questões. O pré-teste do questionário, segundo Mattar (1999), consiste em saber como ele se comporta em uma situação real de coleta de dados. Dessa maneira pode-se verificar:

- Se os termos utilizados nas perguntas são de compreensão dos respondentes.

- Se as perguntas estão sendo entendidas como deveriam ser.

- Se as opções de respostas nas perguntas fechadas estão completas. 
- Se a seqüência das perguntas está correta.

- Se não há objeções na obtenção das respostas.

- Se a forma de apresentar a pergunta não está causando desvios, etc.

Os pré-testes podem ser realizados em diferentes estágios de amadurecimento de um instrumento. Nos primeiros estágios, quando o instrumento ainda está em desenvolvimento, o pré-teste poderá ser realizado pelo próprio pesquisador através de entrevista pessoal. Quando o instrumento já estiver no estágio final, o pré-teste deverá ser feito usando exatamente a mesma forma de aplicação que será usada na pesquisa. Em qualquer um dos casos, o teste deverá ser feito junto a respondentes pertencentes à população-alvo da pesquisa (MATTAR, 1999).

Após o preenchimento do questionário do pré-teste, realizou-se uma entrevista presencial e individual, com o objetivo de colher mais informações adicionais.

Depois da obtenção dos dados, realizou-se uma análise sistemática a fim de obter as conclusões prévias e, em caso da real necessidade, atualizar o questionário para envio oficial aos projetos a serem analisados.

Após o término das conclusões prévias, selecionou-se para responder o questionário final dos casos a serem estudados, duas funções estratégicas, o Gerente de Projetos e o Site Manager, que tem como função principal gerenciar todo o projeto e gerenciar a execução das atividades em campo respectivamente.

Foi submetido o questionário aos dois membros para preenchimento individual e após 3 dias foram realizadas entrevistas pessoais a fim de colher informações e/ou documentos adicionais e validar as respostas entre os entrevistados.

Dentre os documentos adicionais, utilizou-se do plano de gerenciamento de projetos, plano de gerenciamento de riscos, contrato e relatório gerencial de cada projeto.

A análise do plano de gerenciamento de projetos e do gerenciamento dos riscos teve por objetivo identificar a maneira como cada projeto foi gerenciado, 
principalmente no que diz respeito aos riscos, complementando as respostas obtidas com o questionário e entrevista.

O contrato teve como principal objetivo conhecer as principais cláusulas que pudessem interferir no gerenciamento dos riscos nos projetos.

O relatório gerencial teve como intuito apresentar os resultados obtidos por cada projeto, mas especificamente o impacto financeiro dos riscos em cada projeto.

Com todo o material obtido, realizou-se análises sobre o gerenciamento de projetos e de riscos na empresa e nos projetos, além da análise do processo decisório utilizado nos projetos para os eventos de riscos. 


\section{RESULTADOS}

Neste capítulo serão apresentados os principais resultados obtidos ao longo da pesquisa, por meio da aplicação das técnicas já apresentadas.

Inicialmente será apresentada a empresa, denominada nesta dissertação de Empresa A, que serviu de base para a análise. Na seqüência, serão apresentados de forma resumida, de acordo com a pertinência em relação às questões do presente trabalho, as respostas frente ao questionário e entrevista, bem como os principais dados de documentos dos 3 projetos estudados. Os projetos nesta dissertação serão identificados como projeto 1,2 e 3 respectivamente.

Por motivo de confidencialidade, o nome da empresa bem como dos projetos não serão divulgados e os valores financeiros são fictícios, mantendo sempre a proporcionalidade entre os projetos a fim de não prejudicar nem tendenciar os resultados apresentados.

\subsection{A EMPRESA A}

A Empresa A é uma empresa multinacional, de caráter privado, fornecedora de equipamentos e serviços para geração e transmissão de energia. Possui mais de 90.000 colaboradores distribuídos em mais de 70 países do mundo, é umas das maiores construtoras mundial de usinas hidrelétricas e fornecedora de turbinas e geradores.

No Setor de Geração de Energia, a empresa atua no fornecimento de equipamentos e serviços para usinas hidrelétricas e também para usinas termelétricas e de sistemas de controle ambiental. Mais de $50 \%$ da eletricidade consumida anualmente no Brasil, $90 \mathrm{GW}$, é gerada por equipamentos fornecidos pela empresa. 
No Brasil, a empresa possui uma participação de mercado de 35\%, e já forneceu equipamentos para mais de 100 projetos no mercado brasileiro nos últimos 10 anos.

Com ampla capacidade industrial, a empresa no Brasil é um importante pólo de exportação, produzindo equipamentos e sistemas para grandes projetos na área de energia.

Na seqüência serão apresentados, de maneira simplificada, os procedimentos de gerenciamento de projetos e riscos adotados pela empresa analisada. Estes documentos fazem parte do departamento de gerenciamento de projetos da empresa analisada, a qual solicitou a não divulgação detalhada dos mesmos.

\subsubsection{Gerenciamento de Projetos na empresa}

O procedimento de gerenciamento de projetos da empresa A, visa uma aplicação sistemática dos processos e ferramentas, sendo estes extremamente necessários, mas não suficientes para entregar os resultados aos projetos com a satisfação do cliente. Segundo o gerente do departamento de riscos da empresa, o gerente de projetos deve antecipar e estar preparado para os eventos incertos.

Estes procedimentos têm como objetivo padronizar o gerenciamento de projetos dentro da empresa, no entanto tendo em vista as características do termo projeto, os mesmos podem ser adaptados em situações particulares.

As principais áreas tratadas pelos procedimentos seguem as melhores práticas adotadas pelo PMI sendo estas:

- Gerenciamento Integração

- Gerenciamento de Escopo

- Gerenciamento Tempo

- Gerenciamento de Custo

- Gerenciamento de Qualidade 
- Gerenciamento dos Recursos Humanos

- Gerenciamento das Comunicações

- Gerenciamento das Aquisições

Tendo em vista a importância dos riscos nos projetos, foi também definido um procedimento exclusivo para o gerenciamento dos riscos, o qual será explicitado no item seguinte.

\subsubsection{Gerenciamento de Riscos na empresa}

Dentre os diversos processos existentes na empresa, há o procedimento de gerenciamento de riscos que visa apoiar os gerentes de projetos na condução dos seus trabalhos e uniformizar o gerenciamento dos riscos, a fim de mitigar os impactos gerados pelos riscos.

A empresa determina que reuniões de riscos sejam realizadas no mínimo trimestralmente com toda a equipe do projeto, a fim de identificar, analisar e monitorar os mesmos, bem como criar planos de ação. Estas reuniões são planejadas e conduzidas pelo Gerente do Projeto, o qual envia um convite com no mínimo 15 dias de antecedência, sendo a participação obrigatória de pelo menos um colaborador de cada departamento.

Na primeira reunião de riscos, a qual deve ocorrer em até sete dias da assinatura do contrato, identifica-se juntamente com a equipe de vendas, os principais riscos no projeto, utilizando dos procedimentos de identificação e análise adotados pela empresa. Nas reuniões subseqüentes, reavaliam-se os principais riscos que ainda encontram-se ativos e após este processo realiza-se um processo de identificação de novos riscos.

$\mathrm{Na}$ identificação dos riscos deve-se utilizar os seguintes itens: descrição e detalhamento do risco, sua probabilidade de ocorrência, seu impacto e suas causas raízes gerando assim a severidade que o risco tem no projeto. 
No processo de análise dos riscos, utiliza-se o critério de avaliação do risco identificado, bem como uma estimativa de custo a ser gasto caso este risco ocorra. Após esta estimativa, identifica-se o plano de ação para mitigar este risco, cabendo ainda identificar o custo desta mitigação.

Para a análise qualitativa, a empresa utiliza uma escala de severidade, que varia de 1 a 2 sendo que o nível 1 significa a necessidade de monitoramento do risco e 0 nível 2 a necessidade de um plano de ação imediato.

O procedimento estabelecido para a análise quantitativa define que deverá ser utilizado o valor do impacto mitigado adicionado ao custo da mitigação como provisão de reservas de contingências.

O processo torna-se um ciclo contínuo, com o monitoramento e controle dos riscos com um novo ciclo se iniciando a cada trimestralmente.

Para o gerenciamento dos riscos, a empresa disponibiliza uma ferramenta chamada Risk management datasheet no qual por questões confidenciais a mesma não pode ser divulgada. Além desta ferramenta, também conta com um departamento de riscos e oportunidades, o qual tem as seguintes funções dentro dos projetos:

- Identificar e implementar novas práticas no gerenciamento de Riscos e Oportunidades;

- Liderar o processo de otimização de novos projetos;

- Aperfeiçoar a ferramenta Risk management datasheet, incluindo informações sobre riscos mitigados (ou não) e oportunidades obtidas ou perdidas;

- Assessorar os Gerentes de Projetos na ferramenta Risk management datasheet e instruções para a realização das sessões de risco e oportunidades;

- Orientar os Gerentes de Projetos na utilização da ferramenta Risk management datasheet;

- Consolidar a base de dados de Riscos e Oportunidades de todos os projetos em execução; 
- Avaliar as sessões de risco e oportunidades;

- Consolidar a base de dados do rating dos projetos em execução;

\subsection{PROJETO 1}

O escopo do Projeto 1 compreende a modernização de 06 unidades geradoras, sendo o escopo da empresa A a reforma dos geradores, novo regulador de velocidade, Sistema Digital e Telecomunicações.

A usina modernizada possuía no início do projeto de modernização, 36 anos de operação com a potência instalada de mais de 1.000 MW. Esta usina, beneficiada pelo programa de modernização do governo, tem um importante papel junto aos estados de São Paulo e Minas Gerais e também junto ao Sistema Interligado Nacional.

Estimou-se que após a modernização realizada as Unidades Geradoras terão uma capacidade geradora por mais 40 anos e com um investimento de somente $15 \%$ do custo de uma nova.

Para a realização deste projeto a Empresa A consorciou-se com outras grandes e renomeadas empresas do mercado energético e civil de forma a realizar um projeto com qualidade e com maior confiabilidade para o cliente final.

O projeto localizou-se no estado de São Paulo e foi financiado com recursos próprios do cliente, sendo o preço de venda superior a $R \$ 50.600 .000,00$ e início somente após assinatura do contrato.

\subsubsection{Do instrumento de pesquisa/entrevista}

Após 3 dias da aplicação do questionário, foi realizada uma entrevista com o gerente do projeto e seu respectivo site manager, a qual complementou os resultados da 
pesquisa e permitiu esclarecer algumas dúvidas referentes às respostas obtidas com o mesmo. Dentre os resultados obtidos, podem-se destacar os principais itens abaixo, sendo as respostas completas apresentadas no Anexo II:

- O escopo estava atrelado à modernização de 6 unidades geradoras;

- A equipe para o gerenciamento do projeto era composta por 4 pessoas 100\% dedicadas ao projeto;

- O consórcio era composto por 7 empresas parceiras;

- Houve mais de 100 subcontratações com fornecedores diferentes;

- A empresa tinha experiência passada de 1 projeto com características similares;

- O gerente de projeto possuía forte experiência em planejamento de projetos internacionais e um grande conhecimento em geração de energia;

- O gerente do projeto não possuía um sólido conhecimento nem experiência em gestão de riscos, embora apresentasse certificações em gerenciamento de projetos;

- Segundo o gerente deste projeto, a empresa possui uma metodologia de gerenciamento de riscos baseada em análises qualitativas e quantitativas. Estas análises são realizadas através de sessões (reuniões) de riscos com toda a equipe do projeto e áreas de interface. Este processo inicia-se com a técnica de brainstorming, buscando identificar os possíveis riscos e oportunidades baseados em dados do contrato e dados históricos;

- Apesar da existência de uma metodologia definida para a análise de riscos, a mesma não define a tolerância aceitável aos riscos analisados, cabendo ao gerente do projeto, após sessões de análise, apresentar os resultados à diretoria caso um determinado risco tenha um impacto negativo relevante no projeto.

- Existe um departamento que auxilia os processos de gerenciamento de riscos, porém este ainda encontra-se em fase inicial de maturidade;

- A empresa determina que reuniões de riscos sejam realizadas no mínimo trimestralmente, no entanto, dependendo da situação em que o projeto se encontra, se faz necessária reuniões mensais, ficando a critério do gerente do projeto a determinação desta freqüência. A participação de 
toda a equipe é obrigatória, porém em muitos casos as reuniões não ocorrem com a presença de todos os envolvidos devido ao compartilhamento de recursos com outros projetos;

- Segundo o Gerente do Projeto, a empresa possui procedimentos claros para o gerenciamento dos riscos, no entanto os mesmos não são conhecidos por todos os departamentos envolvidos nos projetos;

- Para este projeto, houve um plano de gerenciamento de riscos, sendo identificado mais de 50 Riscos, no entanto, analisado qualitativamente e quantitativamente 10 riscos. O plano utilizado neste projeto seguiu aos procedimentos estabelecidos pela empresa, os quais serão apresentados parcialmente por questão de confidencialidade no item 4.1.2;

- Dentre as técnicas e ferramentas para identificação de riscos foram utilizadas análise das premissas, entrevistas, Brainstorming, Delphi e análise SWOT. No entanto, os riscos foram identificados somente em termos do que pode acontecer e seu respectivo impacto. Após o processo de identificação, iniciou-se o processo de análise, o qual considerou os riscos em termos de sua probabilidade de ocorrência e impacto;

- Não houve um registro nem uma análise qualitativa em sua totalidade a fim de ter uma melhor rastreabilidade dos riscos devido à dificuldade em reunir toda a equipe para as reuniões de riscos e também pelo desconhecimento e falta de experiência do gerente de projeto;

- A análise quantitativa foi realizada de maneira parcial, ou seja, sem um estudo detalhado das probabilidades com seus respectivos impactos, obtendo assim uma provisão menos realista;

- Dentre as respostas aos riscos analisados, utilizou-se principalmente a mitigação, através de ações considerando custo estimado para as mesmas, bem como os benefícios esperados. Entretanto, também se utilizou a prevenção e a aceitação, utilizando da intuição junto aos limites aceitáveis;

- Foi utilizado como indicador para medir a evolução dos riscos, o valor total do impacto dos riscos em relação ao preço de venda do projeto. Todos os riscos analisados foram acompanhados pelo Gerente do projeto, no 
entanto as revisões de riscos não foram feitas de acordo com as revisões de projeto;

- As decisões foram tomadas pela equipe do projeto para eventos de riscos planejados e não planejados;

- Não existe um procedimento racional e ferramentas para tomar as decisões no projeto. Neste projeto especificamente, as decisões quanto aos eventos de riscos planejados e não planejados foram tomadas, em alguns momentos, através da experiência da equipe e intuição;

- Embora tenha utilizado em seu projeto experiências passadas, o gerente do projeto acredita que estas auxiliam apenas parcialmente nas decisões, pois nem sempre ações tomadas em um projeto servirão para o outro, mesmo com dificuldades e desafios semelhantes;

\subsubsection{Dos documentos analisados}

\subsubsection{Contrato}

Dentre os documentos fornecidos pela empresa para a análise do projeto, utilizou-se o contrato firmado entre a empresa contratada e o cliente. Dentre as principais cláusulas contratuais diretamente ligadas ao risco pode-se citar:

\footnotetext{
- Prazo

O prazo máximo para desmontagem/montagem, e comissionamento de todas as unidades, não simultaneamente, foi de 43 meses, conforme segue:
}

- 14 meses contados a partir da assinatura do contrato para a conclusão do canteiro de obras e demais atividades necessárias ao início da modernização;

- 08 meses para a execução dos serviços na primeira unidade e 07 meses para cada unidade geradora, considerando os serviços das unidades 2 a 6 , contados a partir da entrega pelo cliente da unidade geradora em condições 
de início dos serviços. Neste prazo, está contemplada a conclusão dos ensaios finais.

\section{- Multas}

\section{口 Por potência insuficiente do gerador}

Caso a potência máxima verificada no comissionamento fosse menor que o valor garantido, a contratada pagaria ao cliente uma quantia equivalente para cada $0,01 \%$ de diferença constatada para cada gerador, após a dedução da tolerância devida à imprecisão da medição resultante do método e aparelhagem utilizados e calculada de acordo com os critérios do IEEE. Se a diferença fosse maior do que $1 \%$ a contratada efetuaria as modificações necessárias de modo que fossem obtidos valores aceitáveis pelo cliente.

\section{a Por rendimento insuficiente do gerador}

Caso o rendimento verificado no COMISSIONAMENTO fosse menor que o valor garantido, desde que a diferença constatada seja menor que 1,0\%, a contratada pagaria ao cliente quantia equivalente para cada $0,01 \%$ de diferença para cada gerador, após a dedução da tolerância devida à imprecisão das mediações resultantes do método e aparelhagem utilizados e calculada de acordo com os critérios do IEEE. Uma diferença superior a 1,0\% seria considerada como inaceitável e a contratada efetuaria as modificações necessárias de modo que fossem estabelecidos no projeto.

\section{- Atraso na geração comercial}

Para cada dia de atraso na entrada em operação comercial de cada unidade em relação ao cronograma contratual, a contratada pagaria ao cliente uma quantia expressiva que por questões confidencias não podem ser informadas.

\subsubsection{Plano de Gerenciamento de Riscos do projeto 1}

Através das atas de reuniões de riscos e da ferramenta utilizada (Risk management datasheet) para o gerenciamento dos riscos, pode-se dizer que neste projeto houve 
o gerenciamento dos riscos, no entanto houve alguns desvios em relação aos procedimentos adotados pela empresa, no que diz respeito à análise qualitativa e principalmente na análise quantitativa que, se utilizado corretamente, poderiam ter auxiliado mais a equipe do projeto na decisão para com os riscos.

No processo de identificação dos riscos identificou-se, principalmente através do Brainstorming, uma quantidade de aproximadamente 50 riscos do projeto sendo que os mesmos não foram categorizados.

No processo de análise qualitativa, utilizou-se as medições dos riscos em termos de probabilidade ocorrência e impacto, apresentando-se assim uma severidade para cada risco, baseado nos critérios definidos pela empresa. No entanto, esta análise realizou-se somente para os riscos que, por experiência da equipe reunida, poderia apresentar maior gravidade no projeto.

No processo de análise quantitativa, calculou-se os impactos em termos de impacto financeiro, juntamente com os custos de mitigação, obtendo-se assim a reserva de contingência para este risco, a qual foi calculada conforme a equação abaixo:

Contingência = Impacto do risco + Custo de mitigação - Valor mitigado

Vale ressaltar que devido ao fato do gerente de projeto possuir pouca experiência em gerenciamento de riscos, não se utilizou um estudo racional, como, $\square$ por exemplo, árvore de decisão ou simulação Monte Carlo, conforme sugere Kerzner (1998), considerando os efeitos da probabilidade, a fim de poder analisar a melhor estratégia de resposta e de provisão financeira para este risco.

Um exemplo que corrobora claramente o explicitado acima foi no risco, denominado nesta dissertação por Delta, no qual após as análises realizadas pela equipe, houve uma discordância sobre qual estratégia a seguir perante a este risco. A partir daí, em função do impasse gerado, o assunto foi levado à direção da empresa para a definição da estratégia a ser seguida, a qual foi decidida segundo os critérios financeiro (menor impacto para a empresa) e importância para o negócio. 


\subsubsection{Plano de Gerenciamento de Projetos do projeto 1}

Observou-se neste projeto a existência de um plano seguindo aos procedimentos adotados pela empresa. Dentre os principais itens encontrados neste plano pode-se citar:

- Análise dos requisitos;

- Definição clara do escopo;

- Premissas;

- Restrições;

- Work Breakdown Structure (WBS);

- Cronograma:

- Análise Caminho Crítico:

- Plano de gerenciamento de Custos:

- Linha de base de custos;

- Plano de qualidade fabril;

- Plano de qualidade de obra;

- Plano de site;

- Análise fazer ou comprar;

- Matriz de responsabilidades;

- Plano de comunicação;

\subsubsection{Resultados do projeto}

Através de um estudo profundo sobre os resultados financeiros deste projeto, obtidos através do relatório gerencial da ferramenta de gestão da empresa (SAP) observou que este projeto atingiu aos objetivos propostos pela empresa, que era atender aos requisitos do projeto, satisfazer ao cliente e gerar lucro. Assim como outros documentos fornecidos pela empresa, este relatório foi disponibilizado para o presente estudo, todavia não teve sua divulgação autorizada. 
No relatório gerencial são apresentadas as causas raízes de cada variação, uma vez que este apresenta os custos incorridos, comparados com seus respectivos orçamentos, sendo estes considerados a um nível de detalhe de pacote de trabalho dentro da WBS. Dentro de cada pacote de trabalho, deve-se explicar as razões de cada variação de forma a obter um registro de todo o gerenciamento do projeto.

O projeto apresentou um ganho de $4,7 \%$, entretanto, devido a uma perda de $1,7 \%$ em razão de alguns eventos de riscos, houve um aumento na margem líquida em 3 pontos percentuais no término do projeto. Este percentual foi calculado pela divisão entre o lucro líquido final no término do projeto e o valor final do contrato, fazendo-se assim a comparação com os mesmos cálculos iniciais.

Dentre as diversas razões para este ganho de 4,7\%, pode-se citar que os principais fatores foram boas negociações com fornecedores, otimização de projeto executivo pela engenharia e otimização de horas de projeto.

Quanto à variação dos riscos, os mesmos foram responsáveis pela redução de 1,7\% na margem líquida do projeto, sendo que 1,2\% foi devido ao risco Delta, que além de complexo, tinha diversas estratégias que conseqüentemente poderia resultar em diversos impactos.

Dentre os outros riscos ocorridos, houve um impacto negativo de 0,5\% na margem do projeto. Do total de 10 riscos analisados, dentre os mais de 50 identificados, houve a ocorrência de apenas 3 riscos.

\subsection{PROJETO 2}

O Projeto 2 tem como escopo a modernização de 8 unidades de uma usina hidrelétrica. Geradores e auxiliares (8 unidades), trocadores de calor (6 unidades), Instrumentação (8 unidades), Regulador de Velocidade (8 unidades), Sistema de Proteção, materiais de montagem e supervisão de obra. 
A usina modernizada possuía no início do projeto de modernização, 43 anos de operação com a potência instalada de mais de 1.000 MW. Esta usina, beneficiada pelo programa de modernização do governo, tem um importante papel junto aos estados de São Paulo e Minas Gerais e também junto ao Sistema Interligado Nacional.

Estimou-se que após a modernização realizada as Unidades Geradoras terão uma capacidade geradora por mais 40 anos e com um investimento de somente $15 \%$ do custo de uma nova.

Para a realização deste projeto a Empresa A consorciou-se com outras grandes e renomeadas empresas do mercado energético e civil de forma a realizar um projeto com qualidade e com maior confiabilidade para o cliente final.

Está localizado no estado de Minas Gerais e foi financiado com recursos próprios do cliente, sendo o preço de venda de mais de $R \$ 50.000 .00,00$ e início das atividades a partir da data de assinatura do contrato.

\subsubsection{Do instrumento de pesquisa/entrevista}

Após 3 dias da aplicação do questionário, foi realizada uma entrevista com o gerente do projeto e seu respectivo site manager, a qual complementou os resultados da pesquisa e permitiu esclarecer algumas dúvidas referentes às respostas obtidas com o mesmo. Dentre os resultados obtidos, podem-se destacar os principais itens abaixo, sendo as respostas completas apresentadas no Anexo II:

- O escopo estava atrelado à modernização de 8 unidades geradoras;

- A equipe para o gerenciamento do projeto era composta de 5 pessoas 100\% dedicadas ao projeto;

- O consórcio era composto por 5 empresas parceiras;

- Houve mais de 100 subcontratações com fornecedores diferentes; 
- A empresa tinha experiência passada de 2 projetos com características similares;

- O gerente de projeto possuía 6 anos de experiência em gerenciamento de projetos e um bom conhecimento em geração de energia;

- O gerente do projeto possuía um bom conhecimento e experiência em gestão de riscos, prova esta que sempre aplicou a mesma em seus projetos. Durante a entrevista, o gerente de projetos enfatizou a importância da gestão de riscos para a mitigação das perdas no projeto;

- O gerente de projetos informou que mesmo utilizando o gerenciamento de riscos, já deparou com incertezas desconhecidas, as quais prejudicaram fortemente seus projetos, uma vez que os planos de ação tiveram que ser tomados de maneira emergencial.

- Segundo o gerente de projetos, a empresa possui uma metodologia de gerenciamento de risco, no entanto, a mesma precisa ser aprimorada nos quesitos de análises e planos de ação. A metodologia de gerenciamento de riscos adotada pela empresa foi previamente apresentada no item 4.1.2;

- Apesar da existência de uma metodologia definida para a análise de riscos, a mesma não define a tolerância aceitável aos riscos analisados, cabendo ao gerente do projeto, após sessões de análise, apresentar os resultados à diretoria caso um determinado risco tenha um impacto negativo relevante no projeto.

- Existe um departamento que auxilia nas seções de riscos trimestrais, no entanto ainda estão em fase inicial de maturidade;

- Segundo o gerente de projeto a empresa estipula a realização trimestral das reuniões de riscos, com a presença obrigatória de toda a equipe. Especificamente no projeto 2, relata que, apesar da dificuldade, as reuniões de riscos eram realizadas mensalmente com a equipe do projeto e trimestralmente com todos os stakeholders internos da empresa;

- Houve um plano de gerenciamento de riscos para este projeto, sendo analisado qualitativamente e quantitativamente 16 riscos, de diversas categorias. No entanto houve a identificação e o registro de mais de 80 riscos que não foram analisados. O plano utilizado neste projeto também 
seguiu aos procedimentos adotados pela empresa, o qual foi apresentado previamente no item 4.1.2;

- Dentre as técnicas e ferramentas para identificação de riscos foram utilizadas análise das premissas, entrevistas, Brainstorming, Técnica de grupo Nominal, Técnica Delphi e análise SWOT. Os riscos foram identificados considerados em termos do que pode acontecer, seu respectivo impacto, como e porque os riscos aconteceram. Após o processo de identificação, os riscos foram analisados considerando sua probabilidade de ocorrência e impacto;

- A análise quantitativa foi realizada considerando um estudo das probabilidades e alternativas com seus respectivos impactos, sendo utilizada como ferramenta para alguns riscos a árvore de decisão, obtendo-se resultados satisfatórios. A maneira como esta ferramenta foi utilizada no projeto 2 , bem como seus objetivos, será melhor detalhada posteriormente;

- Dentre as respostas aos riscos analisados, utilizou-se principalmente a mitigação, através de ações considerando custo estimado para as mesmas, bem como os benefícios esperados. Entretanto também se utilizou a prevenção, a transferência, através da terceirização de algumas atividades, o compartilhamento, através de parcerias e a aceitação, utilizando-se da intuição junto aos limites aceitáveis;

- Foi utilizado como indicador para medir a evolução dos riscos, o valor total do impacto dos riscos em relação ao preço de venda do projeto. Todos os riscos analisados foram acompanhados pelo Gerente do projeto, no entanto as revisões de riscos não foram feitas de acordo com as revisões de projeto;

- As decisões sempre foram tomadas pela equipe do projeto, tanto para evento de riscos planejados quanto para não planejados;

- Não existe na empresa um procedimento racional e ferramentas para tomar as decisões no projeto. Isto depende do Gerente de Projetos. Neste projeto especificamente, as decisões quanto aos eventos de riscos planejados e não planejados foram tomadas, em sua maioria, com 
medidas prescritivas. Em poucos momentos utilizou-se da experiência da equipe e intuição;

- Houve um processo seqüencial para tomada de decisão, no entanto o mesmo foi criado pelo Gerente do Projeto, o qual considerava as seguintes etapas: Informação, análise das possibilidades, definição da estratégia, definição da decisão a ser tomada, aprovação e validação.

- O gerente de projeto acredita que experiências passadas de outros projetos auxiliam apenas parcialmente no processo decisório, no entanto considera uma metodologia bem aplicada mais eficaz;

\subsubsection{Dos documentos analisados}

\subsubsection{Contrato}

\section{- Prazo}

O prazo máximo para desmontagem/montagem, e comissionamento de todas as unidades, não simultaneamente, foi de 50 meses, conforme segue:

- 09 meses contados a partir da assinatura do contrato para a preparação do canteiro da obra.

- 08 meses para a execução dos serviços na primeira unidade e 07 meses para cada unidade geradora. Neste prazo, está contemplada a conclusão dos ensaios finais.

\section{- Multas}

\section{Por potência insuficiente do gerador}

Caso a potência máxima verificada no comissionamento fosse menor que o valor garantido, a contratada pagaria ao cliente uma quantia equivalente para cada 0,01\% de diferença constatada para cada gerador, após a dedução da tolerância devida à imprecisão da medição resultante do método e aparelhagem utilizados e calculada de acordo com os critérios do IEEE. Se a diferença fosse maior do que $1 \%$ a 
contratada efetuaria as modificações necessárias de modo que fossem obtidos valores aceitáveis pelo cliente.

\section{a Por rendimento insuficiente do gerador}

Caso o rendimento verificado no COMISSIONAMENTO fosse menor que o valor garantido, desde que a diferença constatada seja menor que 1,0\%, a contratada pagaria ao cliente quantia equivalente para cada $0,01 \%$ de diferença para cada gerador, após a dedução da tolerância devida à imprecisão das mediações resultantes do método e aparelhagem utilizados e calculada de acordo com os critérios do IEEE. Uma diferença superior a 1,0\% seria considerada como inaceitável e a contratada efetuaria as modificações necessárias de modo que fossem estabelecidos no projeto.

\section{- Atraso na geração comercial}

Para cada dia de atraso na entrada em operação comercial de cada unidade em relação ao cronograma contratual, a contratada pagaria ao cliente uma quantia expressiva que por questões confidencias não podem ser informadas.

\subsubsection{Plano de Gerenciamento de Riscos do projeto 2}

Através das atas de reuniões de riscos e da ferramenta utilizada (Risk management datasheet) para o gerenciamento dos riscos, pode-se dizer que neste projeto houve o gerenciamento dos riscos. No entanto, houve a utilização de uma ferramenta chave no processo de análise quantitativa, o qual não faz parte dos procedimentos adotados pela empresa, que foi a árvore de decisão. Esta acabou beneficiando a equipe do projeto na análise e conseqüentemente na definição da estratégia de resposta aos riscos.

No processo de identificação dos riscos identificou-se através, principalmente do Brainstorming e da técnica de grupo nominal, uma quantidade de aproximadamente 80 riscos do projeto sendo os mesmos organizados de acordo com sua categoria. 
No processo de análise qualitativa, utilizou-se as medições dos riscos em termos de probabilidade de ocorrência e impacto, apresentando-se assim uma severidade para cada risco, baseado nos critérios definidos pela empresa. Esta análise foi utilizada para mais de 80 riscos, na qual pôde ser feito um estudo detalhado dos riscos que seriam avaliados quantitativamente e dos riscos que seriam registrados para monitoramento.

No processo de análise quantitativa, calculou-se os impactos em termos de impacto financeiro, no entanto em todos os cálculos considerou-se a probabilidade de ocorrência como fator de ponderação, utilizando como reserva de contingência o cálculo final do Valor Monetário Esperado, representado pela equação abaixo:

Contingência $=\mathrm{VME}_{1}+\mathrm{VME}_{2}+\mathrm{VME}_{3} \ldots .+\ldots . . \mathrm{VME}_{\mathrm{n}}$

Sendo:

$\mathrm{VME}_{\mathrm{n}}=\mathrm{P}_{\mathrm{n}} \times \mathrm{I}_{\mathrm{n}}$

$\mathrm{P}_{\mathrm{n}}=$ Probabilidade de ocorrência do risco $\mathrm{n}$

$\mathrm{I}_{\mathrm{n}}=$ Impacto do risco $\mathrm{n}$

Um exemplo que corrobora claramente o explicitado acima foi no risco, denominado nesta dissertação por Alpha, no qual após as análises realizadas pela equipe, houve a definição de qual fornecedor seria contratado, levando em consideração o menor impacto para o projeto.

Utilizou-se a árvore de decisão para avaliar os riscos aos quais o projeto estava exposto quando da definição do fornecedor do sistema a ser implantado no projeto.

Além desse sistema ser um equipamento importante, era um dos riscos com severidade ALTA. Daí a necessidade de tal avaliação.

Foram avaliados os fornecedores "A", "B" e "C". O custo do sistema e as condições de venda de cada um se encontram abaixo. 
Fornecedor "A": $\quad \mathrm{R} \$ 50.000,00 /$ Sistema

$\mathrm{R} \$ 120 /$ Hora (pacotes até 30 hs.)

$R \$ 100 /$ Hora (pacotes de 100 hs ou mais.)

$\mathrm{R} \$ 150$ hora avulsa

Fornecedor "B": $\quad \mathrm{R} \$ 46.000,00 /$ Sistema

$\mathrm{R} \$ 130 /$ Hora (pacotes até 30 hs.)

$R \$ 120 /$ Hora (pacotes de 100 hs ou mais)

$\mathrm{R} \$ 160$ hora avulsa

Fornecedor "C": $\quad \mathrm{R} \$ 48.000,00 /$ Sistema

$\mathrm{R} \$ 105 /$ Hora qualquer quantidade

A estimativa do time do projeto para as probabilidades de haver excesso de horas (por falta de qualidade, retrabalho, problemas internos) foram as seguintes:

- Probabilidade de não haver perda

$-10 \%(0,10)$

- Probabilidade de haver 10\% de perda

- $40 \%(0,40)$

- Probabilidade de haver acima de $10 \%$ de perda - $\quad 50 \%(0,50)$

A estimativa era que fossem necessárias somente as horas previstas no contrato. Para mitigar o risco da falta de um profissional devido ao alto grau de perda que poderia haver durante os testes, estimou-se comprar 100 horas adicionais de reserva.

Dentro desta estratégia e considerando as probabilidades de perda de horas mostradas acima, tínha-se 3 possíveis cenários de custos das horas para cada fornecedor, a saber:

\section{Fornecedor "A":}

Probabilidade de $10 \%$ de não haver perda de horas

Custo ("A" $-10 \%$ ) $=50.000+100 \times R \$ 100,00=R \$ 60.000,00$

Probabilidade de $40 \%$ de haver perda de $10 \%$ de horas

Custo ("A" - 40\%) $=50.000+110 \times R \$ 100,00=R \$ 61.000,00$ 
Probabilidade de $50 \%$ de haver perda de jornal superior a $10 \%$

Custo ("A" - 50\%) $=50.000+120 \times R \$ 100,00=R \$ 62.000,00$

\section{Fornecedor "B":}

Probabilidade de $10 \%$ de não haver perda de horas

Custo ("A" $-10 \%$ ) $=46.000+100 \times R \$ 120,00=R \$ 58.000,00$

Probabilidade de $40 \%$ de haver perda de $10 \%$ de horas

Custo ("A" - 40\%) $=46.000+110 \times \mathrm{R} \$ 120,00=\mathrm{R} \$ 59.200,00$

Probabilidade de $50 \%$ de haver perda de jornal superior a $10 \%$

Custo ("A" - 50\%) $=46.000+120 \times R \$ 120,00=R \$ 60.400,00$

\section{Fornecedor "C":}

Probabilidade de $10 \%$ de não haver perda de horas

Custo ("A" $-10 \%$ ) $=48.000+100 \times R \$ 105,00=R \$ 58.500,00$

Probabilidade de $40 \%$ de haver perda de $10 \%$ de horas

Custo ("A" - 40\%) $=48.000+110 \times R \$ 105,00=R \$ 59.550,00$

Probabilidade de $50 \%$ de haver perda de jornal superior a $10 \%$ Custo (“A"- $50 \%)=48.000+120 \times R \$ 105,00=R \$ 60.600,00$

O cálculo do VME (Valor Esperado), o qual definiu o fornecedor, levou em conta os custos acima calculados multiplicados por suas respectivas probabilidades de ocorrência para cada cenário, conforme estimados pelo time de projeto. Assim, obteve-se:

VME "A" $=R \$ 60.000,00 \times 0,10+R \$ 61.000,00 \times 0,40+62.000,00 \times 0,50=R \$$ $61.400,00$

VME "B" $=R \$ 58.000,00 \times 0,10+R \$ 59.200,00 \times 0,40+60.400,00 \times 0,50=R \$$ $59.680,00$

VME "C" $=R \$ 58.500,00 \times 0,10+R \$ 59.550,00 \times 0,40+60.600,00 \times 0,50=R \$$ $59.970,00$ 
Neste cenário, o fornecedor "B" foi o contratado para fornecer o sistema, dado o seu menor custo no momento da análise. Entretanto coube uma análise adicional, na qual, considerando que o preço da hora avulsa do fornecedor "B" era o mais elevado ( $R \$ 160,00 /$ hora), o time de projeto não poderia perder o foco na busca por um índice de perda de horas não superior aos $20 \%$ estimados.

A Figura 17 abaixo representa a árvore de decisão utilizada para auxiliar a equipe do projeto na tomada da decisão sobre este evento de risco.

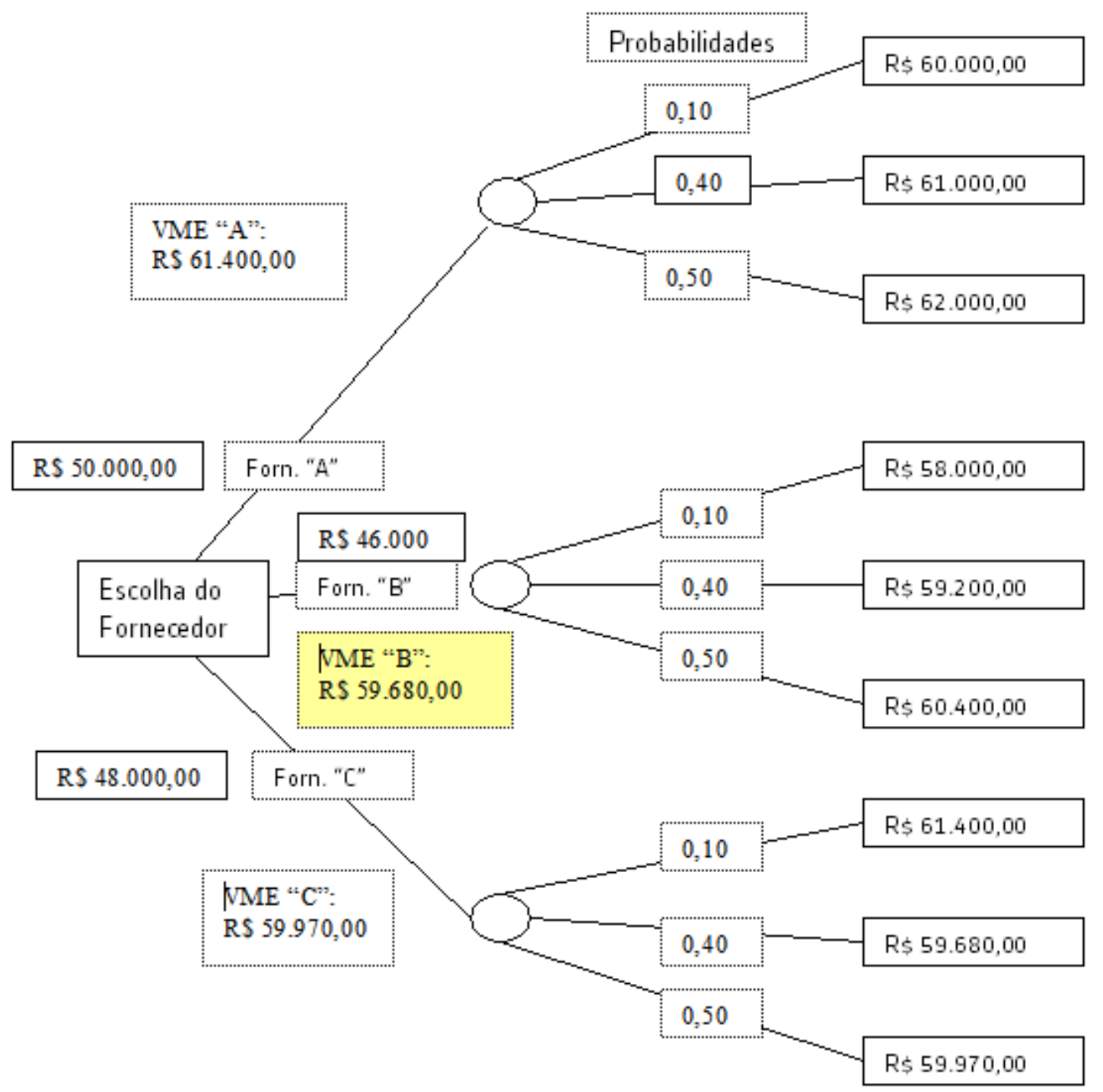

Figura 17. Árvore de decisão

Fonte: Elaborado pelo autor 


\subsubsection{Plano de Gerenciamento de Projetos do projeto 2}

Observou-se neste projeto a existência de um plano seguindo aos procedimentos adotados pela empresa. Dentre os principais itens encontrados neste plano pode-se citar:

- Análise dos requisitos;

- Definição clara do escopo;

- Premissas;

- Restrições;

- WBS;

- Cronograma:

- Análise Caminho Crítico:

- Plano de gerenciamento de Custos:

- Linha de base de custos;

- Plano de qualidade fabril;

- Plano de qualidade de obra;

- Plano de site;

- Análise fazer ou comprar;

- Matriz de responsabilidades;

- Plano de comunicação;

- Linha de base de tempo;

- Controle integrado de mudanças.

\subsubsection{Resultados do projeto}

Através de um estudo profundo sobre os resultados financeiros deste projeto, obtidos através do relatório gerencial da ferramenta de gestão da empresa (SAP), observou que este projeto atingiu aos objetivos propostos pela empresa, que era atender aos requisitos do projeto, satisfazer ao cliente e gerar lucro. Assim como 
outros documentos fornecidos pela empresa, este relatório foi disponibilizado para o presente estudo, todavia não teve sua divulgação autorizada.

O projeto apresentou um ganho de 9,1\%, entretanto, devido a uma perda de 1,1\% em razão de alguns eventos de riscos, houve um aumento na margem líquida em 8 pontos percentuais no término do projeto. Este foi calculado pela divisão entre 0 lucro líquido final no término do projeto e o valor final do contrato, fazendo-se assim a comparação com os mesmos cálculos iniciais.

Dentre as diversas razões para este ganho de 9,1\%, pode-se citar que os principais fatores foram boas negociações com fornecedores, otimização de projeto executivo pela engenharia, otimização de horas de projeto e melhora nos índices de reajuste do contrato. Vale ressaltar que no relatório gerencial é apresentado as causas raízes de cada variação, uma vez que este apresenta os custos incorridos, comparados com seus respectivos orçamentos, sendo estes considerados a um nível de detalhe de pacote de trabalho dentro da WBS. Dentro de cada pacote de trabalho, deve-se explicar as razões de cada variação de forma a obter um registro de todo 0 gerenciamento do projeto.

Quanto à variação dos riscos, houve a ocorrência de um risco desconhecido e totalmente imprevisto pela equipe do projeto, ocasionando um atraso de geração comercial para o cliente e conseqüentemente uma perda de 2,2\% na margem líquida do projeto. No entanto, devido à ocorrência de somente 4 riscos dos 16 analisados, não houve a utilização de toda a contingência prevista no projeto, propiciando um ganho de $1,1 \%$ na margem líquida do projeto. Com isso, o impacto final dos riscos no projeto reduziu em 1,1\% a margem líquida do mesmo. 


\subsection{PROJETO 3}

O Projeto 3 tem como escopo a modernização de 6 unidades de aproximadamente $60 \mathrm{MW}$ de uma usina hidrelétrica. Além da modernização dos geradores, realizou-se também nos sistemas digitais, auxiliares equipamentos da subestação, regulação de velocidade e sistema de monitoramento por TV.

A usina modernizada possuía no início do projeto de modernização, 46 anos de operação com a potência instalada de aproximadamente $500 \mathrm{MW}$. Esta usina foi beneficiada pelo programa de modernização do governo e tem um importante papel junto ao estado de Minas Gerais e também junto ao Sistema Interligado Nacional.

Estimou-se que após a modernização realizada as Unidades Geradoras terão uma capacidade geradora por mais 40 anos e com um investimento de somente $15 \%$ do custo de uma nova.

Para a realização deste projeto a Empresa A consorciou-se com outras grandes e renomeadas empresas do mercado energético e civil de forma a realizar um projeto com qualidade e com maior confiabilidade para o cliente final.

Está localizado no estado de Minas Gerais e foi financiado com recursos próprios do cliente, sendo o preço de venda de mais de $R \$ 35.000 .000,00$ e início das atividades a partir da data de assinatura do contrato.

\subsubsection{Do instrumento de pesquisa/entrevista}

Após 3 dias da aplicação do questionário, foi realizada uma entrevista com o gerente do projeto e seu respectivo site manager, a qual complementou os resultados da pesquisa e permitiu esclarecer algumas dúvidas referentes às respostas obtidas com 
o mesmo. Dentre os resultados obtidos, podem-se destacar os principais itens abaixo, sendo as respostas completas apresentadas no Anexo II:

- O escopo estava atrelado à modernização de 06 unidade geradoras;

- A equipe para o gerenciamento do projeto era composta de 8 pessoas $100 \%$ dedicadas ao projeto;

- O consórcio era composto por 5 empresas parceiras. Com o cliente os contatos limitavam a 8 departamentos diferentes;

- Houve menos de 100 subcontratações com fornecedores diferentes;

- A empresa não tinha experiência passada de projetos com características similares;

- O gerente de projeto possuía forte experiência em gerenciamento de projetos, MBA em gerenciamento de projetos e possuía um alto conhecimento em geração de energia, no entanto, no período em que gerenciou este projeto, não possuía conhecimento metodológico em gerenciamento de riscos;

- Para este gerente, a grande dificuldade na execução deste projeto foi a obtenção do comprometimento dos envolvidos, uma vez que a empresa não possuía uma metodologia de gerenciamento de riscos;

- O gerente de projeto se deparou diversas vezes com incertezas desconhecidas para a qual não havia planos, o que gerou conseqüências negativas ao projeto;

- O gerente de projeto relatou que na empresa existem reuniões de riscos feitas no mínimo a cada 3 meses, na quais se reúnem a equipe do projeto para avaliar riscos e oportunidades já levantadas e também para levantar novos riscos e oportunidades. Nenhuma técnica em específico é utilizada se não for determinada pelo gerente de projeto. O mesmo ressalta que a metodologia de gerenciamento de riscos só foi aplicada para o projeto analisado 3 após seu início;

- O gerente de projetos menciona que atualmente na empresa há a figura de um gerente de riscos, entretanto, cabe ao gerente de projetos a identificação dos riscos, análise e resposta aos riscos encontrados. Nos 3 
primeiros anos de gerenciamento do projeto não havia o papel do gerente de riscos;

- Apesar da dificuldade, as reuniões de riscos foram realizadas trimestralmente somente no final do projeto e a participação de toda a equipe era obrigatória;

- A empresa começou a adotar procedimentos após 3 anos de execução do projeto e mesmo assim ainda existia uma grande dificuldade em determinar qual era o valor e o grau de exposição de cada risco, ficando a cargo do gerente de projetos definir de acordo com sua experiência;

- Após 3 anos de início do projeto, houve um plano de gerenciamento de riscos, sendo identificado mais de 20 Riscos, no entanto, analisado qualitativamente e quantitativamente 4 riscos. O plano utilizado neste projeto seguiu aos procedimentos estabelecidos pela empresa, os quais serão apresentados parcialmente por questão de confidencialidade no item 4.1.2;

- Dentre as técnicas e ferramentas para identificação de riscos remanescentes foram utilizadas entrevistas, Brainstorming e análise SWOT, no entanto, os riscos foram identificados somente em termos do que pode acontecer e seu respectivo impacto. Após o processo de identificação dos riscos remanescentes, não houve uma análise adequada considerando sua probabilidade de ocorrência e impacto;

- Os riscos quando analisados, foram considerados somente o aspecto financeiro;

- Não houve uma análise quantitativa adequada;

- Dentre as respostas aos poucos riscos analisados utilizou-se principalmente a mitigação, através de ações considerando custo estimado para as mesmas, bem como os benefícios esperados. Entretanto também se utilizou a prevenção, o melhoramento, através da procura em facilitar ou fortalecer a causa de um evento e aceitação utilizando-se da intuição junto aos limites aceitáveis;

- Não houve um indicador que medisse a evolução dos riscos. Todos os riscos foram acompanhados de maneira parcial e as revisões de riscos não foram feitas de acordo com as revisões de projeto; 
- Não houve registro de riscos;

- As decisões foram tomadas pelo gerente de projetos mesmo para eventos de riscos desconhecidos que ocorreram durante o projeto;

- Não existe um procedimento racional e ferramentas para tomar as decisões no projeto. Neste projeto especificamente, as decisões quanto aos eventos de riscos foram tomadas, em sua maioria, através da experiência do gerente do projeto e intuição;

- Sempre quando utilizou a intuição em projetos anteriores para tomar decisões, a maioria dos resultados foram negativos, no entanto houve resultados satisfatórios.

- Nas decisões para eventos de riscos, o gerente do projeto sempre considerou o aspecto financeiro como critério de análise.

\subsubsection{Dos documentos analisados}

\subsubsection{Contrato}

\section{- Prazo}

O prazo máximo para desmontagem/montagem, e comissionamento de todas as unidades, não simultaneamente, foi de 36 meses, conforme segue:

- 06 meses para a execução dos serviços na primeira unidade e 06 meses para cada unidade geradora. Neste prazo, está contemplada a conclusão dos ensaios finais.

\section{- Multas}

\section{口 Por potência insuficiente do gerador}

Caso a potência máxima verificada no comissionamento fosse menor que o valor garantido, a contratada pagaria ao cliente uma quantia equivalente para cada $0,01 \%$ de diferença constatada para cada gerador, após a dedução da tolerância devida à imprecisão da medição resultante do método e aparelhagem utilizados e calculada 
de acordo com os critérios do IEEE. Se a diferença fosse maior do que $1 \%$ a contratada efetuaria as modificações necessárias de modo que fossem obtidos valores aceitáveis pelo cliente.

\section{a Por rendimento insuficiente do gerador}

Caso o rendimento verificado no COMISSIONAMENTO fosse menor que 0 valor garantido, desde que a diferença constatada seja menor que 1,0\%, a contratada pagaria ao cliente quantia equivalente para cada $0,01 \%$ de diferença para cada gerador, após a dedução da tolerância devida à imprecisão das mediações resultantes do método e aparelhagem utilizados e calculada de acordo com os critérios do IEEE. Uma diferença superior a 1,0\% seria considerada como inaceitável e a contratada efetuaria as modificações necessárias de modo que fossem estabelecidos no projeto.

\section{- Atraso na geração comercial}

Para cada dia de atraso na entrada em operação comercial de cada unidade em relação ao cronograma contratual, a contratada pagaria ao cliente uma quantia expressiva que por questões confidencias não podem ser informadas.

\subsubsection{Plano de Gerenciamento de Riscos do projeto 3}

Observou-se que nos 3 primeiros anos de projeto, não foi utilizada nenhuma ferramenta e nem procedimentos para o gerenciamento dos riscos. Em função disto, coube ao gerente do projeto administrar o percentual de contingência deixada por vendas para os prováveis riscos, baseando-se nas informações obtidas do relatório gerencial. Esta administração era feita através do gerenciamento da melhor resposta no momento em que os eventos de riscos tornavam-se fatos.

Após 3 anos de projeto, iniciou-se o processo de gerenciamento de riscos e, através das poucas atas de reuniões de riscos e da ferramenta utilizada (Risk management datasheet) para o gerenciamento dos riscos, pode-se mesmo assim dizer que neste 
projeto houve parcialmente o gerenciamento dos riscos, pois havia desvios em relação aos procedimentos que acabavam de ser adotados pela empresa.

Observou-se uma dificuldade muito grande em definir os planos de ação para os poucos riscos analisados neste período, uma vez que as análise qualitativas e quantitativas não foram utilizadas totalmente de acordo com os novos procedimentos adotados pela empresa.

No processo de identificação dos riscos identificou-se, principalmente através do Brainstorming, uma quantidade de aproximadamente 20 riscos sendo que os mesmos não foram categorizados.

No processo de análise qualitativa, utilizou-se somente as medições de impacto. No entanto, realizou-se esta análise somente nos 4 riscos, uma vez que o projeto já se encontrava próximo do fim.

No processo de análise quantitativa, calculou-se parcialmente os impactos em termos de impacto financeiro, juntamente com os custos de mitigação, obtendo-se assim a reserva de contingência para este risco, a qual foi calculada parcialmente conforme a equação abaixo:

Contingência $=$ Impacto do risco + Custo de mitigação - Valor mitigado

Vale ressaltar que devido ao fato do gerente de projeto possuir pouca experiência em gerenciamento de riscos, não se utilizou um estudo racional, como, $\square$ por exemplo, árvore de decisão ou simulação Monte Carlo, conforme sugere Kerzner (1998), considerando os efeitos da probabilidade, a fim de poder analisar a melhor estratégia de resposta e de provisão financeira para este risco.

Observa-se claramente que, nas poucas análises realizadas, as informações não se encontravam com um nível de detalhe suficiente, que permitisse utilizar algum método racional para auxiliar na tomada de decisão. Com isso, coube ao gerente do projeto definir estimativas de impacto através da experiência e feeling em todos os riscos que encontrava. 


\subsubsection{Plano de Gerenciamento de Projetos do projeto 3}

Observou-se neste projeto, que mesmo sem a existência de uma metodologia de riscos, houve um plano de gerenciamento de projetos utilizando como principal entrada, os procedimentos adotados pela empresa. Dentre os principais itens encontrados neste plano pode-se citar:

- Análise dos requisitos;

- Definição clara do escopo;

- Premissas;

- Restrições;

- WBS;

- Cronograma:

- Análise Caminho Crítico:

- Plano de gerenciamento de Custos:

- Linha de base de custos;

- Plano de qualidade fabril;

- Plano de qualidade de obra;

- Plano de site;

- Análise fazer ou comprar;

- Matriz de responsabilidades;

- Plano de comunicação;

Nos 3 primeiros anos de projeto, apesar de não haver uma metodologia de gerenciamento de riscos, mencionava-se superficialmente no plano de gerenciamento de projetos sobre a importância de identificar e elaborar planos de mitigação para os riscos, no entanto não abordava procedimentos, ferramentas e técnicas para auxiliar o gerente de projetos na realizar um bom gerenciamento. 


\subsubsection{Resultados do projeto}

Através de um estudo profundo sobre os resultados financeiros deste projeto, obtidos através do relatório gerencial da ferramenta de gestão da empresa (SAP), observou que este projeto não atingiu aos objetivos propostos pela empresa, que era atender aos requisitos do projeto, satisfazer ao cliente e gerar lucro. Assim como outros documentos fornecidos pela empresa, este relatório foi disponibilizado para o presente estudo, todavia não teve sua divulgação autorizada.

Observou-se uma perda da margem líquida em 6 pontos percentuais no término do projeto. Este foi calculado pela divisão entre o lucro líquido final no término do projeto e o valor final do contrato, fazendo-se assim a comparação com os mesmos cálculos iniciais.

Dentre as diversas razões para esta perda, pode-se citar a falta de gerenciamento dos riscos neste projeto, contribuindo assim para uma perda de $5 \%$ do total de $6 \%$ já mencionado.

Quanto ao impacto dos riscos, fez-se um estudo comparativo considerando num primeiro momento, os 3 primeiros anos e num segundo o período remanescente.

Com isso, observou-se que dos $5 \%$ de impacto na margem, $4 \%$ foi relativo aos 3 primeiros anos, período este em que não havia metodologia de riscos na empresa nem muito menos no projeto. $01 \%$ remanescente foi relativo a 2 riscos que se tornaram fato dentro os 4 riscos analisados, gerando assim o impacto mencionado.

A tabela 10 abaixo apresenta um quadro resumo dos resultados obtidos pelos 3 projetos: 
Tabela 10 - Resumo dos resultados

\begin{tabular}{|c|c|c|c|}
\hline & PROJETO 1 & PROJETO 2 & PROJETO 3 \\
\hline Resultado Final & $3 \%$ & $8 \%$ & $-6 \%$ \\
\hline Ganho de Projeto & $4,7 \%$ & $9,1 \%$ & $-1 \%$ \\
\hline Perdas de Riscos & $\begin{array}{l}1,7 \% \text { sendo } 1,2 \% \\
\text { de um risco } \\
\text { complexo }\end{array}$ & $\begin{array}{l}1,1 \% \text { sendo: } \\
2,2 \% \text { risco não } \\
\text { previsto e } 1,1 \% \\
\text { savings }\end{array}$ & $\begin{array}{l}-5 \% \text { sendo: } \\
-4 \% \text { nos } 3 \\
\text { primeiros anos e } \\
-1 \% \text { após }\end{array}$ \\
\hline
\end{tabular}

Fonte: Elaborado pelo autor 


\section{ANÁLISE}

De acordo com os resultados apresentados, identificaram-se como principais pontos de análise os itens abaixo, os quais serão discutidos na seqüência:

- Experiência dos gerentes dos projetos

A experiência dos gerentes de projetos não teve uma variação significativa que pudesse interferir na execução de seus respectivos projetos em termos de conhecimento, habilidades e técnicas conforme proposto pelo PMI (2004), entretanto, identificou-se que o diferente grau de conhecimento dos mesmos com relação a gerenciamento de riscos, contribuiu proporcionalmente com os resultados alcançados ao término do projeto.

O projeto 2 tratou os riscos considerando sua probabilidade, impacto e principalmente sua causa raiz, conforme Smith e Merritt (2002), mostrando uma maior preocupação com uma melhor estruturação das informações e conseqüentemente favorecendo a análise e respostas mais eficazes perante aos eventos de riscos. Isto foi atribuído ao fato do gerente deste projeto destacar-se em relação aos demais no quesito conhecimento metodológico de gerenciamento de riscos.

O projeto 1, embora também tenha atingido resultados satisfatórios ao término de sua execução, pressupõe-se que estes poderiam ter sido melhores, caso seu gerente tivesse maior conhecimento metodológico, uma vez que poderia ter sido utilizado mais procedimentos que o suportasse no processo decisório, como por exemplo, o uso da árvore de decisão e análise de Monte Carlo, frente aos eventos de riscos.

Quanto ao projeto 3, levando-se em consideração que a quantidade de riscos é muito maior no início do projeto conforme Dinsmore (2003) e que nos 3 primeiros anos de execução a empresa não tinha uma metodologia de gerenciamento de 
riscos, acredita-se que se o gerente do projeto tivesse maior conhecimento metodológico em gerenciamento de riscos, os resultados deste projeto poderiam ter sido melhores, uma vez que grande parte das perdas neste projeto quanto aos riscos foram apresentadas neste período.

\section{- Gerenciamento de Riscos}

Apesar de Kerzner (2004) dizer da importância de obter uma metodologia de riscos organizada e entendida por todos, foi observado que, apesar da empresa possuir uma metodologia de riscos, a mesma não é claramente conhecida por todos os envolvidos nos projetos, com exceção dos gerentes de projetos.

No entanto, nos primeiros anos de execução do projeto 3 , a empresa não possuía uma metodologia definida para o gerenciamento de riscos para os projetos. Neste período, os resultados financeiros apresentados pelo o projeto 3 foram muito ruins. Conforme dados apresentados no capítulo de resultados, o relatório gerencial mostrou que o principal motivo para estes resultados foi a ocorrência de eventos riscos no projeto.

Após a implementação desta metodologia, houve uma melhora dos resultados, uma vez que ao término do projeto houve a perda de somente $1 \%$ na margem líquida, diferentemente do ocorrido nos 3 primeiros anos, no qual a perda foi de $4 \%$. Neste caso específico, o gerenciamento de riscos foi o responsável pela melhora dos resultados.

No projeto 1, apesar da empresa já possuir a metodologia de gerenciamento de riscos, a mesma não foi aplicada em sua totalidade, conforme sugere PMI (2004). Contudo, o projeto obteve resultados positivos ao seu término.

O projeto 2 aplicou os conceitos utilizados na metodologia de gerenciamento de riscos definidos pela empresa e utilizou ferramentas adicionais como a árvore de decisão, obtendo assim resultados ainda mais satisfatórios. 
A metodologia de riscos da empresa analisada contempla as principais etapas para gerenciamento de riscos, como identificação, análise, plano de respostas e monitoramento, conforme sugere PMI (2004), no entanto não detalha e nem apresenta as técnicas e ferramentas recomendadas para cada fase para melhorar a eficácia do gerenciamento de riscos.

Visando um melhor detalhamento do gerenciamento de riscos utilizado nos 3 projetos, a análise foi realizada de acordo com as etapas utilizadas na metodologia.

\section{- Quanto ao planejamento de riscos}

Mesmo havendo a participação efetiva dos colaboradores chaves nas reuniões de riscos, observou-se o baixo comprometimento da equipe, o que se pode atrelar ao desconhecimento da importância do gerenciamento de riscos para a melhor execução do projeto.

Houve a participação do departamento de gerenciamento de riscos, no entanto, devido a baixa maturidade dos facilitadores, a coordenação destas reuniões sempre ficou a cargo do gerente de projeto, o que pode ser corroborado no projeto 2, no qual o gerente deste projeto, por ter mais experiência metodológica de gerenciamento de riscos, utilizou um plano mais detalhado, obtendo um melhor resultado no final no projeto.

\section{- Quanto à identificação dos riscos}

Utilizou-se como ferramenta no processo de identificação dos riscos, conforme proposto por PMI (2004), a documentação do projeto, brainstorming, entrevistas com especialistas e análise SWOT. No entanto, o projeto 2 foi o que utilizou uma quantidade maior destas ferramentas, bem como foi o que apresentou o melhor desempenho ao seu término.

Desta forma, entende-se que um dos fatores que contribuíram para este resultado foi à adoção de uma metodologia para a identificação e gerenciamento de riscos 
mais cuidadosa e detalhada, a qual fez uso de diversas ferramentas e técnicas conforme apresentado na seção 4.1.2.

Apesar de ter acontecido à identificação dos riscos também nos demais projetos analisados, somente o projeto 2 utilizou uma categorização/Estrutura Analítica de Riscos (EAR), e uma lista dos riscos identificados conforme recomenda o PMI (2004), obtendo-se assim uma melhor rastreabilidade dos riscos e conseqüentemente um melhor controle com relação aos resultados finais do projeto.

- Quanto à análise qualitativa dos riscos

Observou-se nos projetos 1 e 2 a utilização de uma matriz e processo de análise de probabilidade e impactos bem definidos. No entanto, o projeto 2 foi o único a utilizar esta análise para todos os riscos identificados, além de priorizá-los, conforme sugere PMI (2004), complementando a afirmativa de que a utilização correta de uma metodologia de gerenciamento de riscos contribui para resultados satisfatórios ao término do projeto, haja vista que este projeto foi o que obteve o melhor desempenho.

O projeto 1, embora também tenha apresentado resultados satisfatórios ao seu término, utilizou somente uma matriz de risco para os principais riscos. Com base na análise do projeto 2 , acredita-se que, se seu gerenciamento de riscos tivesse sido mais abrangente como o realizado no projeto 2 , o projeto 1 poderia ter apresentado resultados melhores do que os obtidos.

- Quanto à análise quantitativa dos riscos

Assim como na análise qualitativa, o projeto 2 diferenciou-se dos demais ao utilizar o método do Valor Monetário Esperado para calcular os impactos dos riscos, bem como a utilização da árvore de decisão para definição da melhor estratégia para o evento de risco, conforme sugere PMI (2004) e Kerzner (1998), justificando a importância deste método para o processo decisório e conseqüentemente no resultado do projeto. 
- Quanto ao plano de respostas aos riscos

Mesmo diversos autores abordando diversas estratégias de respostas aos riscos, os 3 projetos utilizaram em sua maioria, a mitigação.

No projeto 3, observou-se que nos 3 primeiros anos, as respostas aos riscos eram desenvolvidas na medida em que os riscos iam se materializando, o que interferiu, em muito, na eficácia da resposta e conseqüentemente do resultado, devido urgência necessária ao tratamento. Após a implementação da metodologia, utilizouse de um plano de respostas para os 4 riscos analisados, podendo-se verificar uma melhoria nos resultados.

Observou-se nos projetos 1 e 2 um bom nível de desenvolvimento dos processos, entretanto, não houve uma aderência na elaboração das respostas para as oportunidades, indicando ainda não ser uma prática consolidada na empresa.

- Quanto ao monitoramento dos riscos

Outro fato que contribuiu para a eficácia do gerenciamento de riscos no desempenho dos projetos está atrelado à constância do monitoramento efetuado durante a execução dos mesmos. Esta afirmação pôde ser comprovada com os resultados do projeto 1 e 2 , no qual o monitoramento era realizado de forma trimestral e mensal, respectivamente. No projeto 3 , no qual no início não houve este monitoramento, os resultados obtidos foram piores em relação aos demais.

\section{- Processo decisório}

De acordo com Ansoff (1990), para se ter uma boa decisão, necessita-se dos enfoques normativo/prescritivo e descritivo. Esta afirmação pode ser corroborada com os casos estudados, mais especificamente no projeto 2, o qual além de utilizar o processo descritivo em alguns momentos, utilizou-se também de ferramentas prescritivas para a obtenção da melhor estratégia junto aos eventos de riscos, apoiando-o no processo decisório. 
No que diz respeito ao enfoque descritivo, observou-se que a experiência e o repertório dos gerentes de projetos contribuíram em alguns momentos para 0 processo decisório junto aos eventos de riscos não planejados, entretanto, pode-se mencionar que somente a experiência e o repertório não contribuem efetivamente para a tomada de decisões frente aos eventos de riscos, conforme apontado por Clemen e Reilly (2001). O projeto 3 pode ser considerado um exemplo para esta afirmação uma vez que, durante o período em que não houve o gerenciamento de riscos, utilizou-se somente dos aspectos descritivos para elaborar planos de respostas, obtendo resultados negativos para o projeto neste período.

Clemen e Reilly (2001) afirmam que uma boa decisão envolve a compreensão profunda do problema e necessita ser definida através de etapas relevantes.

Para a tomada racional de decisão frente aos eventos de riscos, torna-se imprescindível uma compreensão profunda e uma análise detalhada dos mesmos, que pode ser eficazmente obtida através de uma metodologia de gerenciamento de riscos.

Dada as considerações supracitadas, observou-se nos casos estudados uma melhor utilização da metodologia de gerenciamento de riscos nos casos 2,1 e 3 respectivamente e, conseqüentemente, uma melhor estruturação do processo decisório. 


\section{CONSIDERAÇÕES FINAIS}

Frente a toda revisão bibliográfica efetuada e dados coletados, com suas respectivas análises, acredita-se que o trabalho desenvolvido nesta dissertação atingiu os objetivos propostos.

Neste item, são abordadas as principais conclusões alcançadas, a relevância do trabalho, os limites da pesquisa e, por fim, a sugestão de novas linhas de estudo.

\subsection{CONCLUSÃO}

A revisão bibliográfica empreendida evidenciou a relevância do gerenciamento de projetos e do gerenciamento de riscos para o atendimento dos objetivos de um determinado projeto, além de apresentar seus processos, conceitos e ferramentas. Além disso, evidenciou a importância dos aspectos descritivos e prescritivos para a tomada de decisão frente a um evento de risco. Entretanto, observou-se que na prática, o modelo prescritivo é o que contribui de forma mais assertiva para o processo decisório frente aos eventos de risco e conseqüentemente para um melhor resultado do projeto.

Os casos analisados permitiram afirmar que o gerenciamento de riscos influenciou o processo decisório dos gerentes de projetos, uma vez que, através da ferramenta SAP, foi possível isolar a variável risco das demais no que diz respeito às causas das variações de margem no ciclo de vida do projeto.

Levando em consideração que os projetos 2 e 1, considerando esta ordem, foram os que utilizaram da melhor forma a metodologia de gerenciamento de riscos desde 0 princípio, e, confrontando com os resultados obtidos acerca da redução de margem, pode-se dizer que a metodologia de gerenciamento de riscos contribuiu no processo decisório dos gerentes de projetos e conseqüentemente nos resultados dos projetos. 
O projeto 3, no qual o gerente de projeto passou a aplicar uma metodologia para o seu gerenciamento apenas após 3 anos de execução, apresentou nos 3 primeiros anos uma perda financeira de $4 \%$ na margem do projeto devido a ocorrência de alguns riscos, o que poderia ter sido evitado com a utilização de uma metodologia de gerenciamento de riscos. Após a implantação da metodologia, a perda referente aos riscos foi reduzida a $1 \%$, evidenciando os benefícios da adoção de métodos para 0 resultado do projeto.

Com isso, pode-se afirmar que os projetos que realizaram um gerenciamento dos riscos de forma mais aprofundada, subsidiaram o gerente do projeto no processo de tomada de decisão quanto ao tratamento dos eventos de perigo, contribuindo para a definição da melhor estratégia para sua mitigação, visando sempre o menor impacto financeiro, atendimento aos objetivos do projeto e a satisfação do cliente.

Acredita-se que o trabalho aqui apresentado, pode ser considerado um fator motivacional na implementação e/ou melhoria da metodologia de gerenciamento dos riscos nas empresas, a fim de colaborar com o processo decisório dos gerentes de projetos e conseqüentemente nos resultados dos projetos.

Para tanto, sugere-se que a metodologia de riscos deva seguir, no mínimo, as seguintes etapas:

\section{Planejamento de Riscos}

Dentro do processo de planejamento de riscos, deverá conter, no mínimo, as seguintes informações:

- Metodologia a ser aplicada;

- Papeis e responsabilidades de cada membro do projeto;

- Orçamento destinado ao gerenciamento de riscos;

- Prazos para a realização do gerenciamento de riscos e seus procedimentos;

- Categorização dos riscos de maneira sistemática. 


\section{Identificação de Riscos}

Dentro do processo de identificação de riscos, deverá conter, no mínimo, as seguintes informações:

- Lista das possíveis técnicas para identificação dos riscos;

- Lista dos riscos identificados em termos de probabilidade e impacto.

\section{Análise qualitativa de Riscos}

Dentro do processo análise qualitativa de riscos, deverá conter, no mínimo, as seguintes informações:

- Elaboração da matriz de tolerância de riscos, segundo os critérios definidos pela empresa;

- Atualização da lista de riscos identificados em termos de probabilidade e impacto;

- Priorização dos riscos identificados, segundo sua categorização;

- Listas dos riscos que deverão ser analisados quantitativamente;

- Listas dos riscos que deverão ser somente monitorados.

\section{Análise quantitativa de Riscos}

Dentro do processo análise quantitativa de riscos, deverá conter, no mínimo, as seguintes informações:

- Estudo probabilístico dos riscos em termos de alcance dos objetivos financeiros e de tempo;

- Estudo numérico dos impactos;

- Cálculo do valor monetário esperado;

- Utilização da árvore de decisão para riscos complexos;

- Priorização dos riscos quantificados. 


\section{Plano de Respostas de Riscos}

Dentro do processo plano de respostas de riscos, deverá conter, no mínimo, as seguintes informações:

- Definição da melhor resposta para cada risco, considerando os objetivos do projeto;

- Atualização do plano, segundo as respostas planejadas.

\section{Monitoramento e controle dos Riscos}

Dentro do processo monitoramento e controle dos riscos, deverá conter, no mínimo, as seguintes informações:

- Seguir os procedimentos adotados pela empresa;

- Realizar, no mínimo reuniões mensais;

- Realização do monitoramento em todos os riscos analisados;

- Realização de uma nova identificação e análise;

- Atualização do plano de projeto.

\subsection{RELEVÂNCIA}

Levando-se em consideração que o gerenciamento de riscos ainda não pode ser considerado como uma disciplina madura, este trabalho mostra aos gerentes de projetos a relevância em adotar uma metodologia de riscos em seus projetos, tendo em vista os resultados positivos que a mesma proporciona.

A pesquisa de White e Fortune (2002) mostra que o gerenciamento de riscos é utilizado em torno de $49,5 \%$ dos projetos, sendo assim, este trabalho vem a ser um instrumento motivador para todos os gerentes de projetos, pois apresenta os benefícios de se utilizar o gerenciamento de riscos nos projetos. 
Outra relevância deste estudo é a baixa quantidade de pesquisas que analisam a influência da metodologia de gerenciamento de riscos nos processos decisórios dos gerentes de projetos de forma a se obter melhores resultados na execução dos projetos.

\subsection{LIMITES}

Esta pesquisa apresentou algumas limitações, as quais se fazem necessário mencionar:

- Quantidade limitada de projetos e empresas

Nesta pesquisa, inicialmente foram consideradas 3 empresas para análise, no entanto somente uma empresa aceitou participar, tendo assim uma quantidade limitada de empresas estudadas.

Visando atingir aos objetivos desta dissertação, optou-se por utilizar projetos com a maior semelhança possível entre eles sendo identificado somente 3 dentro da empresa analisada.

- Quantidade limitada de informações

A quantidade de informações referentes aos projetos foi limitada, uma vez que as entrevistas forma realizadas somente com os gerentes de projetos e site managers. A fim de mitigar este item, conseguiram-se todos os arquivos dos projetos.

- Conceito de oportunidade

Apesar de a teoria abordar o conceito de oportunidade como sendo um risco positivo, nesta dissertação não foi analisada as oportunidades nos projetos. 


\subsection{PROPOSIÇÕES PARA NOVAS PESQUISAS}

Mesmo com algumas limitações, conforme acima mencionadas, foi possível chegar às conclusões apresentadas, desejando que as mesmas possam embasar e auxiliar novos trabalhos, a fim de complementar o presente estudo.

Ao passo que a prática de gerenciamento de projetos tem-se tornado cada vez mais constante nas organizações, como forma de obter vantagem competitiva, se faz necessário maiores estudos acerca do impacto de uma metodologia de riscos no processo decisório dos gerentes de projetos.

Sugere-se que outros autores possam complementar este trabalho através da análise do processo decisório mediante eventos de riscos em outros tipos de projetos, diferente de modernização de usinas hidroelétricas, bem como utilizar uma quantidade maior de empresas para comparações e análises.

A fim de contribuir para futuras pesquisas nesta área, espera-se que pesquisas também sejam feitas levando-se em consideração a influência das lições aprendidas nos processos decisórios, assim como a influência dos aspectos cognitivos. 


\section{REFERÊNCIAS}

AGOSTINHO, A.A., THOMAZ, S.M. \& GOMES, L.C. Conservação da biodiversidade em águas continentais do Brasil. Megadiversidade 1(1): 70-78, 2005.

AGOSTINHO, A.A., GOMES, L.C. \& PELICICE, F.M. Ecologia e manejo de recursos pesqueiros em reservatórios do Brasil. EDUEM, Maringá, 2007.

AKINTOYE, A.S.; MACLEOD, M.J. Risk analysis and management in construction. International Journal of Project Management, v. 15, n. 1, p. 31-38, 1997.

ALBENY, R.M. Análise da importância da mensuração e controle do valor da exposição a riscos em projetos de desenvolvimento de produtos complexos. São Paulo, 2007. 117p. Dissertação (Mestrado). Escola Politécnica da Universidade de São Paulo - Departamento de Engenharia Naval e Oceânica, 2007.

ALMEIDA, Kezer Marcus Morais de. Análise da gestão de riscos aplicada na aquisição de bens e serviços para os projetos de bens de capital. São Paulo, 2008. 164 p. Dissertação (Mestrado) - Escola Politécnica da Universidade de São Paulo. Departamento de Engenharia Naval e Oceânica, 2008.

ANSOFF, H. Igor. A nova estratégia empresarial. São Paulo: Atlas, 1990.

ARTTO, Karlos A., HAWK, David L. Industry models of risk management in their future. Ins: 30th Annual Project Management Institute Seminars \& Symposium, 1999, Philadelphia, EUA. Disponível em: http://www.risksig.com. Acesso em: 15 jan. de 2009.

ASSOCIAÇÃO BRASILEIRA DE NORMAS TÉCNICAS. ISO/IEC GUIA 73: gestão de riscos - vocabulário - recomendações para uso em normas. Rio de Janeiro, 2005. 
BAKER, S.; PONNIAH, D.;SMITH, S. Survey of risk management in major U.K. companies. Journal of Professional Issues in Engineering Education and Practice, July, 1999.

BARON, J. Thinking and deciding. 2. ed. London: Cambridge University Press, 1994.

BATEMAN, Thomas S; SNELL, Scott. Administração: novo cenário competitivo. 2a. ed. São Paulo: Atlas, 2006.

BAZERMAN, Max H. Processo decisório. 5. Ed. Rio de Janeiro: Elsevier, 2004

BAZERMAN, M. Judgment in Managerial Decision Making. 6th ed. New York: John Wiley and Sons, 2006.

BERNSTEIN, Peter L. Desafio aos Deuses: A Fascinante História do Risco. Rio de Janeiro: Campus, 1997. 389 p.

BETTMAN, J.R.; JOHNSON, E.J.; PAYNE, J.W. Consumer Decision Making. Ins: T.S. Robertson, H. Kassarjian (Eds.). Handbook of consumer Behavior. New Jersey: Prentice Hall, 1991.

BLOCK, T.R.; FRAME, D. The Project Office. Menlo Park, California: Crisp Management Library, 1998.

BROWNE, Mairéad. Organizational decision making and information. Norwood, New Jersey: Ablex Publishing Corporation, 1992.

BUENO, F. S. Grande Dicionário Etimológico - Prosódico da Língua Portuguesa. Santos, São Paulo: Brasília Ltda, 1974. v.7. 
CAMPAGNA, E. "Metodología de Proyectos de Investigación". FCU, Montevideo, 1996.

CASAROtTO, N. F.; FÁVERO, J. S.; CASTRO, J. E. E. Gerência de Projetos / Engenharia Simultânea. São Paulo: Atlas, 1999.

CERVO, A.L.; BERVIAN, P.A. Metodologia Científica: 3. Edição. São Paulo, McGraw-Hill do Brasil, 1983.

CHAPMAN, R. J. The effectiveness of working group risk identification and assessment techniques. International Journal of Project Management, v. 16, n. 6, p. 333-343, 1998.

CLARK, R. C.; PLEDGER, M.; NEEDLER, H. M. J. Risk analysis in the evaluation of non-aerospace projects. Project management, v 8, n 1, February, 1990.

CLELAND; IRELAND. Gerência de Projetos. Rio de Janeiro: Reichmann \& Affonso, 2002.

CLEMEN, Robert T. e REILLY, Terence. Making hard decisions. 2nd ed. Pacific Grove: Duxbury Thomson Learning, 2001.

CLEMEN, Robert T. e REILLY, Terence. Making Hard Decisions. USA:Duxbury, 1996.

COPPENDALE, J. Manage risk in product and process development and avoid unpleasant surprises. Engineering Management Journal. p.35-38, fev. 1995.

CRAWFORD, J. K. The Strategic Project Office - A Guide to Improving Organizational Performance. New York: Marcel Dekker, 2002. 
CURY, A. Organização e métodos: uma visão holística. 6. ed. São Paulo: Atlas, 1983.

DAFT, Richard L. Administração. 6ª . ed. LTC Editora: Rio de Janeiro, 2005.

DAVIS, D. Business research for decision making. 4. ed. USA: Duxbury, 1996.

DINSMORE, Paul C. The AMA handbook of project management : American Management Association, 1993.

DINSMORE, Paul Campbell, CAVALIERI, Adriana. Como se tornar um profissional em gerenciamento de projetos: livro-base de "preparação para certificação PMP® - Project Management Professional". Rio de Janeiro:

Qualitymark, 2003.

DINSMORE, P. C.; NETO, F. H. S. Gerenciamento de projetos: como gerenciar seu projeto com qualidade, dentro do prazo e custos previstos. Rio de Janeiro: Qualitymark, 2004.

EDWARDS, W and FASOLO, B. Decision technology. Annu. Rev. Psychol. [S.I.], [s.v.], p.581-606, 2001.

ELETROBRÁS. Empresa de capital misto com controle acionário do Governo Federal. Disponível em: http://www.memoria.eletrobras.gov.br. Acessado em 15 jul. de 2009.

EPLEY, N.; GILOVICH, T. When effortful thinking influences judgmental anchoring: differential effects of forewarning and incentives on self-generated and externally provided anchors. Journal of Behavioral Decision Making, v. 18, p.199-212, 2005. 
FERMA - FEDERATION OF EUROPEAN RISK MANAGEMENT ASSOCIATIONS. Norma de Gestão de Riscos. AIRMIC, ALARM, IRM: 2002, translation copyright FERMA: 2003.

FLEURY A.; FLEURY M. T. L. Estratégias Empresariais e Formação de Competências. São Paulo: Atlas, 2001.

FORSBERG, K. et al. Visualizing project management: a model for business and technical success. John Wiley \& Sons, Inc, 1996.

GIL, Antonio Carlos. Métodos e técnicas de pesquisa social. 5. ed. São Paulo: Atlas, 1999.

GILOVICH, T.; GRIFFIN, D. Heuristics and Biases: then and now. In: GILOVICH, T.;GRIFFIN, D.; KAHNEMAN, D. (Eds.). Heuristics and Biases: the psychology of intuitive judgment. Cambridge: Cambridge University Press, 2002.

GITMAN, L.J. Princípios de administração financeira: manual do software. 7.ed. São Paulo: Harbra, 1997.

GOLDBERG, M.; WEBER, C. Evaluation of the risk analysis and cost management (RACM) model. Washington, D.C: Institute for Defense Analysis, 1998. (Paper 3338)

GOMES, Carlos F.S., THOR: Um algoritmo híbrido de apoio multicritério à decisão para processos decisórios com alternativas discretas. Tese (Doutorado em Engenharia) - COPPE, Universidade Federal do Rio de Janeiro, Rio de Janeiro, 1999

HALL, D.; HULETT, D. Projeto de riscos universais. Newtown Square: PMI, 2002. (Relatório final sobre riscos universais em projetos, relatório do grupo de riscos do PMI mundial). 
HOUAISS, A.; VILLAR, M. S. Dicionário Houaiss da Língua Portuguesa. Rio de Janeiro: Objetiva, 2001.

HOWARD, R. Decision analysis: practice and promise. Management Science. Vol. 34, № 6, June 1988, USA.

HULETT, D. T. Key characteristics of a mature risk management process. New York: International Institute for Learning, 2002.

KAHNEMAN, D; TVERSKY, A. Subjective probability: a judgment of representativeness. Cognitive Psychology, v.3, p.430-454, 1972.

KAHNEMAN, D. A Perspective on Judgment and Choice. American sychologist, v.58, n.9, p.697-720, 2003.

KERZNER, H. Advanced Project Management: Best Practices on Implementation. 2nd Edition, John Wiley \& Sons, 2004.

KERZNER, Harold. Project management: a systems approach to planning, scheduling, and controlling. 6th ed. New York: John Wiley \& Sons, 1998. 1180 p.

KERZNER, Harold. Project Management: A System Approach to Planning, Scheduling, and Controlling.7th ed. USA: John Wiley \& Sons, 2001b, Cap. 17: Risk Management, p. 530-555.

KERZNER, $H$. Project Management: a systems approach to planning, scheduling, and controlling. 9th. New Jersey: John Wiley \& Sons, Inc, 2005.

KERZNER, H. Gestão de Projetos: As Melhores Práticas. Porto Alegre: Bookman, 2002. 
KUNREUTHER, $\mathrm{H}$. Risk Analysis and Risk Management in an Uncertain World. Risk Analysis, v. 22, n. 4, 2002.

LAKATOS E. M.; MARCONI M. A. Metodologia Científica. São Paulo: Atlas, 2007.

LINDBLOM, Charles Edward. O Processo de Decisão Política. Brasília, Ed. UNB: 1981.

LYONS, T.; SKITMORE, M. Project risk management in the Queensland engineering construction industry: a survey. International Journal of Project Management, v. 22, n.1, p. 51-61, 2004.

LUPPE, Marcos Roberto. A heurística da ancoragem e seus efeitos no julgamento: decisões de consumo. São Paulo, 2006. 118 p. Dissertação (Mestrado) - Faculdade de Economia, Adminstração e Contabilidade da Universidade de São Paulo, 2006.

MALHOTRA, Naresh. Marketing Research: an applied orientation. 2nd. Ed. Upper Saddle River: N.J.: Prentice-Hall, 1996.

MARKOWITZ, H. M. Portfolio selection: efficient diversification of investments. New York : Wiley, [1959]. 344p.

MATTAR, Fauze Najib. Pesquisa de Marketing. 5. ed. São Paulo: Atlas, 1999. 337 p. McCRAY,

MAXIMIANO, A. C. A. Administração de Projetos. São Paulo: Editora Atlas, 2002.

MODARRES, M. Risk analysis in engineering: techniques, tools, and trends. Boca Raton: Taylor \& Francis Group, 2006. 
MODICA, Jose Eduardo. Riscos de Projetos de docagem de navios petroleiros. São Paulo, 2009. 121 p. Dissertação (Mestrado) Escola Politécnica da Universidade de São Paulo, Departamento de Engenharia Naval e Oceânica, 2009.

MORGAN, M. G.; HENRION, M. Uncertainty, a guide to dealing with uncertainty in quantitative risk and policy analysis. Cambridge: CambridgeUniversity Press, 1990.

NBR ISO 10006. Gestão da Qualidade - Diretrizes para a qualidade no gerenciamento de Projetos. ABNT - Associação Brasileira de Normas Técnicas, 2000.

OLSSON, C. Risk management in emerging markets. London: Prentice Hall, 2002.

OLSSON, R. In search of opportunity management: Is the risk management process enough? International Journal of Project Management, n. 25, p. 745-752, 2007.

PÁDUA, Elisabete Matallo Marchesini de. Metodologia da Pesquisa: Abordagem Teórico- Prática. 6. ed. Campinas: Papirus, 2000. 120 p.

PATAH, Leandro Alves. Alinhamento estratégico de estrutura organizacional de projetos: uma análise de múltiplos casos. São Paulo, 2004. 205 p. Dissertação (Mestrado) Escola Politécnica da Universidade de São Paulo, Departamento de Engenharia de Produção, 2004.

PEREIRA, M. J. L. B.; FONSECA, J. G. M. Faces da decisão: as mudanças de paradigmas e o poder da decisão. São Paulo, Makron Books, 1997.

PERMINOVA, O.; GUSTAFSSON, M.; WIKSTRÖM, K. Defining uncertainty in projects - a new perspective. International Journal of Project Management, n. 26, p. 73-79, 2008. 
PINTO, Ricardo L. Evolução da estrutura organizacional ao longo do ciclo de vida do projeto: um estudo de caso. São Paulo, 2002. Dissertação (Mestrado em Administração) - Departamento de Administração da Faculdade de Economia, Administração e Contabilidade da Universidade de São Paulo, 2002.

PRINCE. Managing successful projects with PRINCE 2. London: Central Computers and Telecommunications Agency (CCTA), 2002.

PRITCHARD, Carl L. Risk Management: Concepts and Guidance. 2. ed. USA: ESI Intl, $2001.340 \mathrm{p}$.

PROJECT MANAGEMENT INSTITUTE. A guide to the project management body of knowledge - PMBOK Guide. Newtown Square: PMI, 2008.

PROJECT MANAGEMENT INSTITUTE - PMI. PMBOK guide: Um guia do conjunto de conhecimentos do gerenciamento de projetos. Pennsylvania: Project Management Institute, 3 ed, 2004.

QUELOPANA, Maria Eliana Marroquin. Conhecimento e decisão : um estudo sobre a relação entre o conhecimento e a qualidade de decisão. São Paulo, 2003. 141 p. Dissertação (Mestrado) - Faculdade de Economia e Administração da Universidade de São Paulo, 2003.

RABECHINI, R. J.; CARVALHO, M.M. Concepção de um Programa de

Gerência de Projetos em Instituição de Pesquisa. Revista Valenciana Dèstudis Autonòmics. Espanha: Valência, 1999.

RAFELE, Carlo, HILLSON, David, GRIMALDI, Sabrina. Understanding project risk exposure using the two-dimensional risk breakdown matrix. In: Project Management Institute lobal Congress, 2005, Edimburgo, Escócia. Disponível em: http://www.risk-doctor.com. Acesso em: 04 Jul. 2009.

RAFTERY, John. Risk Analysis in Project Management. Great Britain: E \& FN Spon, $1994.143 \mathrm{p}$. 
RAZ, Tzvi, HILLSON, David. A comparative review of risk management standards. Risk Management: An International Journal, v. 7, n. 4, p. 53-66, 2005. Disponível em: http:Ilwww.risk-doctor.com. Acesso em: 04.04.2009.

RAZ, T.; MICHAEL, E. Use and benefits of tools for project risk management. International Journal of Project Management, v. 19, n. 1, p. 9-17, 2001.

ROBBINS, Stephen Paul. Administração: mudanças e perspectivas. São Paulo: Saraiva, 2000.

ROYER, Paul S. Risk management: The undiscovered dimension of project management. Project Management Journal, v.31, n. 1, p-13, 2000.

SILVA, E. L. Metodologia da Pesquisa e Elaboração da Dissertação: 3 edição Florianópolis - Laboratório de Ensino à Distância da UFSC, 2001.

SIMON, Herbert A. A behavioral model of rational choice. Quarterly Journal of Economics. [S.I.], v. 69, [s.n.], p.99-118, 1955.

SIMON, Herbert A. A capacidade de decisão e liderança. Rio de Janeiro, Fundo de Cultura, 1963.

SIMON, H. A. Administrative Behavior: study of decision-making processes in administrative organization. New York: Macmillan, 1997

SIMON, Herbert A. Rationality as process and as product of thought. In: BELL, David E., RAIFFA, Howard e TVERSKY, Amos. Decision making: descritive, normative and prescritive interactions. Cambridge: Cambridge University Press, 1988.

SKJONG, R.; WENTWORTH, B. H. Expert Judgment and Risk Perception. In: International Offshore and Polar Engineering Conference, 11., 17-22, June, 2001, 
Stavanger, Norway. Anais... Stavanger: The International Society of Offshore and Polar Engineers, 2001. p. 537-544.

SLOVIC, P. \& FISCHHOFF, B. \& LICHTENSTEIN, S. (1982) Facts versus fears: understanding perceived risk. In: KAHNEMAN, D. \& SLOVIC, P. \& TVERSKY, A. (edit.) Judgment under uncertainty: heuristics and biases UK: Cambridge University Press, 1982.

SMITH, Preston G., MERRITT, Guy M.. Proactive risk management: controlling uncertainty in product development. Nova York: Productivity, 2002.

STAKE, R. E. (1995) The art of case study research. California: Sage.

STONER, J. A. F.; FREEMAN, R. E. Administração. 5ª ed. Rio de Janeiro: Prentice Hall do Brasil, 1992.

THE STANDISH GROUP. CHAOS Report Shows Project Success Rates Have Improved by $50 \%$. Disponível em http://www.standishgroup.com/press/ article.php?id=2. Acesso em 29 Nov. 2008.

TVERSKY, A.; KAHNEMAN, D. Belief in the law of small numbers. Psychological Bulletin, v.76, p.105-110, 1971.

TVERSKY, A.; KAHNEMAN, D. The Framing of Decisions and the Psychology of Choice. Science, v.211, p.453-458, 1981.

TUMAN, G. J. Development and Implementation of Effective Project Management Information and Control Systems. Em CLELAND, D. I; KING, W. R. Project Management Handbook. New York: Van Nostrand Reinhold, 1983.

TURBAN, E. \& MEREDITH, J. R. Fundamentals of management science. 6. ed. Boston: Irwin, 1994. 
VALERIANO, D.L. Gerência em projetos: pesquisa, desenvolvimento e engenharia. São Paulo: Makron Books, 1998.

VERZUH, E. The Fast Forward MBA in Project Management. New York: John Wiley \& Sons: 1999.

WIDEMAN, R. Max (editor). Project \& program risk management: a guide to managing project risks \& opportunities. Newton Square: Project Management Institute, 1992.

WHITE, Diana, FORTUNE, Joyce. Current practice in project management - an empirical study. InternationalJournal of Project Management, n. 20, p-11, 2002.

YATES, J. F. \& STONE, E. R. The risk construct. In: YATES, J. F. (edit.) Risktaking behavior. England: John Wiley \& Sons, 1994.

YIN, R. K. Estudos de casos, planejamento e métodos. Porto Alegre: Bookman, 2002.

ZWIKAEL, O.; GLOBERSON, S. From Critical Success Factors to Critical Success. Processes. International Journal of Production Research, v. 44, n. 17, p. 3433-3449, 2006. 


\section{APÊNDICE A - QUESTIONÁRIO DE PESQUISA}

\section{Parte 1 - Informações do projeto}

1. Qual é o escopo do projeto?

2. Como está estruturada a equipe do projeto?

3. Qual é o prazo para execução do projeto?

4. Quais são as condições contratuais no quesito de multas?

5. Quantas e quais são as interfaces deste projeto?

6. Há muitas subcontratações? Se sim quantos fornecedores aproximadamente há neste projeto?

$\square \operatorname{Sim} \square$ Não

$\square$ Até $100 \quad \square>100 \quad \square>500$

7. Há experiências passadas da empresa para este tipo de projetos?

$\square \operatorname{Sim} \quad \square$ Não

\section{Parte 2 - Experiência do Gerente do projeto}

01. Qual a sua experiência em gerenciamento de projetos?

02. Qual sua formação?

03. Qual o valor médio dos projetos gerenciados por você? E qual foi o ramo em que mais atuou?

04. Há quanto tempo gerencia projetos de Modernização de Usinas Hidrelétricas?

05. Qual a sua experiência em gerenciamento de riscos?

06. Em todos os projetos que você gerenciou, houve uma análise estruturada de riscos? Comente das dificuldades e/ou facilidades.

07. Você já deparou com alguma incerteza desconhecida que num determinado momento afetou seu projeto? Comente.

\section{Parte 3 - Gerenciamento de riscos}

01. A empresa adota alguma metodologia de gerenciamento de riscos para os projetos? Em caso de afirmativo, comente a metodologia utilizada bem como sua opinião a respeito da mesma.

$\square \operatorname{Sim} \quad \square$ Não 
02. Você sabe qual é a tolerância da empresa quanto aos riscos? Comente.

$\square \operatorname{Sim} \square$ Não

03. Existe na empresa um gerente de riscos que auxilia nos processos de identificação, análise e respostas de prováveis riscos ao projeto?

$\square \operatorname{Sim} \square$ Não

04. A empresa possui reuniões de riscos? No caso de afirmativo, há a participação de toda a equipe ou somente do gestor do projeto? Comente.

$\square \operatorname{Sim} \square$ Não

05. A responsabilidade para o gerenciamento de riscos é documentada e entendida dentro da empresa?

$\square \operatorname{Sim} \quad \square$ Não

06. Qual é freqüência das reuniões para analisar os riscos? Este prazo é determinado pela empresa ou cada gerente define o de seu projeto?

07. Sua empresa tem uma política documentada de gerenciamento de riscos?

Sim

$\square$ Não

08. Para este projeto especificamente, houve um plano de gerenciamento de riscos?

Em caso afirmativo, detalhe o plano.

$\square \operatorname{Sim} \quad \square$ Não

09. Para este projeto, houve categorização dos riscos?

$\square$ Sim, em sua totalidade $\quad \square$ Parcialmente $\quad \square$ Não

10. Quais tipos de risco foram analisados no projeto?

11. Foram utilizadas para a identificação dos riscos algumas das técnicas abaixo?

Comente sua experiência com as mesmas para este projeto?

$\square$ Revisões da documentação

$\square$ Brainstorming

$\square$ Análise da Lista de Verificação

$\square$ Técnica de Grupo Nominal

$\square$ Análise de Premissas

$\square$ Método CSM

$\square$ Técnica Delphi

$\square$ Análise SWOT

$\square$ Entrevistas

12. Foi identificado os riscos em termos de:

$\square$ O que pode acontecer?

$\square$ Área de impacto $\square$ Como e porque os riscos apareceram?

Fonte do risco? 
13. A metodologia utilizada no projeto foi capaz de analisar e separar os riscos aceitáveis menores dos riscos maiores, as oportunidades das ameaças, além de fornecer dados para auxiliar na avaliação e no tratamento dos riscos?

$\square$ Sim, em sua totalidade $\quad \square$ Parcialmente $\quad \square$ Não

14. Quais métodos/ferramentas foram utilizados para identificar os riscos do projeto? 15. Os riscos identificados foram adequadamente definidos: evento, probabilidade e impacto?
Sim, em sua totalidade
$\square$ Parcialmente
Não

16. Os riscos identificados foram apropriadamente registrados?

$\square$ Sim, em sua totalidade

$\square$ Parcialmente

Não

17. Foi realizada uma análise qualitativa dos riscos, resultando em uma análise eficaz sobre a probabilidade e impacto dos riscos sobre os objetivos do projeto?

$\square$ Sim, em sua totalidade $\quad \square$ Parcialmente $\quad \square$ Não

18. Os riscos foram analisados em termos de:

$\square$ Probabilidade

$\square$ Impacto

$\square$ Impacto financeiro

$\square$ Impacto reputacional

$\square$ Alcance dos objetivos

$\square$ Outros (Especifique abaixo)

19. Foi realizada uma análise quantitativa dos riscos, resultando em uma análise eficaz sobre a probabilidade e impacto dos riscos sobre os objetivos do projeto?

$\square$ Sim, em sua totalidade $\quad \square$ Parcialmente $\quad \square$ Não

20. Foi utilizada a árvore de decisão para a análise de risco do projeto? Comente.

$\square \operatorname{Sim} \square$ Não

21. Quais estratégias de resposta a riscos foram utilizadas em seu projeto?

$\square$ Prevenção

$\square$ Aceitação

$\square$ Transferência

$\square$ Exploração

$\square$ Mitigação

$\square$ Compartilhamento

$\square$ Melhoramento

22. Para a definição da estratégia de resposta foram utilizados:

$\square$ Uma avaliação da efetividade dos controles existentes e das respostas ao riscos Assessment dos custos e benefícios dos riscos analisados

$\square$ Priorização dos riscos e seleção dos que necessitam de um gerenciamento ativo

$\square$ Priorização to tratamento dos riscos onde há restrição de recursos na implementação da resposta. 
23. Sempre quando houve uma alteração no projeto, a equipe atuou para verificar os riscos?

$\square$ Sim, em sua totalidade $\quad \square$ Parcialmente $\quad \square$ Não

24. Houve um acompanhamento dos riscos por parte dos responsáveis?

$\square$ Sim, em sua totalidade $\quad \square$ Parcialmente $\quad \square$ Não

25. Houve um registro de todos os riscos ocorridos ou não?

$\square$ Sim, em sua totalidade $\quad \square$ Parcialmente $\quad \square$ Não

26. Foi utilizado algum formulário de registro das informações de riscos?

$\square \operatorname{Sim} \quad \square$ Não

27. Foi utilizado algum indicador para mediar a eficiência do gerenciamento de riscos no projeto?

$\square \operatorname{Sim} \square$ Não

\section{Parte 4 - Processos decisórios}

01. Como são tomadas as decisões relativas aos riscos no projeto? Individual ou em grupo?

02. Após as análises dos riscos no projeto, como é elaborado o plano de respostas dos mesmos?

03. Como são tomadas as decisões no decorrer do projeto para eventos de riscos não planejados?

04. Utiliza-se de algum método prescritivo (racional) para tomar decisões nos projetos?

05. Existe alguma ferramenta para ajudá-lo nos processos decisórios? Qual?

06. Existe algum processo seqüencial para se tomar uma decisão no projeto? Se sim quais são as etapas?

07. Você acredita que sua experiência o ajuda nas decisões sobre eventos de riscos? Por quê?

08. Houve algum momento em que você teve que utilizar a intuição para tomar a decisão quanto a um evento de risco não planejado? Qual foi o resultado?

09. Diante de uma situação de tomada de decisão para com os riscos, de que forma as alternativas foram avaliadas? 


\section{APÊNDICE B - RESPOSTA COMPILADA DO QUESTIONÁRIO DE PESQUISA}

\section{Parte 1 - Informações do projeto}

\section{Qual é o escopo do projeto?}

\begin{tabular}{|l|l|}
\hline PROJETO 1 & $\begin{array}{l}\text { Modernização de 06 unidades geradoras, composta pela reforma dos } \\
\text { geradores, novo regulador de velocidade, Sistema Digital e Telecomunicações. }\end{array}$ \\
\hline PROJETO 2 & $\begin{array}{l}\text { Reparação e reforma de } 8 \text { unidades geradoras. Geradores e auxiliares (8 } \\
\text { unidades), trocadores de calor (6 unidades), Instrumentação (8 unidades), } \\
\text { Regulador de Velocidade (8 unidades), Sistema de Proteção, materiais de } \\
\text { montagem e supervisão de obra. }\end{array}$ \\
\hline PROJETO 3 3 & $\begin{array}{l}\text { Reforma e Modernização de uma usina em funcionamento, contemplando o } \\
\text { Sistema de Regulação de Velocidade, sistema Digital de Supervisão, e } \\
\text { Controle Novo para casa de força e Subestação, reforma de trafo elevadores e } \\
\text { Circuito interno de Televisão. }\end{array}$ \\
\hline
\end{tabular}

2. Como está estruturada a equipe do projeto?

\begin{tabular}{|l|l|}
\hline PROJETO 1 & $\begin{array}{l}01 \text { Gerente de Projetos, 01 Planejador de Projetos, 01 Controlador de Projetos } \\
\text { e 01 Qualidade do projeto. }\end{array}$ \\
\hline PROJETO 2 & 01 Gerente de Projetos, 02 planejadores, 01 Controller e 01 Qualidade \\
\hline PROJETO 3 & $\begin{array}{l}02 \text { Gerentes de Projetos, 02 Planejadores de Projeto, 02 Financeiros, 02 } \\
\text { Supervisores alocados em campo em tempo integral e reforço da equipe de } \\
\text { campo no comissionamento. }\end{array}$ \\
\hline
\end{tabular}

3. Qual é o prazo para execução do projeto?

\begin{tabular}{|l|l|}
\hline PROJETO 1 & $\begin{array}{l}\text { 06 meses de modernização, somados de 1 mês de comissionamento por } \\
\text { máquina. O escopo que não é voltado para casa de máquinas deve ser } \\
\text { executado em paralelo. }\end{array}$ \\
\hline PROJETO 2 & $\begin{array}{l}50 \text { meses (09 meses para a preparação do canteiro da obra. 08 meses para a } \\
\text { execução dos serviços na primeira unidade e 07 meses para cada unidade } \\
\text { geradora). }\end{array}$ \\
\hline PROJETO 3 & 36 meses sendo 6 meses para cada unidade \\
\hline
\end{tabular}

4. Quais são as condições contratuais no quesito de multas?

\begin{tabular}{|l|l|}
\hline PROJETO 1 & $\begin{array}{l}\text { Por mora - 0,1\% diário sobre valor contrato; Inadimplemento - 2,5\% diário } \\
\text { sobre valor contrato; Potência Insuficiente do gerador - } \mathrm{R} \$ 11.523,00 \text { para } \\
\text { cada 0,01\% de diferença; Por rendimento insuficiente do gerador - } \\
\mathrm{R} \$ 33.159,00 \text { para cada 0,01\% de diferença; Atraso na geração Comercial - } \mathrm{R} \$ \\
49.631,00 .\end{array}$ \\
\hline PROJETO 2 & $\begin{array}{l}\text { Por mora - 0,1\% diário sobre valor contrato; Inadimplemento - 2,5\% diário } \\
\text { sobre valor contrato; Potência Insuficiente do gerador - } 10.379,00 \text { para cada } \\
0,01 \% \text { de diferença; Por rendimento insuficiente do gerador - } \mathrm{R} \$ 29.868,00 \\
\text { para cada 0,01\% de diferença; Atraso na geração Comercial - } \mathrm{R} \$ 44.705,00 .\end{array}$ \\
\hline PROJETO 3 & $\begin{array}{l}\text { Multa diária por não geração de energia de } \mathrm{R} \$ 27.500,00 \text { limitada a } 10 \% \text { do } \\
\text { valor total do contrato. }\end{array}$ \\
\hline
\end{tabular}


5. Quantas e quais são as interfaces deste projeto?

\begin{tabular}{|l|l|}
\hline PROJETO 1 & O consórcio era composto por 7 empresas \\
\hline PROJETO 2 & O consórcio era composto por 5 empresas \\
\hline PROJETO 3 & $\begin{array}{l}\text { Interfaces internas no consórcio }-4 \text { consorciadas e externa com o cliente, } 8 \\
\text { departamentos diferentes. }\end{array}$ \\
\hline
\end{tabular}

6. Há muitas subcontratações? Se sim quantos fornecedores aproximadamente há neste projeto?

PROJETO 1 Houve mais de 100 subcontratações com fornecedores diferentes

PROJETO 2 Houve mais de 100 subcontratações com fornecedores diferentes

PROJETO 3 Sim - Até 100

7. Há experiências passadas da empresa para este tipo de projetos?

\begin{tabular}{|l|l|}
\hline PROJETO 1 & Sim -1 \\
\hline PROJETO & Sim -2
\end{tabular}

\begin{tabular}{|l|l|}
\hline PROJETO 2 & Sim -2 \\
\hline
\end{tabular}

PROJETO 3

\section{Parte 2 - Experiência do Gerente do projeto}

01. Qual a sua experiência em gerenciamento de projetos?

\begin{tabular}{|l|l|}
\hline PROJETO 1 & $\begin{array}{l}\text { Atuou como Planejador de projeto em times de gerenciamento de projetos de } \\
\text { exportação para China, Venezuela, Colômbia e Canadá. Construção e } \\
\text { reformas de usinas nacionais de pequeno, médio e grande porte. Desde } \\
\text { nov/09 atua como PM de projetos de reforma de usinas hidroelétricas. }\end{array}$ \\
\hline PROJETO 2 & 06 anos de experiência em gerenciamento de projetos \\
\hline PROJETO 3 & 09 anos em gerenciamento de Projetos \\
\hline
\end{tabular}

02. Qual sua formação?

\begin{tabular}{|l|l|}
\hline PROJETO 1 & $\begin{array}{l}\text { Engenheiro de Produção Mecânica, PMP e MBA em Gerenciamento de } \\
\text { Projetos }\end{array}$ \\
\hline PROJETO 2 & Engenheiro eletricista, PMP e MBA em Gerenciamento de Projetos \\
\hline PROJETO 3 & $\begin{array}{l}\text { Engenheiro Mecânico, PMP, pós graduado em Gerenciamento de projetos e } \\
\text { MBA em Gerenciamento de Projetos. }\end{array}$ \\
\hline
\end{tabular}

03. Qual o valor médio dos projetos gerenciados por você? E qual foi o ramo em que mais atuou?

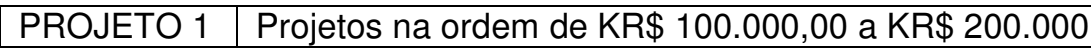

PROJETO 2 Projetos na ordem de $10 \mathrm{MR} \$$

PROJETO 3 MR $\$ 100$, sempre atuando nos projetos de reforma e modernização 
04. Há quanto tempo gerencia projetos de Modernização de Usinas Hidrelétricas?

\begin{tabular}{|l|l|}
\hline PROJETO 1 & 2 anos \\
\hline PROJETO 2 & 2 anos \\
\hline PROJETO 3 & 09 anos, no entanto quando estava gerenciando este projeto tinha 2 anos \\
\hline
\end{tabular}

05. Qual a sua experiência em gerenciamento de riscos?

\begin{tabular}{|l|l|}
\hline PROJETO 1 & 1,5 anos \\
\hline PROJETO 2 & 6 anos \\
\hline PROJETO 3 & 03 anos \\
\hline
\end{tabular}

06. Em todos os projetos que você gerenciou, houve uma análise estruturada de riscos? Comente das dificuldades e/ou facilidades.

\begin{tabular}{|l|l|}
\hline PROJETO 1 & $\begin{array}{l}\text { Na maioria das vezes sim, porém existem casos em contrato de reforma e } \\
\text { modernização onde no momento da identificação de um certo risco, fica difícil e } \\
\text { muitas vezes, impossível de se calcular tal impacto. Normalmente quando isso } \\
\text { ocorre, o risco sempre é supervalorizado. }\end{array}$ \\
\hline PROJETO 2 & $\begin{array}{l}\text { Em todos os projetos que gerenciei sempre procurei gerenciar os riscos. A } \\
\text { grande dificuldade para a realização foi sempre motivar as pessoas a } \\
\text { participarem dos workshops e reuniões. }\end{array}$ \\
\hline PROJETO 3 & $\begin{array}{l}\text { Até certo tempo na empresa, as análises de riscos eram realizadas somente } \\
\text { para projetos de maiores valores. As maiores dificuldades no gerenciamento } \\
\text { dos riscos são: conseguir o envolvimento dos departamentos, o pouco } \\
\text { conhecimento e envolvimento da engenharia devido ao pouco envolvimento } \\
\text { deste departamento com a área de montagem externa, a dificuldade de fazer } \\
\text { com que as consorciadas sigam ou passem informações com relação a riscos } \\
\text { de fornecimentos e/ou reforma e garantir o plano de ação. }\end{array}$ \\
\hline
\end{tabular}

07. Você já deparou com alguma incerteza desconhecida que num determinado momento afetou seu projeto? Comente.

\begin{tabular}{|l|l|}
\hline PROJETO 1 & Até o momento não. \\
\hline PROJETO 2 & $\begin{array}{l}\text { Sim e resultado foi muito difícil para o projeto uma vez que tive uma redução } \\
\text { de margem no projeto. }\end{array}$ \\
\hline PROJETO 3 & $\begin{array}{l}\text { Sim, principalmente quando o fato encontrado não está muito bem definido no } \\
\text { escopo contrato e/ou matriz de interface, tanto internamente no consórcio, } \\
\text { como com o cliente final. Principalmente detalhes que não foram verificados } \\
\text { antes do início da modernização e que depois no momento do } \\
\text { comissionamento voltam a acontecer o o cliente final informa que nunca tinha } \\
\text { ocorrido e depois que você verifica em outra máquina, detecta o mesmo } \\
\text { problema. }\end{array}$ \\
\hline
\end{tabular}




\section{Parte 3 - Gerenciamento de riscos}

01. A empresa adota alguma metodologia de gerenciamento de riscos para os projetos? Em caso de afirmativo, comente a metodologia utilizada bem como sua opinião a respeito da mesma.

\begin{tabular}{|l|l|}
\hline PROJETO 1 & $\begin{array}{l}\text { Metodologia baseada em analises qualitativas e quantitativas através de } \\
\text { sessões de risco e oportunidade com toda a equipe do projeto e áreas de } \\
\text { interface. O processo tem início num primeiro instante onde é feito um } \\
\text { brainstorming dos possíveis riscos e oportunidades baseados em dados do } \\
\text { contrato e dados históricos de outros projetos. Em minha opinião, tal } \\
\text { metodologia possui bastante base teórica, porém ainda se faz necessário o } \\
\text { desenvolvimento da cultura e do conhecimento das pessoas; }\end{array}$ \\
\hline PROJETO 2 & $\begin{array}{l}\text { Possui, no entanto a mesma precisa ser aprimorada em análise e planos de } \\
\text { ação uma vez que ambos itens são totalmente dependentes da experiência da } \\
\text { equipe. }\end{array}$ \\
\hline PROJETO 3 & $\begin{array}{l}\text { Existem reuniões de risco feitas no mínimo a cada 3 meses onde reúne-se a } \\
\text { equipe do projeto para avaliar riscos e oportunidades já levantadas e também } \\
\text { levantamento de novos riscos e oportunidades. Nenhuma técnica em } \\
\text { específico é utilizada se não for determinada pelo gerente de projetos. No } \\
\text { entanto isto somente foi aplicado para este projeto após 3 anos de seu início. }\end{array}$ \\
\hline
\end{tabular}

02. Você sabe qual é a tolerância da empresa quanto aos riscos? Comente.

\begin{tabular}{|l|l|}
\hline PROJETO 1 & Desconheço \\
\hline PROJETO 2 & Não \\
\hline PROJETO 3 & $\begin{array}{l}\text { Sim. A empresa assume riscos de altos valores e impactos e fica a cargo do } \\
\text { gerente de projeto achar alternativas, soluções e traçar planos de ação para } \\
\text { mitigar ou aceitar o risco de forma que não se tenha grande impacto financeiro } \\
\text { no projeto. }\end{array}$ \\
\hline
\end{tabular}

03. Existe na empresa um gerente de riscos que auxilia nos processos de identificação, análise e respostas de prováveis riscos ao projeto?

\begin{tabular}{|l|l|}
\hline PROJETO 1 & $\begin{array}{l}\text { Existe uma área destinada a tratar dos assuntos riscos e oportunidades, porém } \\
\text { os trabalhos de elaboração de claim sejam eles prós ou contra a empresa. Em } \\
\text { outras palavras, como toda área recém estruturada, é necessário um tempo de } \\
\text { qual caracterizo como maturidade para começar a trazer resultados } \\
\text { significativos. }\end{array}$ \\
\hline PROJETO 2 & Existe um departamento que auxilia, no entanto sem muita experiência \\
\hline PROJETO 3 & $\begin{array}{l}\text { Não - O gerente de riscos existe, mas fica a cargo do gerente de projeto a } \\
\text { identificação, análise e resposta aos riscos encontrados. }\end{array}$ \\
\hline
\end{tabular}

04. A empresa possui reuniões de riscos? No caso de afirmativo, há a participação de toda a equipe ou somente do gestor do projeto? Comente.

\begin{tabular}{|l|l|}
\hline PROJETO 1 & $\begin{array}{l}\text { A participação de toda a equipe é obrigatória, porém em muitos casos ainda é } \\
\text { difícil de fazer reuniões de riscos onde boa parte dos recursos dos projetos são } \\
\text { compartilhados, o que dificulta muito o agendamento de forma a tender a } \\
\text { agenda de todos. }\end{array}$ \\
\hline PROJETO 2 & $\begin{array}{l}\text { Sim, obrigatoriamente a cada } 3 \text { meses. No entanto, fazia com a equipe } \\
\text { mensalmente }\end{array}$ \\
\hline PROJETO 3 & $\begin{array}{l}\text { Sim - É obrigatória a presença de toda a equipe de projeto, porém nem sempre } \\
\text { a participação destas pessoas é efetiva. }\end{array}$ \\
\hline
\end{tabular}


05. A responsabilidade para o gerenciamento de riscos é documentada e entendida dentro da empresa?

\begin{tabular}{|l|l|}
\hline PROJETO 1 & Sim \\
\hline PROJETO 2 & Sim \\
\hline PROJETO 3 & $\begin{array}{l}\text { Sim - Porém existe grande dificuldade de determinar qual é o valor e o grau de } \\
\text { exposição de cada risco, ficando a cargo do gerente de projetos devido a sua } \\
\text { experiência realizar estas análises. }\end{array}$ \\
\hline
\end{tabular}

06. Qual é freqüência das reuniões para analisar os riscos? Este prazo é determinado pela empresa ou cada gerente define o de seu projeto?

\begin{tabular}{|l|l|}
\hline PROJETO 1 & $\begin{array}{l}\text { Trimestral. Este é o prazo mínimo determinado pela empresa. Dependendo da } \\
\text { atual situação do projeto, se faz necessárias reuniões ao mínimo mensais. Tal } \\
\text { freqüência fica a critério do Gerente de projeto e o respectivo Gerente de } \\
\text { contrato. }\end{array}$ \\
\hline PROJETO 2 & $\begin{array}{l}\text { Trimestral exigido pela empresa e fica a cargo do PM realizar outras que lhe } \\
\text { convém. }\end{array}$ \\
\hline PROJETO 3 & $\begin{array}{l}\text { A empresa determina a realização mínima a cada 03 meses, porém o gerente } \\
\text { de projetos pode determinar outra frequêencia ou então chamar reuniões } \\
\text { específicas para analisar riscos específicos. }\end{array}$ \\
\hline
\end{tabular}

07. Sua empresa tem uma política documentada de gerenciamento de riscos?

\begin{tabular}{|l|l|}
\hline PROJETO 1 & Sim \\
\hline PROJETO 2 & Sim \\
\hline PROJETO 3 & Sim \\
\hline
\end{tabular}

08. Para este projeto especificamente, houve um plano de gerenciamento de riscos? Em caso afirmativo, detalhe o plano.

\begin{tabular}{|l|l|}
\hline PROJETO 1 & $\begin{array}{l}\text { Sim - Inicialmente são coletados os resultados do brainstorming. Este resultado } \\
\text { é planilhado e a partir deste primeiro ponto é feita a análise quantitativa e } \\
\text { qualitativa. Na seqüência, são definidos os planos de mitigação em detalhe } \\
\text { para cada risco e por fim o acompanhamento até que o risco incorra ou é } \\
\text { eliminado. }\end{array}$ \\
\hline PROJETO 2 & $\begin{array}{l}\text { Sim. Após a identificação faz-se uma análise qualitativa com o intuito de } \\
\text { realizar um filtro dos riscos que serão analisados quantitativamente. Após a } \\
\text { análise quantitativa, traça-se um plano de ação para estes riscos. }\end{array}$ \\
\hline PROJETO 3 & $\begin{array}{l}\text { Sim - eram feitas reuniões trimestrais de riscos liderada pelos gerentes de } \\
\text { projeto, que começaram a acontecer após 03 anos de andamento do projeto, } \\
\text { eram levantados os riscos, quantificados, qualificados e traçados planos de } \\
\text { ações quando necessário. }\end{array}$ \\
\hline
\end{tabular}

09. Para este projeto, houve categorização dos riscos?

\begin{tabular}{|l|l|}
\hline PROJETO 1 & Não \\
\hline PROJETO 2 & Sim \\
\hline PROJETO 3 & Não \\
\hline
\end{tabular}


10. Quais tipos de risco foram analisados no projeto?

\begin{tabular}{|l|l|}
\hline PROJETO 1 & $\begin{array}{l}\text { Principalmente riscos voltados a atraso de geração, término dos trabalhos e } \\
\text { diferenças de taxas governamentais. }\end{array}$ \\
\hline PROJETO 2 & Contratuais, de imagem e técnicos \\
\hline PROJETO 3 & $\begin{array}{l}\text { Divergências de escopo, riscos financeiros, riscos de penalidades por atrasos, } \\
\text { riscos dos consorciados, riscos no cronograma (planejamento). }\end{array}$ \\
\hline
\end{tabular}

11. Foram utilizadas para a identificação dos riscos algumas das técnicas abaixo? Comente sua experiência com as mesmas para este projeto?

\begin{tabular}{|l|l|}
\hline PROJETO 1 & $\begin{array}{l}\text { Análise das premissas, entrevistas, Brainstorming, Técnica Delphi } \\
\text { e análise SWOT. }\end{array}$ \\
\hline PROJETO 2 & $\begin{array}{l}\text { Análise das premissas, entrevistas, Brainstorming, Técnica Delphi, Técnica de } \\
\text { grupo nominal e análise SWOT. }\end{array}$ \\
\hline PROJETO 3 & $\begin{array}{l}\text { Brainstorming, entrevistas e Análise Swot - As técnicas foram aplicadas em } \\
\text { situações específicas do projeto e no momento surtiram um bom efeito, } \\
\text { ajudando a mitigar riscos e em outras situações ajudando a realizar ações } \\
\text { corretivas e procedimento para evitarmos os riscos em outros projetos. }\end{array}$ \\
\hline
\end{tabular}

12. Foi identificado os riscos em termos de:

PROJETO 1 1 O que pode acontecer / área de impacto

PROJETO 2 O que pode acontecer / área de impacto/ Causa

PROJETO 3 O que pode acontecer / área de impacto

13. A metodologia utilizada no projeto foi capaz de analisar e separar os riscos aceitáveis menores dos riscos maiores, as oportunidades das ameaças, além de fornecer dados para auxiliar na avaliação e no tratamento dos riscos?

\begin{tabular}{|l|l|}
\hline PROJETO 1 & Parcialmente \\
\hline PROJETO 2 & Sim \\
\hline PROJETO 3 & Parcialmente \\
\hline
\end{tabular}

14. Os riscos identificados foram adequadamente definidos: evento, probabilidade e impacto?

\begin{tabular}{|l|l|}
\hline PROJETO 1 & Sim \\
\hline PROJETO 2 & Sim \\
\hline PROJETO 3 & Não \\
\hline
\end{tabular}

15. Os riscos identificados foram apropriadamente registrados?

\begin{tabular}{|l|l|}
\hline PROJETO 1 & Parcialmente \\
\hline PROJETO 2 & Sim \\
\hline PROJETO 3 & Parcialmente \\
\hline
\end{tabular}

16. Foi realizada uma análise qualitativa dos riscos, resultando em uma análise eficaz sobre a probabilidade e impacto dos riscos sobre os objetivos do projeto?

\begin{tabular}{|l|l|}
\hline PROJETO 1 & Parcialmente \\
\hline PROJETO 2 & Parcialmente \\
\hline PROJETO 3 & Não \\
\hline
\end{tabular}


17. Os riscos foram analisados em termos de:

\begin{tabular}{|l|l|}
\hline PROJETO 1 & Probabilidade / Impacto financeiro. \\
\hline PROJETO 2 & $\begin{array}{l}\text { Probabilidade / Impacto, porém foram considerados outros aspectos além do } \\
\text { financeiro como imagem da empresa e objetivos do projeto. }\end{array}$ \\
\hline PROJETO 3 & Impacto Financeiro \\
\hline
\end{tabular}

18. Foi realizada uma análise quantitativa dos riscos, resultando em uma análise eficaz sobre a probabilidade e impacto dos riscos sobre os objetivos do projeto?

\begin{tabular}{|l|l|}
\hline PROJETO 1 & Parcialmente \\
\hline PROJETO 2 & Parcialmente \\
\hline PROJETO 3 & Não \\
\hline
\end{tabular}

19. Foi utilizada a árvore de decisão para a análise de risco do projeto? Comente.

\begin{tabular}{|l|l|}
\hline PROJETO 1 & Não \\
\hline PROJETO 2 & Sim. Foi utilizada para alguns riscos e os resultados foram satisfatórios \\
\hline PROJETO 3 & Não \\
\hline
\end{tabular}

20. Quais estratégias de resposta a riscos foram utilizadas em seu projeto?

\begin{tabular}{|l|l|l|l|}
\hline PROJETO 1 & Mitigação/ Prevenção / Aceitação & \\
\hline PROJETO 2 & $\begin{array}{l}\text { Mitigação/ Prevenção / Aceitação / Melhoramento/ Transferência e e } \\
\text { Compartilhamento }\end{array}$ \\
\hline PROJETO 3 & Prevenção/ Mitigação / Melhoramento / Aceitação & \\
\hline
\end{tabular}

21. Para a definição da estratégia de resposta foram utilizados:

\begin{tabular}{|l|l|}
\hline PROJETO 1 & $\begin{array}{l}\text { Priorização dos riscos e seleção dos que necessitam de um gerenciamento } \\
\text { ativo. }\end{array}$ \\
\hline PROJETO 2 & $\begin{array}{l}\text { Priorização dos riscos e seleção dos que necessitam de um gerenciamento } \\
\text { ativo. }\end{array}$ \\
\hline PROJETO 3 & $\begin{array}{l}\text { Priorização dos riscos e seleção dos que necessitam de um gerenciamento } \\
\text { ativo. }\end{array}$ \\
\hline
\end{tabular}

22. Sempre quando houve uma alteração no projeto, a equipe atuou para verificar os riscos?

\begin{tabular}{|l|l|}
\hline PROJETO 1 & Parcialmente \\
\hline PROJETO 2 & Sim \\
\hline PROJETO 3 & Parcialmente \\
\hline
\end{tabular}

23. Houve um acompanhamento dos riscos por parte dos responsáveis?

\begin{tabular}{|l|l|}
\hline PROJETO 1 & Parcialmente \\
\hline PROJETO 2 & Sim \\
\hline PROJETO 3 & Parcialmente \\
\hline
\end{tabular}


24. Houve um registro de todos os riscos ocorridos ou não?

\begin{tabular}{|l|l|}
\hline PROJETO 1 & Parcialmente \\
\hline PROJETO 2 & Sim \\
\hline PROJETO 3 & Não \\
\hline
\end{tabular}

25. Foi utilizado algum formulário de registro das informações de riscos?

\begin{tabular}{|l|l|}
\hline PROJETO 1 & Sim \\
\hline PROJETO 2 & Sim \\
\hline PROJETO 3 & Sim \\
\hline
\end{tabular}

26. Foi utilizado algum indicador para medir a eficiência do gerenciamento de riscos no projeto?

\begin{tabular}{|l|l|}
\hline PROJETO 1 & Sim \\
\hline PROJETO 2 & Sim \\
\hline PROJETO 3 & Não \\
\hline
\end{tabular}

\section{Parte 4 - Processos decisórios}

01. Como são tomadas as decisões relativas aos riscos no projeto? Individual ou em grupo?

PROJETO 1 Sempre em grupo, e posteriormente apresentado à diretoria da empresa.

PROJETO 2 Sempre com a equipe

PROJETO 3 Geralmente são tomadas pelo gerente de projeto.

02. Após as análises dos riscos no projeto, como é elaborado o plano de respostas dos mesmos?

\begin{tabular}{|l|l|l}
\hline PROJETO 1 & Principalmente baseado e fatos históricos.
\end{tabular}

\begin{tabular}{l|l} 
PROJETO 2 & Através de um estudo das possibilidades identificadas pela equipe
\end{tabular}

\begin{tabular}{|l|l|l|}
\hline PROJETO 3 & O gerente de projeto junto com planejamento elabora o plano de resposta e
\end{tabular} apresenta para o restante da equipe analisar.

03. Como são tomadas as decisões no decorrer do projeto para eventos de riscos não planejados?

\begin{tabular}{|l|l|}
\hline PROJETO 1 & $\begin{array}{l}\text { As decisões são discutidas pelo time imediatamente no momento em que o } \\
\text { evento ocorre, buscando assim possibilidades para que tal risco não ocorra. }\end{array}$ \\
\hline PROJETO 2 & Sempre em grupo e imediatas \\
\hline PROJETO 3 & $\begin{array}{l}\text { São realizadas reuniões específicas com os departamentos necessários e } \\
\text { traçado um plano de ação para mitigar, eliminar ou aceitar o risco. }\end{array}$ \\
\hline
\end{tabular}

04. Utiliza-se de algum método prescritivo (racional) para tomar decisões nos projetos?

\begin{tabular}{|l|l|}
\hline PROJETO 1 & Não. As decisões sempre são tomadas partindo do ponto financeiro. \\
\hline PROJETO 2 & $\begin{array}{l}\text { Sim. Embora a empresa não determine, utilizei em alguns momentos a árvore } \\
\text { de decisão e o VME como ferramentas para meu auxiliar nas decisões. }\end{array}$ \\
\hline PROJETO 3 & Não \\
\hline
\end{tabular}


05. Existe alguma ferramenta para ajudá-lo nos processos decisórios? Qual?

\begin{tabular}{|l|l|}
\hline PROJETO 1 & Não \\
\hline PROJETO 2 & Não \\
\hline PROJETO 3 & Não \\
\hline
\end{tabular}

06. Existe algum processo seqüencial para se tomar uma decisão no projeto? Se sim quais são as etapas?

\begin{tabular}{|l|l|}
\hline PROJETO 1 & Não \\
\hline PROJETO 2 & $\begin{array}{l}\text { Sim, no entanto foi criado por mim sendo: Informação, análise das } \\
\text { possibilidades, definição da estratégia, definição da definição a ser tomada, } \\
\text { aprovação e validação }\end{array}$ \\
\hline PROJETO 3 & Não \\
\hline
\end{tabular}

07. Você acredita que sua experiência o ajuda nas decisões sobre eventos de riscos? Por quê?

\begin{tabular}{|l|l|}
\hline PROJETO 1 & $\begin{array}{l}\text { Parcialmente. Eventualmente você encontrará as mesmas dificuldades e } \\
\text { desafios nos variados projetos de reforma, e nem sempre a ação tomada no } \\
\text { passado, funciona em casos onde você não tem as mesmas premissas. }\end{array}$ \\
\hline PROJETO 2 & $\begin{array}{l}\text { Mesmo tendo utilizado, acredito que a experiência ajuda parcialmente nas } \\
\text { decisões. Acredito que uma boa metodologia bem aplicada seja mais eficaz. }\end{array}$ \\
\hline PROJETO 3 & $\begin{array}{l}\text { A experiência ajuda na hora das decisões de eventos de risco já vivenciados } \\
\text { em outros projeto, para riscos que ainda não tenham sido vivenciados é } \\
\text { necessário o envolvimento de mais pessoas. }\end{array}$ \\
\hline
\end{tabular}

08. Houve algum momento em que você teve que utilizar a intuição para tomar a decisão quanto a um evento de risco não planejado? Qual foi o resultado?

\begin{tabular}{|l|l|}
\hline PROJETO 1 & $\begin{array}{l}\text { Em alguns momentos sim. O resultado foi algumas vezes positivo e negativo } \\
\text { na maioria das vezes. }\end{array}$ \\
\hline PROJETO 2 & $\begin{array}{l}\text { Sim: Em alguns momentos os resultados foram positivos, entretanto na maioria } \\
\text { foram negativos. }\end{array}$ \\
\hline PROJETO 3 & Sim. O resultado foi as vezes positivo e as vezes negativo. \\
\hline
\end{tabular}

09. Diante de uma situação de tomada de decisão para com os riscos, de que forma as alternativas foram avaliadas?

\begin{tabular}{|l|l|}
\hline PROJETO 1 & As alternativas são principalmente avaliadas pela probabilidade de impacto. \\
\hline PROJETO 2 & $\begin{array}{l}\text { As alternativas são sempre avaliadas considerando o menor impacto geral do } \\
\text { projeto. }\end{array}$ \\
\hline PROJETO 3 & Sempre visando a que iria causar um menor impacto financeiro no projeto. \\
\hline
\end{tabular}

